Dr. Nadja Müller*

\title{
Das Geldwäscheregister nach Art. 30 und 31 der Vierten Geldwäscherichtlinie und seine Vereinbarkeit mit der Rechtsprechung des EuGH zur Vorratsdatenspeicherung
}

DOI 10.1515/zstw-2016-0034

Nach Art. 30 und 31 der Vierten Geldwäscherichtlinie, die bis zum 26. 06. 2017 umzusetzen ist, sollen personenbezogene Daten aller wirtschaftlichen Eigentümer von Gesellschaften, juristischen Personen, Express Trusts und vergleichbaren Rechtspersonen oder -vereinbarungen in einem zentralen Register gesammelt werden, um Geldwäscheverpflichteten, zuständigen Behörden und u.U. Personen mit einem berechtigten Interesse zum Zwecke der Geldwäsche- und Terrorismusbekämpfung den Zugriff darauf zu ermöglichen. Damit soll verhindert werden, „dass das Finanzsystem zum Zwecke der Geldwäsche und der Terrorismusfinanzierung genutzt wird“" . Zugriff auf das Register kann dabei unter anderem investigativen Journalisten gewährt werden².

Welche Bedeutung dieser neuen Art des Journalismus zukommen kann, zeigen die sog. Panama Papers, deren Eigentümer nur schwer feststellbar sind ${ }^{3}$. Vor dem Hintergrund des medialen Interesses an den geleakten Daten und den damit aufgedeckten illegalen Machenschaften von teils in der Öffentlichkeit stehenden Personen wird der Ruf nach der „Austrocknung sog. Steueroasen“ laut und eine verstärkte Bekämpfung der Geldwäsche gefordert. Angesichts der Briefkastenfirmen und des damit verbundenen Ziels, den wahren Inhaber bzw. wirtschaftlich Berechtigten zu verschleiern, erscheint die Forderung nach einem Geldwäscheregister und der damit einhergehenden Offenlegung wirtschaftlicher Eigentümer wie es die Vierte Geldwäscherichtlinie vorsieht - in einem neuen Licht. Es verwundert daher nicht, dass Finanzminister Schäuble die Enthüllungen im Rahmen

1 ABl. EU v. 05. 06. 2015, L 141/75, Erwägungsgrund 1.

2 Siehe auch Reppelmund, EuZW 2015, 164.

3 Süddeutsche Zeitung, zu finden unter http://panamapapers.sueddeutsche.de/articles/56ff9a 28a1bb8d3c3495ae13 (Stand aller Internetquellen: 12. 12. 2016).

*Kontaktperson: Nadja Müller, Akademische Mitarbeiterin am Lehrstuhl von Prof. Dr. Gerhard Dannecker an der Ruprecht-Karls-Universität Heidelberg 
der Panama Papers zum Anlass nimmt, einen 10 Punkte-Plan als internationalen Vorstoß gegen Briefkastenfirmen und Steueroasen $\mathrm{zu}$ initiieren, der als einen Schwerpunkt die Schaffung „weltweit völlige[r] Transparenz“4 das in diesem Zusammenhang „Transparenzregister“55 genannte Geldwäscheregister, zum Gegenstand hat. Schäubles Plan sieht dazu u.a. faktisch eine Abschaffung der Verjährung der Steuerhinterziehung vor (was hier nicht weiter bewertet werden soll), schärfere Verwaltungssanktionen gegen Unternehmen sowie die Vereinheitlichung sog. „schwarzen Listen“ als internationalen Pranger für nicht kooperierende Länder ${ }^{6}$. Ein zentraler Aspekt soll jedoch die verstärkte Bekämpfung der Geldwäsche sein, die u.a. durch die Schaffung des Geldwäscheregisters erfolgen soll. Nach den Plänen des Finanzministers sollen auf dieses Register in jedem Fall die Steuerverwaltungen Zugriff haben ${ }^{7}$, zudem jedoch auch Nichtregierungsorganisationen und Journalisten, sofern sie „die Ergebnisse ihrer Recherchen auch den zuständigen Behörden zur Verfügung stellen“8. In Deutschland werde man das Register, so Schäuble im April 2016, „,zeitnah“ einführen”.

Entsprechend seiner Ankündigung hat das Bundesfinanzministerium am 15. 12. 2016 den Referentenentwurf zur Änderung u.a. des Geldwäschegesetzes $(\mathrm{GwG})^{10}$ vorgelegt, der bereits einen Änderungsvorschlag der Kommission zur Vierten Geldwäscherichtlinie ${ }^{11}$ berücksichtigt, mit dem deutliche Verschärfungen der Richtlinie einhergehen.

4 Wirtschaftswoche v. 11. 04. 2014, zu finden unter http://www.wiwo.de/politik/deutschland/ panama-papers-schaeubles-10-punkte-plan-gegen-steueroasen/13428626.html.

5 Spiegel Online v. 10. 04. 2016, zu finden unter http://www.spiegel.de/wirtschaft/soziales/ wolfgang-schaeuble-kuendigt-10-punkte-plan-gegen-steuerbetrueger-an-a-1086432.html.

6 Dams, Schäubles Zehn-Punkte-Plan gegen Steuerhinterzieher, in: Die Welt v. 21. 04. 2016, zu finden unter http://www.welt.de/wirtschaft/article154192043/Schaeubles-Zehn-Punkte-Plan-gegen-Steuerhinterzieher.html.

7 Dams, Schäubles Zehn-Punkte-Plan gegen Steuerhinterzieher, in: Die Welt v. 21. 04. 2016, zu finden unter http://www.welt.de/wirtschaft/article154192043/Schaeubles-Zehn-Punkte-Plan-gegen-Steuerhinterzieher.html.

8 Wirtschaftswoche v. 11. 04. 2014, zu finden unter http://www.wiwo.de/politik/deutschland/ panama-papers-schaeubles-10-punkte-plan-gegen-steueroasen/13428626.html.

9 ZEIT ONLINE v. 10. 04. 2016, zu finden unter http://www.zeit.de/politik/deutschland/2016-04/ wolfgang-schaeuble-geldwaesche-zehn-punkte-plan.

10 Referentenentwurf des Bundesministeriums der Finanzen, Entwurf eines Gesetzes zur Umsetzung der Vierten EU-Geldwäscherichtlinie, zur Ausführung der EU-Geldtransferverordnung und zur Neuorganisation der Zentralstelle für Finanztransaktionsuntersuchungen v. 22. 07. 2016, zu finden unter http://www.bundesfinanzministerium.de/Content/DE/Downloads/Gesetze/ 201702-22-eu-geldwaescherichtlinie.pdf?_blob=publicationFile\&v=7.

11 Kommission, Vorschlag für eine RICHTLINIE DES EUROPÄISCHEN PARLAMENTS UND DES RATES zur Änderung der Richtlinie (EU) 2015/849 zur Verhinderung der Nutzung des Finanz- 
Damit werden die im Rahmen dieses Beitrags aufgeworfenen Fragen um die Vierte Geldwäscherichtlinie nicht etwa obsolet - sie stellen sich vielmehr in verschärfter Form: Der Kommissionsvorschlag zur Änderung der Vierten Geldwäscherichtlinie (wie auch die entsprechenden Änderungen des GwG-E) sehen als wesentliche Kernpunkte die Ausweitung des Kreises der wirtschaftlichen Eigentümer, den grundsätzlich freien Zugang zu den Daten über den wirtschaftlichen Eigentümer in einem öffentlichen Register sowie eine Vernetzung der nationalen in einem unionsweiten Register vor ${ }^{12}$. Nachfolgend soll aufgezeigt werden, dass bereits die Regelungen der Vierten Geldwäscherichtlinie sehr weit reichen und mit dem Recht auf Schutz personenbezogener Daten (Art. 8 GRC) und mit Blick auf die Entscheidung des EuGH zur Vorratsdatenspeicherung ${ }^{13}$ nicht vereinbar sind.

\section{Vorgaben des Art. 30 der Vierten Geldwäscherichtlinie}

\section{Nennung der wirtschaftlichen Eigentümer}

Nach Art. 30 der Vierten Geldwäscherichtlinie müssen Gesellschaften oder sonstige juristische Personen angemessene, präzise und aktuelle Angaben zu ihren wirtschaftlichen Eigentümern, einschließlich genauer Angaben zum wirtschaftlichen Interesse, einholen und aufbewahren und diese Informationen den Verpflichteten der Geldwäsche ${ }^{14}$, wenn sie Sorgfaltspflichten gegenüber ihren Kunden gemäß Kapitel II ${ }^{15}$ nachkommen, vorlegen. Dem Wortlaut zufolge haben die

systems zum Zwecke der Geldwäsche und der Terrorismusfinanzierung und zur Änderung der Richtlinie 2009/101/EG, COM(2016) 450 final v. 5. 7. 2016.

12 Kommission, COM(2016) 450 final v. 05. 07. 2016, S. 4 ff.; eingehend zum Änderungsvorschlag der Vierten Geldwäscherichtlinie und zum Referentenentwurf des GwG N. Müller, NZWiSt $3 / 2017,87 \mathrm{ff}$.

13 EuGH, 08. 04. 2014, Rs. C-293/12 und C-594/12 (Digital Rights Ireland und Seitlinger u.a.); unlängst bestätigt durch EuGH, 21. 12. 2016, Rs. C-203/15 u. C-698/15 (Tele2 Sverige); so auch Krais, CCZ 2015, 251, 252.

14 Geldwäscheverpflichtete sind Personen, die aufgrund ihrer beruflichen Tätigkeit verstärkt mit „riskanten“ Geschäften bzw. Transaktionen in Berührung kommen, etwa Kreditinstitute und ihre Mitarbeiter, Notare, Wirtschaftsprüfer und Steuerberater, Dienstleister für Trusts oder Gesellschaften, Immobilienmakler, Anbieter von Glücksspieldiensten etc., siehe Art. 2 der Vierten Geldwäscherichtlinie; siehe auch $\S 2$ GWG.

15 Danach haben Geldwäscheverpflichtete unter bestimmten Voraussetzungen (etwa bei Begründung einer Geschäftsbeziehung oder verdächtigen Transaktionen) die Identität des Kunden 
Gesellschaften oder sonstigen juristischen Personen die Angaben selbst proaktiv zu eruieren und ständig zu aktualisieren und vorzuhalten, um sie bei Bedarf zur Verfügung stellen zu können. Bezweckt werden soll damit laut den Erwägungsgründen, die Person, die als wirtschaftlich Berechtigter ${ }^{16}$ hinter einer Gesellschaft oder juristischen Person steht bzw. die Gesellschaft oder juristische Person leitet oder beherrschenden Einfluss ausübt, ausfindig zu machen ${ }^{17}$.

Gemäß Art. 3 Ziff. 6 der Vierten Geldwäscherichtlinie versteht man unter dem „wirtschaftlichen Eigentümer“ alle natürlichen Personen, in deren Eigentum oder unter deren Kontrolle der Kunde letztlich steht, und/oder die natürlichen Personen, in deren Auftrag eine Transaktion oder Tätigkeit ausgeführt wird. Dazu zählen bei Gesellschaften alle natürlichen Personen, in deren Eigentum oder unter deren Kontrolle eine juristische Person steht; das Eigentum bzw. die Kontrolle können dabei über das direkte oder indirekte Halten eines ausreichenden Anteils von Aktien oder Stimmrechten, über eine Beteiligung an jener juristischen Person, einschließlich in Form von Inhaberaktien, oder durch andere Formen der Kontrolle ausgeübt werden ${ }^{18}$. Hält eine natürliche Person einen Aktienanteil von $25 \%$ zuzüglich einer Aktie oder eine Beteiligung von mehr als 25\% an einem Kunden, so gilt dies als Indiz für direktes Eigentum. Hält eine Gesellschaft, die von einer oder mehreren natürlichen Personen kontrolliert wird, oder halten mehrere Gesellschaften, die von derselben natürlichen Person oder denselben natürlichen Personen kontrolliert werden, einen Aktienanteil von 25\% zuzüglich einer Aktie oder eine Beteiligung von mehr als $25 \%$ am Kunden, so gilt dies als Hinweis auf indirektes Eigentum. Laut Art. 3 Ziff. 6 der Vierten Geldwäscherichtlinie bleibt es den Mitgliedstaaten unbenommen zu beschließen, dass bereits ein niedrigerer Prozentsatz als Hinweis auf Eigentum oder Kontrolle gelten kann ${ }^{19}$.

oder auch des wirtschaftlich Berechtigten eines Rechtsträgers festzustellen, Informationen über den Zweck einer Geschäftsbeziehung einzuholen oder eine solche kontinuierlich zu überwachen, siehe Art. 12 und 13 der Vierten Geldwäscherichtlinie.

16 Zur Definition des wirtschaftlich Berechtigten, siehe Art. 3 Ziff. 6 der Vierten Geldwäscherichtlinie; danach wird eine direkte oder indirekte Beteiligung an Gesellschaften von mehr als $25 \%$ als Indiz für eine wirtschaftliche Berechtigung gesehen; eingehend dazu Krais, CCZ 2015, 251, 254.

17 ABl. EU v. 05. 06. 2015, L 141/75, Erwägungsgrund 13.

18 Es wird noch ergänzt, dass es sich bei dieser juristischen Person nicht um eine an einem geregelten Markt notierte Gesellschaft handelt, die dem Unionsrecht entsprechenden Offenlegungspflichten bzw. gleichwertigen internationalen Standards, die angemessene Transparenz der Informationen über die Eigentumsverhältnisse gewährleisten, unterliegt, s. Art. 3 Ziff. 6 a) i) der Vierten Geldwäscherichtlinie.

19 Der Kommissionsvorschlag zur Änderung der Vierten Geldwäscherichtlinie sieht hier eine Herabsetzung des Prozentsatzes auf 10\% vor, so dass es zu einer weiteren Ausweitung des Kreises der wirtschaftlich Berechtigten kommt, s. Kommission, $\operatorname{COM(2016)} 450$ final v. 05. 07. 2016, S. 35. 
Laut Art. 3 Ziff. 6 der Vierten Geldwäscherichtlinie können unter bestimmten Voraussetzungen Personen aus der Führungsebene der Gesellschaft als wirtschaftliche Eigentümer bestimmt werden. Dies soll dann der Fall sein, wenn nach Ausschöpfung aller Möglichkeiten und sofern keine Verdachtsmomente vorliegen, keine Person nach den vorstehenden Kriterien ermittelt worden ist oder wenn der geringste Zweifel daran besteht, dass es sich bei der ermittelten Person um den wirtschaftlichen Eigentümer handelt. Zentes und Glaab weisen zutreffend auf die mit dieser Regelung einhergehende starke Erweiterung des wirtschaftlichen Eigentümers in der Vierten zur Dritten Geldwäscherichtlinie hin ${ }^{20}$. Kunz und Schirmer führen diese Regelung auf die Empfehlung Nr. 10 FATF zurück, in der in ähnlichen Fällen die Identifizierung eines „senior managing official“ empfohlen wird. Die hierzu laut gewordenen Bedenken, dass es so zu einer Vermischung der Begrifflichkeiten des ,wirtschaftliche Berechtigten“ und des „Vertretungsberechtigten“ kommen könnte ${ }^{21}$, teilen sie nicht, bedauern jedoch, dass vage bleibt, wer zum Kreis dieser Personen aus der Führungsebene gehören soll ${ }^{22}$. Krais kritisiert diesbezüglich zu Recht, dass die „Pflicht alle (!) Mitglieder der Führungsebene beim Kunden als (fiktive) wirtschaftliche Berechtigte $\mathrm{zu}$ identifizieren“ dazu führt, dass unter Umständen ein (häufig öffentlich nicht bekannter) breiter Personenkreis, der weder direkt noch indirekt Eigentum oder Kontrolle ausübt, angegeben werden muss, weil der wirtschaftliche Berechtigte nicht feststellbar ist oder an seiner Richtigkeit „geringste (!) Zweifel“ bestehen ${ }^{23}$.

Mit der Bereitstellung der Daten über die genannten Personen soll insbesondere Situationen, wie sie in Panama durch die Gründung von Briefkastenfirmen offshore entstanden sind, entgegengewirkt werden.

\section{Zugriffsberechtigung}

Nach Art. 30 Vierte Geldwäscherichtlinie soll den zuständigen Behörden oder zentralen Meldestellen ermöglicht werden, zeitnah auf in einem nationalen Register vorgehaltene Daten zuzugreifen. Zugriffsberechtigt sind dabei die zuständigen Behörden und zentralen Meldestellen ohne Einschränkung, also auch nichtanlassbezogen, während die nach der Geldwäscherichtlinie Verpflichteten im Rahmen ihrer Sorgfaltspflicht (nach Kapitel II) und alle sonstigen Personen nur zugreifen können, sofern sie ein berechtigtes Interesse nachweisen können. Aus

20 Zentes/Glaab, BB 2013, 707, 712.

21 So Rößler, WM 2015, 1406, 1408.

22 Kunz/Schirmer, BB 2015, 2435, 2438.

23 Krais, CCZ 2015, 251, 254. 
dem Wortlaut der Norm ergibt sich kein Anhaltspunkt für eine Konkretisierung dieses berechtigten Interesses; lediglich die Erwägungsgründe zeigen, dass es sich bei diesen weiteren zugriffsberechtigten Personen um solche handeln soll, die ein „legitimes Interesse im Zusammenhang mit Geldwäsche, Terrorismusfinanzierung und damit zusammenhängenden Vortaten - wie Bestechung, Steuerstraftaten und Betrug - nachweisen können“. Insofern stellen die Erwägungsgründe zwar einen Bezug zum Zweck der Geldwäscherichtlinie her, lassen jedoch offen, ob dieses berechtigte Interesse auch rein präventiv geltend gemacht werden kann. Bedenklich ist die Weite und Unbestimmtheit der Begrifflichkeit des „berechtigten Interesses“, die auch durch einen Rückgriff auf die Erwägungsgründe nicht ausreichend konkretisiert werden kann. Zudem stellen die Erwägungsgründe einen nur unspezifischen Bezug zu den Vortaten der Geldwäsche her, der den Anschein erweckt, als könnte der reine Verdacht einer Vortat (noch im Vorfeld des Geldwäscheverdachts) ein berechtigtes Interesse im genannten Sinne begründen. Diese Problematik verschärft sich noch dadurch, dass die geldwäscherelevanten Vortaten von Mitgliedstaat zu Mitgliedstaat variieren können und - so z.B. in Belgien und England - sämtliche Straftaten Vortaten der Geldwäsche sein können.

Weiter heißt es in Art. 30 der Richtlinie, dass Personen oder Organisationen, die ein berechtigtes Interesse geltend machen, mindestens Angaben zu Namen, Geburtsdatum, Staatsangehörigkeit und Wohnsitzland des wirtschaftlichen Eigentümers sowie $\mathrm{zu}$ Art und Umfang des wirtschaftlichen Interesses erhalten sollen, was bedeutet, dass die Mitgliedstaaten grundsätzlich auch ein weitergehendes Informationsrecht begründen können (so auch Erwägungsgrund 15 der Richtlinie $^{24}$ ). Allerdings muss der Datenzugang im Einklang stehen mit den Vorschriften zum Datenschutz und „kann einer Online-Registrierung und der Zahlung einer Gebühr unterliegen“ (vergleichbar dem Handelsregisterauszug). Mit Blick auf diese Regelung stellt sich die Frage, ob das Führen des zentralen Registers (das verpflichtend vorgegeben ist) in Form eines Online-Registers möglicherweise den Mitgliedstaaten als Umsetzungsoption frei überlassen bleibt („Kann“-Vorschrift). Aus dem Gesamtzusammenhang des Absatzes geht dies nicht eindeutig hervor, es erscheint aus folgenden Überlegungen jedoch als eher unwahrscheinlich: Art. 30 Abs. 5 Satz 3 der Richtlinie regelt zum einen allein den Zugang zu den vorgehaltenen Daten und die diesbezüglichen Hürden. So müssen zum einen Datenschutzvorschriften beachtet werden, zum anderen kann demjenigen, der auf die Daten zugreifen will, abverlangt werden, dass er sich registrieren lässt, also seinerseits persönliche Daten angibt, und darüber hinaus mit einer Gebühr

24 ABl. EU v. 05. 06. 2015, L 141/76, Erwägungsgrund 15. 
belegt wird, die allerdings nur die verursachten Verwaltungskosten decken darf. Gegenstand der Regelung scheint demnach nur zu sein, die möglichen Pflichten bzw. Belastungen des Nutzers zu regeln, nicht aber insgesamt das Führen eines Online-Registers in das Ermessen der Mitgliedstaaten zu stellen ${ }^{25}$.

Vor diesem Hintergrund bleibt fraglich und offen, wie bei einem OnlineDatenzugriff sichergestellt werden kann, dass tatsächlich nur Personen mit berechtigtem Interesse auf die vorgehaltenen Informationen zugreifen können. Wenn schon der bloße Verdacht einer Vortat zur Geldwäsche ein berechtigtes Interesse begründet, liegt - sobald ein Online-Zugriff möglich ist - eine mehr oder weniger allgemeine Zugänglichkeit der Daten vor und die Sicherstellung eines Bezugs zu geldwäscherelevanten Sachverhalten ist praktisch nicht mehr möglich. Dies gilt umso mehr, als die Regelung zur Online-Registrierung des Nutzers eine „Kann“-Vorschrift darstellt, eine solche Registrierung sowie die Verwaltungsgebühr nicht zwingend eingeführt werden müssen. Eine Nichteinführung würde aber zwangsläufig mit sich bringen, dass anonym und ohne jedes berechtigte Interesse auf das Register zugriffen werden könnte, dieses also öffentlich würde ${ }^{26}$. Dies gilt umso mehr als die Verwaltungsgebühr selbst - die lediglich kostendeckend sein darf - aufgrund ihrer vermutlich geringen Höhe kaum geeignet sein dürfte, Interessierte von einem nicht durch ein berechtigtes Interesse gedeckten Registerzugriff abzuhalten. Zwar gibt es hierzulande bereits verschiedene Register, aus denen u.a. nach Glaubhaftmachung eines berechtigten Interesses Auskunft erteilt wird, so etwa z. B. das Register über Halter- und Fahrzeugdaten. Der BGH betrachtet dieses Register wegen des begrenzen Personenkreises, der nach Darlegung eines berechtigten Interesses darauf zugreifen darf, als nicht öffentliches Register. Ferner geht er davon aus, dass erwartet werden dürfe, dass die zuständigen Behörden überprüften, ob die gesetzlichen Voraussetzungen für eine Auskunft vorlägen. Zum anderen sei davon auszugehen, dass sich der Bürger grundsätzlich rechtstreu verhalte, also nur anfrage, wenn er ein berechtigtes Interesse an der Auskunft habe ${ }^{27}$. Unabhängig davon, ob man diese Ausführungen des BGH für überzeugend erachtet, soll nachfolgend dargestellt werden, dass mit dem Register nach Art. 30 der Vierten Geldwäscherichtlinie eine andere Aus-

25 Das im Kommissionsvorschlag zur Änderung der Vierten Geldwäscherichtlinie vorgesehene unionsweite Register bestätigt diese Einschätzung, s. Kommission, $\operatorname{COM(2016)~} 450$ final v. 05. 07. 2016, S. 22.

26 So jetzt der Kommissionsvorschlag zur Änderung der Vierten Geldwäscherichtlinie bzw. der Referentenentwurf des Bundesministeriums der Finanzen v. 15. 12. 2016, die nun ein grundsätzlich öffentliches Register vorsehen, eingehend dazu N. Müller, NZWiSt 3/2017, 87 ff. und NZWiSt 4/2017, $121 \mathrm{ff}$.

27 BGHSt. 48, $28 \mathrm{ff}$. 
gangslage geschaffen wird, da schon der Bezug zum bloßen Verdacht des Vorliegens geldwäscherelevanter Vortaten jedem Zugriff infolge eines berechtigten Interesses Tür und Tor öffnet und das Register quasi öffentlich macht.

Im Weiteren sieht Art. 30 Abs. 7 der Richtlinie vor, dass die zentralen Meldestellen und zuständigen Behörden abgerufene Daten an zuständige Behörden und zentrale Meldestellen anderer Mitgliedstaaten weitergeben können. Mit Blick auf das vorstehend Ausgeführte erscheint es darüber hinaus nicht ausgeschlossen, dass etwa durch Kreditinstitute solche Daten auch an Filialen in anderen Mitgliedstaaten weitergegeben werden und dass Personen und Organisationen mit berechtigtem Interesse die Informationen an Dritte weitergeben.

Art. 30 Abs. 9 der Richtlinie sieht für den Informationszugriff durch Personen mit berechtigtem Interesse oder Verpflichtete im Rahmen ihrer Sorgfaltspflicht in Ausnahmefällen eine Einschränkung des Datenzugriffs vor, nämlich wenn eine Einzelfallprüfung unter außergewöhnlichen Umständen ergibt, dass der Informationszugriff den wirtschaftlichen Eigentümer dem Risiko von Betrug, Entführung, Erpressung, Gewalt oder Einschüchterung aussetzen würde oder der wirtschaftliche Eigentümer minderjährig oder anderweitig geschäftsunfähig ist. Dass dem wirtschaftlichen Eigentümer der Nachweis eines Risikos von Betrug, Entführung, Erpressung, Gewalt oder Einschüchterung gelingt, erscheint äußerst fraglich, sieht man von Fällen der Wiederholungsgefahr ab, in denen die Information aber ohnehin bereits in Umlauf und „das Kind bereits in den Brunnen gefallen ist“. Daher dürfte die Ausnahmeregelung nach Art. 30 Abs. 9 der Richtlinie in der Praxis aufgrund der hohen Hürden nur zum Tragen kommen, wenn Minderjährige und Geschäftsunfähige betroffen sind. Dazu später noch mehr.

\section{Art. 31 der Richtlinie}

\section{Nennung der wirtschaftlichen Eigentümer}

Nach Art. 31 Abs. 1 der Richtlinie haben auch Trustees eines Express Trusts (und in Struktur und Funktion Trusts vergleichbare Rechtsvereinbarungen) angemessene, präzise und aktuelle Informationen zu den wirtschaftlichen Eigentümern in Bezug auf den Trust einzuholen bzw. aufzubewahren, namentlich Angaben zur Identität des Settlors, Trustees, ggf. des Protektors, des Begünstigten oder einer sonstigen natürlichen Person, unter deren effektiver Kontrolle der Trust steht. Trustees haben gegenüber den Geldwäscheverpflichteten ihren Status offenzulegen, wenn sie eine Geschäftsbeziehung begründen oder geldwäscherelevante Transaktionen vornehmen. In Art. 3 Ziff. 6 der Vierten Geldwäscherichtlinie wird bezüglich Trusts (und trustähnlichen juristischen Personen) auf den schema- 
tischen Schwellenwert von 25\% verzichtet und dieser durch eine flexiblere Auffangregelung ersetzt ${ }^{28}$.

\section{Zugriffsberechtigung}

Den zuständigen Behörden oder zentralen Meldestellen muss die Möglichkeit eingeräumt werden, zeitnah auf die Informationen zum wirtschaftlichen Eigentümer nach Art. 31 Abs. 1 der Richtlinie zugreifen zu können (ohne dass der Betroffene dabei gewarnt wird). Die Angaben müssen in einem zentralen Register aufbewahrt werden, wenn mit dem Trust steuerliche Folgen verbunden sind (die Einschränkung erfuhr wegen ihrer Unklarheit und Umgehungsmöglichkeit im Gesetzgebungsprozess Kritik ${ }^{29}$ ). Auch Geldwäscheverpflichtete sollen im Rahmen ihrer Sorgfaltspflicht nach Kapitel II Zugriff auf die im Register vorgehaltenen Daten haben.

Personen oder Organisationen mit einem berechtigten Interesse sind hier nicht als Informationszugriffsberechtigte genannt; insofern liegt hier eine Privilegierung gegenüber der Betroffenen in Art. 30 der Richtlinie vor ${ }^{30}$. Überdies entfällt die Problematik des Online-Zugriffs, sofern nicht mit dem zentralen Register dasselbe gemeint ist wie in Art. 30 der Richtlinie. Ein Verweis auf die dortige Vorschrift findet sich in Art. 31 Abs. 4 der Richtlinie nicht; aus Praktikabilitätsgründen erscheint das Zusammenführen beider Informationsquellen allerdings grundsätzlich möglich und mit Blick auf die geplanten Änderungen der Vierten Geldwäscherichtlinie ${ }^{31}$ auch wahrscheinlich.

Die Probleme, die sich aus Art. 31 der Richtlinie ergeben können, decken sich somit weitestgehend mit den zu Art. 30 genannten, insbesondere wenn auch die in diesem Zusammenhang erhobenen Daten in Form des in Art. 30 bezeichneten Online-Registers geführt werden. Der Zugriff auf ein Online-Register (gegen eine

28 Siehe Kunz/Schirmer, BB 2015, 2435, 2438.

29 Kunz/Schirmer, BB 2015, 2435, 2439: der Kommissionsvorschlag zur Änderung der Vierten Geldwäscherichtlinie differenziert daher stattdessen zwischen gemeinnützigen und unternehmerisch tätigen Trusts und Rechtsvereinbarungen, s. Kommission, $\operatorname{COM}(2016) 450$ final v. 05. 07. 2016, S. $19 \mathrm{f}$.

30 Die Privilegierung wird auch im Kommissionsvorschlag zur Änderung der Vierten Geldwäscherichtlinie beibehalten; während Art. 30 dort einen freien Zugang zu den Registerdaten vorsieht, sind neben anlasslos zugriffsberechtigten Behörden und Geldwäscheverpflichteten nach Art. 31 Personen und Organisationen zugriffsbefugt, die ein berechtigtes Interesse nachweisen können, s. Kommission, COM(2016) 450 final v. 05. 07. 2016, S. $18 \mathrm{ff}$.

31 Kommission, $\operatorname{COM(2016)~} 450$ final v. 05. 07. 2016; eingehend dazu N. Müller, NZWiSt 3/2017, $87 \mathrm{ff}$. und NZWiSt 4/2017, $121 \mathrm{ff}$. 
etwaige Registrierung und Verwaltungsgebühr) lässt nämlich befürchten, dass auch in Bezug auf die Betroffenen des Art. 31 ein anlassloser und unkontrollierbarer Zugriff weiterer Personen als die in der Richtlinie Bezeichneten (möglicherweise auch über die Grenzen des Mitgliedstaates hinaus) möglich wird. Darüber hinaus steht zu befürchten, dass das Wesen des Trusts durch die Pflicht zur Preisgabe der Angaben zu Settlor und Begünstigten (dass diese anonym bleiben können, macht das Wesen des Trusts gerade aus) konterkariert wird; dies soll aber wohl gerade erreicht werden. Kritisch zu sehen ist zudem, dass hier (im Vergleich zu Art. 30 Abs. 9 der Richtlinie) gerade keine Ausnahmeregelung vorgesehen ist ${ }^{32}$. Offen bleibt, weshalb - nur sehr vage - auf Trusts mit steuerlichen Folgen und ,in Struktur und Funktion Trusts vergleichbaren Rechtsvereinbarungen“" abgestellt wird ${ }^{33}$.

\section{Zwischenergebnis}

Art. 30 der Richtlinie gibt den Mitgliedstaaten vor, Gesellschaften und juristische Personen dahingehend in die Pflicht zu nehmen, dass sie präventiv (ohne Bezug zu geldwäscherelevanten Verdachtsfällen) sowie proaktiv Daten zum wirtschaftlichen Eigentümer vorhalten und in einem zentralen Register erfassen. Auf das Register sollen zuständige Behörden und zentrale Meldestellen anlasslos, Verpflichtete im Rahmen ihrer Sorgfaltspflicht und Personen und Organisationen mit „berechtigtem Interesse“ ggf. auch online zugreifen können.

Art. 31 der Richtlinie will über die Mitgliedstaaten Trustees dazu verpflichten, präventiv und proaktiv Daten zum wirtschaftlichen Eigentümer (Settlor, Trustee, ggf. Protektor, Begünstigter oder eine sonstige natürliche Person, unter deren effektiver Kontrolle der Trust steht) vorzuhalten. Auch hier sollen die Daten (in demselben) zentralen Register zuständigen Behörden und zentralen Meldestellen anlasslos zur Verfügung stehen. Die Trusts unterliegen damit - entgegen der in den Erwägungsgründen erwähnten Zielsetzung, einen fairen Wettbewerbs zwischen den Rechtsformen zu schaffen - insgesamt weniger strengen

32 Der Kommissionsvorschlag zur Änderung der Vierten Geldwäscherichtlinie sieht dagegen in Art. 30 sowie in Art. 31 eine zu Art. 30 Abs. 9 der Vierten Geldwäscherichtlinie inhaltsgleiche Ausnahmeregelung vor, s. Kommission, $\operatorname{COM(2016)~} 450$ final v. 05. 07. 2016, S. $38 \mathrm{ff}$.

33 Der Kommissionsvorschlag zur Änderung der Vierten Geldwäscherichtlinie sieht stattdessen eine Differenzierung zwischen gemeinnützigen und unternehmerisch tätigen Trusts und Rechtsvereinbarungen vor, s. Kommission, $\operatorname{COM}(2016) 450$ final v. 05. 07. 2016, S. 19 f.; siehe auch $N$. Müller, NZWiSt 3/2017, 87, 90 f. 
Vorgaben als Gesellschaften und sonstige juristische Personen nach Art. 30 der Richtlinie $^{34}$.

\section{Vereinbarkeit der Art. 30 und 31 der Vierten Geldwäscherichtlinie mit der Grundrechtecharta und dem Datenschutzrecht}

Neben einzelnen Detailfragen ist in diesem Zusammenhang problematisch, ob die Pflicht zu einem präventiven (ohne Bezug zu einem Geldwäscheverdacht) und proaktiven Vorhalten der Daten, insbesondere in Form eines zentralen (Online-) Registers, mit den laut der Richtlinie eindeutig geltenden europäischen Datenschutzvorgaben bzw. mit den in der Grundrechtecharta verankerten Grundrechten (insbesondere Art. 8 GRC) vereinbar ist, bzw. ob es unter Berücksichtigung der Ermessensspielräume der Mitgliedstaaten eine grundrechtsverträgliche Umsetzung der Vorgaben in Art. 30 und 31 der Vierten Geldwäscherichtlinie geben $\mathrm{kann}^{35}$.

\section{Vereinbarkeit mit europäischem Datenschutzrecht}

Laut Erwägungsgrund 42 der Vierten Geldwäscherichtlinie gilt für die Verarbeitung personenbezogener Daten für die Zwecke der Geldwäscherichtlinie die in nationales Recht umgesetzte Datenschutzrichtlinie 95/46/EG des Europäischen Parlaments und des Rates ${ }^{36}$. Für die Verarbeitung personenbezogener Daten durch die Organe und Einrichtungen der Union für die Zwecke der Geldwäscherichtlinie gilt die Verordnung (EG) Nr. 45/2001 des Europäischen Parlaments und des Rates. ${ }^{37}$

34 Der Kommissionsvorschlag zur Änderung der Vierten Geldwäscherichtlinie nimmt insofern eine deutliche Verschärfung vor, als in Art. 30 ein öffentlicher Registerzugang und in Art. 31 ein gestaffelter Datenzugang vorgesehen ist, siehe N. Müller, NZWiSt 3/2017, 87 ff. und NZWiSt 4/2017, $121 \mathrm{ff}$.

35 Kritisch dazu auch Krais, CCZ 2015, 251, 252.

36 Beschluss des Gemeinsamen EWR-Ausschusses vom 25. 06. 1999 Nr. 83/1999.

37 Siehe nur ABl. EU v. 05. 06. 2015, L 141/79, Erwägungsgrund 42. 


\section{a) Datenschutzrichtlinie $95 / 46 /$ EG}

\section{aa) Ziele}

Datenverarbeitungssysteme nach der Richtlinie 95/46/EG sollen laut den Erwägungsgründen zwei Hauptintentionen verfolgen, die sich zum Teil diametral gegenüberstehen. Zum einen geht es um die Errichtung und das Funktionieren des Binnenmarktes, also die Sicherstellung eines freien Waren-, Personen-, Dienstleistungs- und Kapitalverkehrs, und dass zu diesem Zweck personenbezogene Daten auch zwischen den Mitgliedstaaten übermittelt werden können, zum anderen müssen jedoch die Grundrechte der von der Datenverarbeitung betroffenen Personen gewahrt bleiben ${ }^{38}$. Bezüglich der Umsetzung haben die Mitgliedstaaten einen Spielraum ${ }^{39}$, der jedoch durch die Grundrechte und Grundfreiheiten, insbesondere durch Art. 8 EMRK, begrenzt ist, da ein hohes Schutzniveau in der Gemeinschaft erreicht werden soll ${ }^{40}$.

Die entsprechenden Schutzprinzipien gelten für jede Verarbeitung personenbezogener Daten, sobald die Tätigkeiten des für die Verarbeitung Verantwortlichen in den Anwendungsbereich des Unionsrechts fallen. Einschränkungen gelten für die Bereiche, die die rein persönliche oder familiäre Tätigkeit einer Person oder Belange der Staatssicherheit betreffen ${ }^{41}$. Die Datenschutzrichtlinie berührt auch nicht die Rechtsvorschriften zum Schutz juristischer Personen bei der Verarbeitung von Daten, die sich auf sie beziehen ${ }^{42}$.

\section{bb) Voraussetzungen der Datenverarbeitung}

Personenbezogene Daten sind nach Art. 2 a) der Richtlinie „alle Informationen über eine bestimmte oder bestimmbare natürliche Person (,betroffene Person“)“; Verarbeitung ist jeder „mit oder ohne Hilfe automatisierter Verfahren ausgeführten Vorgang oder jede Vorgangsreihe im Zusammenhang mit personenbezogenen Daten wie das Erheben, das Speichern, die Organisation, die Aufbewahrung, die Anpassung oder Veränderung, das Auslesen, das Abfragen, die Benutzung, die Weitergabe durch Übermittlung, Verbreitung oder jede andere Form der Bereitstellung, die Kombination oder die Verknüpfung sowie das Sperren, Löschen oder

38 RL 95/46/EG v. 24. 10. 1995, ABl. EG v. 23. 11. 1995 Nr. L 281/31, Erwägungsgrund 1-3.

39 RL 95/46/EG v. 24. 10. 1995, ABl. EG v. 23. 11. 1995 Nr. L 281/32, Erwägungsgrund 9.

40 RL 95/46/EG v. 24. 10. 1995, ABl. EG v. 23. 11. 1995 Nr. L 281/32, Erwägungsgrund 10; siehe auch EuGH, 13. 05. 2014, Rs. C-131/12, Rdn. 66 (Google Spain SL).

41 RL 95/46/EG v. 24. 10. 1995, ABl. EG v. 23. 11. 1995 Nr. L 281/32, Erwägungsgrund $12 \mathrm{ff}$.

42 RL 95/46/EG v. 24. 10. 1995, ABl. EG v. 23. 11. 1995 Nr. L 281/33, Erwägungsgrund 24. 
Vernichten“43. Für die Verarbeitung verantwortliche Personen sind nach Art. 2 c) der Richtlinie natürliche oder juristische Personen, Behörden, Einrichtungen oder andere Stellen, die allein oder gemeinsam mit anderen über die Zwecke und Mittel der Verarbeitung von personenbezogenen Daten entscheiden. Die Richtlinie stellt sicher, dass der Datenschutz unabhängig von der Datenverarbeitungstechnik gewährt werden soll ${ }^{44}$.

Als wesentlich erscheinen im vorliegenden Zusammenhang Art. 6 und die Erwägungen in Ziff. 28 ff. der Richtlinie, in denen festgelegt wird, dass die Verarbeitung personenbezogener Daten gegenüber den betroffenen Personen nach Treu und Glauben erfolgen und dem angestrebten Zweck entsprechen muss, dafür erheblich zu sein und nicht darüber hinauszugehen hat. Dabei müssen die Zwecke eindeutig und rechtmäßig sein sowie bei der Datenerhebung festgelegt werden. Die Zweckbestimmungen der Weiterverarbeitung nach der Erhebung dürfen nicht mit den ursprünglich festgelegten Zwecken unvereinbar sein ${ }^{45}$.

Art. 7 der Richtlinie legt die Grundsätze in Bezug auf die Zulässigkeit der Datenverarbeitung fest und statuiert, dass eine Datenverarbeitung nur zulässig ist, wenn entweder die Person darin eingewilligt hat, die Verarbeitung für die Erfüllung einer rechtlichen Verpflichtung erforderlich ist, welcher der für die Verarbeitung Verantwortliche unterliegt, die Verarbeitung erforderlich ist für die Wahrnehmung einer Aufgabe, die im öffentlichen Interesse liegt, oder in Ausübung öffentlicher Gewalt erfolgt und dem für die Verarbeitung Verantwortlichen oder dem Dritten, dem die Daten übermittelt werden, übertragen wurde. Zulässig ist die Verarbeitung auch, soweit sie erforderlich ist zur Verwirklichung des berechtigten Interesses, das von dem für die Verarbeitung Verantwortlichen oder von dem bzw. den Dritten wahrgenommen wird, denen die Daten übermittelt werden, sofern nicht das Interesse oder die Grundrechte und Grundfreiheiten der betroffenen Person, die gemäß Artikel 1 Absatz 1 geschützt sind, überwiegen ${ }^{46}$. Insofern ist anhand einer Güterabwägung festzustellen, ob durch die Implikationen der Umsetzung von Art. 30 und 31 der Vierten Geldwäscherichtlinie die Grundrechte der betroffenen Personen über Gebühr beeinträchtigt werden; dies soll nachfolgend analysiert werden.

43 Art. 2b) der Richtlinie.

44 RL 95/46/EG v. 24. 10. 1995, ABl. EG v. 23. 11. 1995 Nr. L 281/33, Erwägungsgrund 27.

45 RL 95/46/EG v. 24. 10. 1995, ABl. EG v. 23. 11. 1995 Nr. L 281/34, Erwägungsgrund 28; siehe auch EuGH, 13. 05. 2014, Rs. C-131/12, Rdn. 72 (Google Spain SL).

46 RL 95/46/EG v. 24. 10. 1995, ABl. EG v. 23. 11. 1995 Nr. L 281/40. 


\section{cc) Informations- und Auskunftsrechte}

Nach Erwägungsgrund 38 der Richtlinie setzt die Datenverarbeitung nach Treu und Glauben voraus, dass die betroffene Person über die Datenverarbeitung informiert wird - entweder bei Speicherung der Daten oder bei erstmaliger Weitergabe derselben an Dritte. Dies gilt nicht, wenn die betroffene Person bereits informiert ist (so wenn sie selbst die Daten an das Register zu übermitteln hat) oder die Speicherung bzw. Weitergabe ausdrücklich durch das Gesetz vorgesehen ist (was durch die Umsetzung der Vierten Geldwäscherichtlinie ebenfalls vorgesehen ist $)^{47}$.

Die Richtlinie sieht in Erwägungsgrund 42 für die Mitgliedstaaten die Möglichkeit vor, die Auskunfts- und Informationsrechte im Interesse der betroffenen Person einzuschränken ${ }^{48}$. Entsprechend wird in Art. 13 der Richtlinie geregelt, dass Ausnahmen und Einschränkungen des Informationsrechts der betroffenen Person zulässig sind, wenn sie für die öffentliche Sicherheit oder die Verhütung, Ermittlung, Feststellung und Verfolgung von Straftaten oder Verstößen gegen die berufsständischen Regeln bei reglementierten Berufen bzw. infolge eines wichtigen wirtschaftlichen oder finanziellen Interesses eines Mitgliedstaats oder der Europäischen Union notwendig sind ${ }^{49}$.

Sodann sieht Erwägungsgrund 45 vor: „Auch wenn die Daten Gegenstand einer rechtmäßigen Verarbeitung aufgrund eines öffentlichen Interesses, der Ausübung hoheitlicher Gewalt oder der Interessen eines einzelnen sein können, sollte doch jede betroffene Person das Recht besitzen, aus überwiegenden, schutzwürdigen, sich aus ihrer besonderen Situation ergebenden Gründen Widerspruch dagegen einzulegen, daß die sie betreffenden Daten verarbeitet werden. Die Mitgliedstaaten können allerdings innerstaatliche Bestimmungen vorsehen, die dem entgegenstehen." ${ }^{\text {50 }}$

Entsprechend gibt Art. 14 der Richtlinie den betroffenen Personen ein Widerspruchsrecht zumindest gegen die Datenverarbeitung nach Art. 7 e) und f) der Richtlinie, wo es um die Datenverarbeitung zur Erfüllung einer Aufgabe im öffentlichen Interesse oder in Ausübung öffentlicher Gewalt bzw. um die Datenverarbeitung zur Verwirklichung eines berechtigten Interesses geht. Zumindest in solchen Fällen kann die betroffene Person nach Art. 14 a) der Richtlinie ,jederzeit aus überwiegenden, schutzwürdigen, sich aus ihrer besonderen Situation ergebenden Gründen“ gegen die sie betreffende Datenverarbeitung Widerspruch einlegen. Das gilt jedoch nicht, wenn eine im einzelstaatlichen Recht vorgesehene

47 RL 95/46/EG v. 24. 10. 1995, ABl. EG v. 23. 11. 1995 Nr. L 281/35, Erwägungsgrund 38-40.

48 RL 95/46/EG v. 24. 10. 1995, ABl. EG v. 23. 11. 1995 Nr. L 281/35, Erwägungsgrund 42.

49 RL 95/46/EG v. 24. 10. 1995, ABl. EG v. 23. 11. 1995 Nr. L 281/42.

50 RL 95/46/EG v. 24. 10. 1995, ABl. EG v. 23. 11. 1995 Nr. L 281/35, Erwägungsgrund 42. 
Regelung entgegensteht. „Im Fall eines berechtigten Widerspruchs kann sich die vom für die Verarbeitung Verantwortlichen vorgenommene Verarbeitung nicht mehr auf diese Daten beziehen. “51 Ein entsprechender Antrag des Betroffenen muss kostenfrei möglich sein. Daher haben die Mitgliedstaaten sicherzustellen, dass die betroffenen Personen von diesem Recht Kenntnis erlangen ${ }^{52}$.

Soweit also die Datenverarbeitung durch das Register nach Art. 30 und 31 der Vierten Geldwäscherichtlinie auf die Gründe jedenfalls der Art. 7 e) und f) der Richtlinie (,zumindest“) gestützt wird, muss dem von der Datenverarbeitung Betroffenen ein Widerspruchsrecht zugestanden werden, sofern überwiegende, schutzwürdige und sich aus seiner besonderen Situation ergebende Gründe vorliegen und keine einzelstaatliche Regelung dem entgegensteht. In diesem Zusammenhang ist darauf hinzuweisen, dass Art. 31 der Vierten Geldwäscherichtlinie keine Ausnahmeregelung vorsieht und die in Art. 30 Abs. 9 vorgesehene Ausnahmeregelung nur im Einzelfall unter hohen Voraussetzungen eine Ausnahme von der Pflicht zum Vorhalten der Daten vorsieht ${ }^{53}$. Von einem Widerspruchsrecht im dargestellten Sinne kann daher nicht gesprochen werden.

\section{dd) Verarbeitungsverfahren}

Für den Schutz der Rechte und Freiheiten der betroffenen Personen bei der Verarbeitung personenbezogener Daten müssen geeignete technische und organisatorische Maßnahmen getroffen werden $^{54}$. In diesem Zusammenhang stellt sich die Frage, ob das Register, wie es in Art. 30 und 31 der Vierten Geldwäscherichtlinie vorgesehen ist, diesen Anforderungen entspricht - insbesondere, wenn es als Online-Register geführt wird, auf das ggf. gegen Registrierung und Zahlung einer Gebühr zugegriffen werden kann.

Unter Abschnitt IX, in dem es um die Meldung von Datenverarbeitungsvorgängen geht, wird in Art. 18 Abs. 1 der Richtlinie geregelt, dass grundsätzlich jede vollständig oder teilweise automatisierte Datenverarbeitung bei der Kontrollstelle zu melden ist. Eine Vereinfachung bzw. Ausnahme von dieser Meldepflicht ist nach Abs. 2 unter bestimmten Voraussetzungen möglich. Die Meldepflicht nach Abs. 1 entfällt nach Art. 18 Abs. 3 der Richtlinie sogar vollständig, wenn einziger Zweck der Datenverarbeitung „das Führen eines Registers ist, das gemäß den

51 RL 95/46/EG v. 24. 10. 1995, ABl. EG v. 23. 11. 1995 Nr. L 281/42f.

52 RL 95/46/EG v. 24. 10. 1995, ABl. EG v. 23. 11. 1995 Nr. L 281/43.

53 Dies gilt faktisch auch für den Änderungsvorschlag der Richtlinie, da die dort vorgesehene Ausnahmeregelung tatsächlich kaum zum Tragen kommen wird, s. N. Müller, NZWiSt 3/2017, 87, 90 f. und NZWiSt 4/2017, 121, 127.

54 RL 95/46/EG v. 24. 10. 1995, ABl. EG v. 23. 11. 1995 Nr. L 281/35f., Erwägungsgrund 46. 
Rechts- oder Verwaltungsvorschriften zur Information der Öffentlichkeit bestimmt ist und entweder der gesamten Öffentlichkeit oder allen Personen, die ein berechtigtes Interesse nachweisen können, zur Einsichtnahme offensteht. “55 $\mathrm{Da}$ zumindest das Register nach Art. 30 der Vierten Geldwäscherichtlinie Personen und Organisationen mit berechtigtem Interesse offen stehen soll, könnte es unter diese Regelung fallen ${ }^{56}$.

Das Führen eines Online-Registers, das Personen mit einem berechtigten Interesse ggf. gegen Registrierung und Gebühr einen Zugriff ermöglicht, wie es Art. 30 der Vierten Geldwäscherichtlinie vorgesehen ist, wirft die praktische Frage auf, wie in einem automatisierten Vorgang kontrolliert werden kann, ob der Zugriff auf die Daten tatsächlich durch das Vorliegen eines berechtigten Interesses gedeckt war. Die Rechtsverletzung, die eintreten würde, wenn eine Person unberechtigterweise auf die Daten zugreifen könnte, wäre immens: Womöglich stünde zwar eine Sanktion oder ein Schadensersatzanspruch im Raum - dies würde jedoch nichts daran ändern, dass die Information nun tatsächlich im Umlauf wäre. Die besondere Brisanz einer - auch nur einmaligen - Datenschutzlücke ist, dass sich eine in der heutigen digitalen Welt einmal in Umlauf geratene Information quasi nicht mehr „einfangen“ lässt. Dadurch, dass sich die so in Umlauf geratenen Daten nunmehr ungehindert weiter verbreiten können, wird ein möglicher Eingriff in Grundrechte des Betroffenen kontinuierlich vertieft. Dazu nachfolgend mehr.

\section{ee) Datenweitergabe an Drittländer}

Mit Blick auf die Informationsweitergabe in Drittländer ist festzuhalten, dass Erwägungsgrund 56 der Richtlinie dem nicht entgegensteht. Dort heißt es: „Der in der Gemeinschaft durch diese Richtlinie gewährte Schutz von Personen steht der Übermittlung personenbezogener Daten in Drittländer, die ein angemessenes Schutzniveau aufweisen, nicht entgegen. Die Angemessenheit des Schutzniveaus, das ein Drittland bietet, ist unter Berücksichtigung aller Umstände im Hinblick auf eine Übermittlung oder eine Kategorie von Übermittlungen zu beurteilen.“57 Ist ein solches Schutzniveau in Drittländern nicht vorhanden, ist eine Datenweitergabe jedoch verboten (siehe auch Art. 25 der Richtlinie) $)^{58}$.

55 RL 95/46/EG v. 24. 10. 1995, ABl. EG v. 23. 11. 1995 Nr. L 281/44.

56 Dies legt der Kommissionsvorschlag zur Änderung der Vierten Geldwäscherichtlinie nahe, nach dem Art. 30 ein öffentliches Register und Art. 31 einen gestaffelten Datenzugriff vorsieht, siehe $N$. Müller, NZWiSt 3/2017, $87 \mathrm{ff}$. und NZWiSt 4/2017, $121 \mathrm{ff}$.

57 RL 95/46/EG v. 24. 10. 1995, ABl. EG v. 23. 11. 1995 Nr. L 281/36f., Erwägungsgrund 56.

58 RL 95/46/EG v. 24. 10. 1995, ABl. EG v. 23. 11. 1995 Nr. L 281/37, Erwägungsgrund 57. 
Nach Art. 26 der Richtlinie sind davon jedoch Ausnahmen zulässig. So können Daten auch in Drittländer übermittelt werden, die über kein angemessenes Schutzniveau verfügen. Voraussetzung dafür ist, dass die betroffene Person in die Weitergabe einwilligt, die Datenweitergabe im Rahmen eines Vertrages erforderlich ist, „die Übermittlung entweder für die Wahrung eines wichtigen öffentlichen Interesses oder zur Geltendmachung, Ausübung oder Verteidigung von Rechtsansprüchen vor Gericht erforderlich oder gesetzlich vorgeschrieben ist“ oder „die Übermittlung aus einem Register erfolgt, das gemäß den Rechts- oder Verwaltungsvorschriften zur Information der Öffentlichkeit bestimmt ist und entweder der gesamten Öffentlichkeit oder allen Personen, die ein berechtigtes Interesse nachweisen können, zur Einsichtnahme offensteht, soweit die gesetzlichen Voraussetzungen für die Einsichtnahme im Einzelfall gegeben sind“"59.

Da jedenfalls das Register nach Art. 30 der Vierten Geldwäscherichtlinie Personen offenstehen soll, die ein berechtigtes Interesse geltend machen, besteht die Möglichkeit, dass darin vorgehaltene Daten durch diese nicht nur in Drittländer mit vergleichbarem Schutzniveau wie die EU, sondern unter bestimmten Umständen auch in solche ohne ein angemessenes Schutzniveau übermittelt werden.

\section{ff) Zwischenergebnis}

Insgesamt lässt sich festhalten, dass es bei der Datenschutzrichtlinie im Kern darum geht, das Spannungsfeld zwischen dem Funktionieren des Binnenmarktes (Harmonisierung) und überwiegenden Grundrechten und Grundfreiheiten der von der Datenverarbeitung betroffenen Person zu regeln. Den betroffenen Personen steht grundsätzlich ein Widerspruchsrecht nach Art. 14 bei überwiegenden schutzwürdigen Belangen in Fällen des Art. 7 e) und f) der Richtlinie zu. Es hat sich jedoch gezeigt, dass die Verarbeitung von Daten durch Online-Register Risiken birgt, die nicht angemessen abgesichert werden können. Kritisch zu sehen ist insbesondere, dass die Meldepflicht nach Art. 18 Abs. 3 der Richtlinie vollständig entfällt, wenn einziger Zweck der Datenverarbeitung das Führen eines Registers ist, das Personen mit einem berechtigten Interesse zur Einsichtnahme offensteht, wie es bei Art. 30 der Vierten Geldwäscherichtlinie der Fall ist. Die Richtlinie 95/46/EG erlaubt zudem eine Weitergabe personenbezogener Daten innerhalb der EU und des EWR, aber auch in Drittländer mit entsprechenden Schutzmaßnahmen; bei einem Register nach Art. 30 der Vierten Geldwäscherichtlinie erscheint sogar eine Weitergabe an Drittländer ohne entsprechende Schutzmaßnahmen möglich.

59 RL 95/46/EG v. 24. 10. 1995, ABl. EG v. 23. 11. 1995 Nr. L 281/37, Erwägungsgrund 58. 


\section{b) Verordnung (EG) Nr. 45/2001}

Die Verordnung (EG) Nr. 45/2001, auf welche die Vierte Geldwäscherichtlinie Bezug nimmt ${ }^{60}$, ergänzt und präzisiert die Richtlinie 95/46/EG im Bereich der Telekommunikation; dies spielt insofern für das Register nach Art. 30 der Vierten Geldwäscherichtlinie eine Rolle, als dort der Datenzugriff über eine Online-Register (ggf. gegen Registrierung/Gebühr) erfolgen kann (siehe Art. 30 Abs. 5 der Vierten Geldwäscherichtlinie) ${ }^{61}$. Soweit die Vierte Geldwäscherichtlinie den Datenzugriff über ein Online-Register vorsieht, gilt dies nur, soweit die Datenschutzbestimmungen, insbesondere die der Verordnung (EG) Nr. 45/2001, eingehalten sind.

\section{aa) Voraussetzungen der Datenverarbeitung}

Laut Art. 4 der Verordnung dürfen personenbezogene Daten (siehe auch Art. 6 der Richtlinie 95/46/EG) nur nach Treu und Glauben auf rechtmäßige Weise verarbeitet werden, für festgelegte, eindeutige und rechtmäßige Zwecke erhoben und nicht in einer mit diesen Zwecken nicht zu vereinbarenden Weise weiterverarbeitet werden. Personenbezogene Daten müssen den Zwecken entsprechen, für die sie erhoben und/oder weiterverarbeitet werden, dafür erheblich sein und dürfen nicht darüber hinausgehen. Die Rechtmäßigkeit der Verarbeitung richtet sich danach, ob diese entweder für die Wahrnehmung einer Aufgabe erforderlich ist, die aufgrund der Verträge zur Gründung der Europäischen Gemeinschaften oder anderer aufgrund dieser Verträge erlassener Rechtsakte im öffentlichen Interesse oder in legitimer Ausübung öffentlicher Gewalt ausgeführt wird, die dem Organ oder der Einrichtung der Gemeinschaft oder einem Dritten, dem die Daten übermittelt werden, übertragen wurde. Rechtmäßig ist die Verarbeitung auch dann, wenn sie für die Erfüllung einer rechtlichen Verpflichtung, welcher der für die Verarbeitung Verantwortliche unterliegt, erforderlich ist, die betroffene Person eingewilligt hat oder die Verarbeitung für die Durchführung, Erfüllung eines Vertrags betroffenen Person oder die Wahrung lebenswichtiger Interessen dieser Person erforderlich ist (Art. 5 der Verordnung) ${ }^{62}$. Die Bestimmung ähnelt somit dem Art. 7 der Richtlinie 95/46/EG, nur dass dort auch die Verarbeitung der Daten zur Verwirklichung eines berechtigten Interesses des für die Verarbeitung

60 ABl. EG v. 12. 01. 2001, L 8/1.

61 VO (EG) Nr. 45/2001 v. 18. 12. 2000, ABl. EG v. 12. 01. 2001, L 8/2.

62 VO (EG) Nr. 45/2001 v. 18. 12. 2000, ABl. EG v. 12. 01. 2001, L 8/5f.; siehe auch Albrecht, CR 2016, 88, 92. 
Verantwortlichen zulässig ist, sofern nicht überwiegende Interessen der betroffenen Person (Grundrechte oder Grundfreiheiten) dem entgegenstehen.

Art. 6 der Verordnung regelt, dass personenbezogene Daten dann auch für andere als die Zwecke der eigentlichen Erhebung verarbeitet werden dürfen, „wenn die Änderung der Zwecke durch die internen Vorschriften des Organs oder der Einrichtung der Gemeinschaft ausdrücklich erlaubt ist.“ Nach Art. 6 Ziff. 2 der Verordnung dürfen personenbezogene Daten, die ausschließlich zur Gewährleistung der Sicherheit oder Kontrolle der Verarbeitungssysteme oder -vorgänge erfasst werden, mit Ausnahme zum Zwecke der Verhütung, Ermittlung, Feststellung und Verfolgung von schweren Straftaten, für keinen anderen Zweck verwendet werden ${ }^{63}$.

Hinzuweisen ist im Weiteren auf Art. 7 der Verordnung, wo in Bezug auf die Übermittlung personenbezogener Daten innerhalb von oder zwischen Organen oder Einrichtungen der Gemeinschaft festgehalten wird, dass personenbezogene Daten nur dann innerhalb oder zwischen diesen Einrichtungen bzw. Organen übermittelt werden dürfen, wenn dies für die rechtmäßige Aufgabenerfüllung des Empfängers erforderlich ist. Bei einer solchen Übermittlung von Daten sind Empfänger und Verantwortlicher für die Datenverarbeitung für die Zulässigkeit der Datenverarbeitung verantwortlich. „Der für die Verarbeitung Verantwortliche ist verpflichtet, die Zuständigkeit des Empfängers zu prüfen und die Notwendigkeit der Übermittlung dieser Daten vorläufig zu bewerten. Bestehen Zweifel an der Notwendigkeit, holt der für die Verarbeitung Verantwortliche weitere Auskünfte vom Empfänger ein. Der Empfänger stellt sicher, dass die Notwendigkeit der Übermittlung der Daten im Nachhinein überprüft werden kann." ${ }^{64}$ Das bedeutet, dass die Voraussetzungen für die Datenverarbeitung bzw. Datenübermittlung innerhalb bzw. zwischen den Organen der Gemeinschaft vergleichsweise hoch ist. Obschon es sich um Organe und Einrichtungen der Gemeinschaft handelt, muss sichergestellt werden, dass die Datenübermittlung notwendig war. Vor diesem Hintergrund erscheint es zweifelhaft, dass Personen und Organisationen mit berechtigtem Interesse ein Register mit Daten zur Verfügung gestellt werden soll, das nicht annähernd so hohe Schutzmaßnahmen zugunsten des Betroffenen trifft, insbesondere wenn die Möglichkeit eines Online-Zugriffs (ggf. gegen Registrierung/Gebühr) vorgesehen wird, der u.U. nicht einmal im Nachhinein durch die Kontrollstelle verifiziert werden kann (siehe oben) ${ }^{65}$.

63 VO (EG) Nr. 45/2001 v. 18. 12. 2000, ABl. EG v. 12. 01. 2001, L 8/6.

64 VO (EG) Nr. 45/2001 v. 18. 12. 2000, ABl. EG v. 12. 01. 2001, L 8/6.

65 Dies gilt umso mehr, als nach dem Kommissionsvorschlag zur Änderung der Vierten Geldwäscherichtlinie ein unionsweit vernetztes Register geschaffen werden soll, s. Kommission, COM (2016) 450 final v. 05. 07. 2016, S. 22. 
Art. 8 der Verordnung regelt die Übermittlung von Daten an Empfänger, die nicht Einrichtungen und Organe der Gemeinschaft sind und der Richtlinie 95/46/ EG unterworfen sind. An diese werden Daten nur übermittelt, „wenn der Empfänger nachweist, dass die Daten für die Wahrnehmung einer Aufgabe, die im öffentlichen Interesse liegt oder zur Ausübung der öffentlichen Gewalt gehört, erforderlich sind oder wenn der Empfänger die Notwendigkeit der Datenübermittlung nachweist und kein Grund zu der Annahme besteht, dass die berechtigten Interessen der betroffenen Person beeinträchtigt werden könnten." ${ }^{\text {66 }}$ Die Empfänger von Daten, die der Richtlinie 95/46/EG unterworfen sind, haben also den Nachweis zu führen, dass sie die Daten zur Aufgabenerfüllung benötigen; ansonsten ist eine Datenübermittlung nur zulässig, wenn die berechtigten Interessen der betroffenen Person offenbar nicht beeinträchtigt werden können.

Art. 9 der Verordnung regelt die Übermittlung von Daten an Empfänger, die nicht Einrichtungen und Organe der Gemeinschaft sind und nicht der Richtlinie 95/46/EG unterworfen sind. An diese werden Daten nur übermittelt, „wenn ein angemessenes Schutzniveau in dem Land des Empfängers oder innerhalb der empfangenden internationalen Organisation gewährleistet ist und diese Übermittlung ausschließlich die Wahrnehmung von Aufgaben ermöglichen soll, die in die Zuständigkeit des für die Verarbeitung Verantwortlichen fallen." Etwas anderes kann gelten, wenn die betroffene Person in die Datenübermittlung in ein Land ohne angemessenes Schutzniveau eingewilligt hat, die Übermittlung für die Durchführung oder Erfüllung eines Vertrags betroffenen Person oder die Wahrung lebenswichtiger Interessen dieser Person erforderlich ist, „die Übermittlung für die Wahrung eines wichtigen öffentlichen Interesses oder zur Feststellung, Ausübung oder Verteidigung von Rechtsansprüchen vor Gericht erforderlich oder gesetzlich vorgeschrieben ist“, oder „die Übermittlung aus einem Register erfolgt, das gemäß dem Gemeinschaftsrecht zur Unterrichtung der Öffentlichkeit bestimmt ist und entweder der gesamten Öffentlichkeit oder allen Personen, die ein berechtigtes Interesse nachweisen können, zur Einsichtnahme offen steht, soweit die im Gemeinschaftsrecht für die Einsichtnahme festgelegten Voraussetzungen im Einzelfall gegeben sind.“67

Vergleichbar mit der Datenübermittlung an Drittländer in der Richtlinie 95/ 46/EG wird auch im Rahmen der Verordnung zunächst darauf abgestellt, dass ein Empfänger, der weder Adressat der Verordnung noch der Richtlinie 95/46/EG ist, sich in einem Land aufhält, das über ein vergleichbares Schutzniveau hinsichtlich personenbezogener Daten verfügt. Ist dies nicht der Fall, kann eine Datenüber-

66 VO (EG) Nr. 45/2001 v. 18. 12. 2000, ABl. EG v. 12. 01. 2001, L 8/6.

67 VO (EG) Nr. 45/2001 v. 18. 12. 2000, ABl. EG v. 12. 01. 2001, L 8/7. 
mittlung dennoch erfolgen, insbesondere, wenn es entweder zur Rechtsdurchsetzung notwendig, für ein wichtiges öffentliches Interesse erforderlich ist oder es sich um ein Register handelt, das Personen mit einem berechtigten Interesse offen steht.

\section{bb) Rechte der betroffenen Personen}

Die Verordnung sieht - ebenso wie die Richtlinie 95/46/EG - vor, dass betroffene Personen über die Datenverarbeitung informiert werden (was vorliegend - wie gesehen - obsolet ist, weil die betroffenen Personen bzw. die von ihnen Beauftragten die Daten selbst zur Verfügung zu stellen haben) und dass ihnen unter bestimmten Voraussetzungen ein Auskunfts-, Berichtigungs- und Sperrrecht zusteht (siehe Art. $11 \mathrm{ff}$. der Verordnung) ${ }^{68}$.

Art. 18 der Verordnung legt - ebenso wie Art. 14 der Richtlinie 95/46/EG - ein Widerspruchsrecht zugunsten des Betroffenen fest, das diesem jederzeit aus zwingenden, schutzwürdigen, sich aus ihrer besonderen Situation ergebenden Gründen zusteht, sofern nicht Fälle der Datenverarbeitung nach Art. 5 b), c) und d) der Verordnung betroffen sind ${ }^{69}$. Das bedeutet, dass dem Betroffenen ein Widerspruchsrecht gegen die Datenverarbeitung nicht zusteht, wenn diese für die Erfüllung einer rechtlichen Verpflichtung erforderlich ist, welcher der für die Datenverarbeitung Verantwortliche unterliegt (bzw. wenn der Betroffene eingewilligt hat oder es bei der Datenverarbeitung um die Wahrung eines lebenswichtigen Interesses der Person geht). Ist der Verantwortliche beispielsweise nach der Geldwäscherichtlinie verpflichtet, personenbezogene Daten zu verarbeiten, könnte die betroffene Person kein Widerspruch gegen die Datenverarbeitung einlegen. Damit bestimmt die Verordnung die Regelungen, in denen der Widerspruch nicht zulässig ist, während im Vergleich dazu die Richtlinie 95/46/EG mit Art. 7 e) und f) die Regelungen bestimmt, in denen mindestens Widerspruch eingelegt werden darf. Letztlich sind die Bestimmungen aber im Wesentlichen inhaltsgleich.

\section{cc) Ausnahmen und Einschränkungen}

In den Art. 20 ff. der Richtlinie sind Ausnahmen und Einschränkungen vorgesehen, die denen der Richtlinie 95/46/EG entsprechen. Hervorzuheben ist Art. 22 der Verordnung, der die Sicherheit der Verarbeitung regelt. Demnach ,hat der für die Verarbeitung Verantwortliche technische und organisatorische Maßnahmen

68 VO (EG) Nr. 45/2001 v. 18. 12. 2000, ABl. EG v. 12. 01. 2001, L 8/9 ff.

69 VO (EG) Nr. 45/2001 v. 18. 12. 2000, ABl. EG v. 12. 01. 2001, L 8/11. 
zu treffen, die geeignet sind, ein Schutzniveau zu gewährleisten, das den von der Verarbeitung ausgehenden Risiken und der Art der zu schützenden personenbezogenen Daten angemessen ist. Solche Maßnahmen sind insbesondere zu treffen, um einer unbefugten Weitergabe, einem unbefugten Zugriff sowie einer zufälligen oder unrechtmäßigen Vernichtung, einem zufälligen Verlust oder einer Veränderung sowie jeder anderen Form der unrechtmäßigen Verarbeitung personenbezogener Daten vorzubeugen. "70 Dies gilt insbesondere, wenn Daten mit automatischen Mitteln verarbeitet werden (siehe Art. 22 Abs. 2 der Verordnung).

\section{c) Datenschutzgrundverordnung (EU) 2016/679}

Am 14. 04. 2016 wurde die Datenschutzgrundverordnung vom Europäischen Parlament verabschiedet, mit der die Richtlinie 95/46/EG ab Anwendung der Datenschutzgrundverordnung im Jahr 2018 aufgehoben wird ${ }^{71}$. Ziel der Verordnung ist, ein gleichwertiges Datenschutzniveau für natürliche Personen auf der einen und den freien Verkehr personenbezogener Daten in der Union auf der anderen Seite zu gewährleisten - auch hier geht es also um den Ausgleich widerstreitender Interessen. Dabei gilt jedoch der Schutz der Grundrechte und Grundfreiheiten (so Art. 1 der Verordnung) ${ }^{72}$.

\section{aa) Anwendungsbereich}

In den Anwendungsbereich der Verordnung fallen nach Art. 2 der Verordnung ganz oder teilweise automatisierte sowie nichtautomatisierte Verarbeitungen personenbezogener Daten (soweit diese nicht den familiären oder ausschließlich persönlichen Bereichen natürlicher Personen betreffen). Die Verordnung (EG) Nr. 45/2001 soll an die Grundsätze der Datenschutzverordnung angepasst wer$\operatorname{den}^{73}$.

70 VO (EG) Nr. 45/2001 v. 18. 12. 2000, ABl. EG v. 12. 01. 2001, L 8/12f.

71 Siehe Art. 94 Abs. 1 der Datenschutzgrundverordnung, Verordnung (EU) 2016/679 des Europäischen Parlaments und des Rates vom 27. April 2016 zum Schutz natürlicher Personen bei der Verarbeitung personenbezogener Daten, zum freien Datenverkehr und zur Aufhebung der Richtlinie 95/46/EG, Abl. Nr. 119, S. 1, ber. L 314 S. 72; siehe auch Spindler, DB 2016, 937.

72 Erwägungsgrund 170 der Datenschutzgrundverordnung; siehe auch Wedde, EU-DatenschutzGrundverordnung, 2016, S. 11.

73 Erwägungsgrund 17 der Datenschutzgrundverordnung. 


\section{bb) Erwägungsgründe}

Die Datenschutzgrundverordnung weist in ihren Erwägungsgründen darauf hin, dass nach Art. 8 GRC und 16 AEUV jede Person das Recht auf Schutz ihrer personenbezogenen Daten hat ${ }^{74}$, dass es sich dabei aber nicht um ein uneingeschränktes Recht handele, es vielmehr „im Hinblick auf seine gesellschaftliche Funktion gesehen und unter Wahrung des Verhältnismäßigkeitsprinzips gegen andere Grundrechte abgewogen werden“ muss ${ }^{75}$. Es sei jedoch ein hohes Datenschutzniveau zu gewährleisten ${ }^{76}$. Die Ziele und Grundsätze der Richtlinie 95/46/ EG besäßen nach wie vor Gültigkeit, doch habe die Richtlinie nicht verhindern können, dass der Datenschutz in der Union unterschiedlich gehandhabt werde, was u. a. dazu führen könne, dass die Behörden an der Erfüllung ihrer nach dem Unionsrecht obliegenden Aufgaben gehindert sein könnten ${ }^{77}$. Entsprechend müsse es den Mitgliedstaaten möglich sein, „hinsichtlich der Verarbeitung personenbezogener Daten zur Erfüllung einer rechtlichen Verpflichtung oder zur Wahrnehmung einer Aufgabe, die im öffentlichen Interesse liegt oder in Ausübung öffentlicher Gewalt erfolgt, die dem Verantwortlichen übertragen wurde, [...] nationale Bestimmungen, mit denen die Anwendung der Vorschriften dieser Verordnung genauer festgelegt wird, beizubehalten oder einzuführen“78. Die Verordnung hebt zugleich hervor, dass ein unionsweiter wirksamer Schutz personenbezogener Daten „die Stärkung und präzise Festlegung der Rechte der betroffenen Personen sowie eine Verschärfung der Verpflichtungen für diejenigen, die personenbezogene Daten verarbeiten und darüber entscheiden“ erfordert, „ebenso wie - in den Mitgliedstaaten - gleiche Befugnisse bei der Überwachung und Gewährleistung der Einhaltung der Vorschriften zum Schutz personenbezogener Daten sowie gleiche Sanktionen im Falle ihrer Verletzung “79. Dieser Schutz solle zudem technologieneutral sein ${ }^{80}$.

Weiter legt die Datenschutzgrundverordnung im Erwägungsgrund 31 Folgendes fest: „Behörden, gegenüber denen personenbezogene Daten aufgrund einer rechtlichen Verpflichtung für die Ausübung ihres offiziellen Auftrags offengelegt werden, wie Steuer- und Zollbehörden, Finanzermittlungsstellen, unabhängige Verwaltungsbehörden oder Finanzmarktbehörden, die für die Regulierung und Aufsicht von Wertpapiermärkten zuständig sind, sollten nicht als Empfänger

74 Erwägungsgrund 1 der Datenschutzgrundverordnung.

75 Erwägungsgrund 4 der Datenschutzgrundverordnung; siehe auch Albrecht, CR 2016, 88, 89.

76 Erwägungsgrund 6 der Datenschutzgrundverordnung.

77 Erwägungsgrund 9 der Datenschutzgrundverordnung.

78 Erwägungsgrund 10 der Datenschutzgrundverordnung.

79 Erwägungsgrund 11 der Datenschutzgrundverordnung.

80 Erwägungsgrund 15 der Datenschutzgrundverordnung. 
gelten, wenn sie personenbezogene Daten erhalten, die für die Durchführung gemäß dem Unionsrecht oder dem Recht der Mitgliedstaaten - eines einzelnen Untersuchungsauftrags im Interesse der Allgemeinheit erforderlich sind. Anträge auf Offenlegung, die von Behörden ausgehen, sollten immer schriftlich erfolgen, mit Gründen versehen sein und gelegentlichen Charakter haben, und sie sollten nicht vollständige Dateisysteme betreffen oder zur Verknüpfung von Dateisystemen führen. Die Verarbeitung personenbezogener Daten durch die genannten Behörden sollte für die Zwecke der Verarbeitung den geltenden Datenschutzvorschriften entsprechen." ${ }^{\text {" } 11} \mathrm{Ob}$ vor diesem Hintergrund ein unionsweites Register mit präventiv zum wirtschaftlich Berechtigten vorgehaltenen Daten - wie es nun der Kommissionsvorschlag zur Änderung der Vierten Geldwäscherichtlinie vorsieht ${ }^{82}$ - zulässig sein kann, erscheint fragwürdig.

Hervorzuheben ist, dass in der Datenschutzgrundverordnung als Zugriffsberechtigung ebenfalls ein berechtigtes Interesse genannt wird. So heißt es im Erwägungsgrund 47, dass sich die Rechtmäßigkeit der Verarbeitung auch aus „berechtigten Interessen eines Verantwortlichen, auch eines Verantwortlichen, dem die personenbezogenen Daten offengelegt werden dürfen, oder eines Dritten“ ergeben kann, „,sofern die Interessen oder die Grundrechte und Grundfreiheiten der betroffenen Person nicht überwiegen; [...]. Da es dem Gesetzgeber obliegt, per Rechtsvorschrift die Rechtsgrundlage für die Verarbeitung personenbezogener Daten durch die Behörden zu schaffen, sollte diese Rechtsgrundlage nicht für Verarbeitungen durch Behörden gelten, die diese in Erfüllung ihrer Aufgaben vornehmen. Die Verarbeitung personenbezogener Daten im für die Verhinderung von Betrug unbedingt erforderlichen Umfang stellt ebenfalls ein berechtigtes Interesse des jeweiligen Verantwortlichen dar"83. Offen bleibt, weshalb hier auf den Betrug abgestellt wird bzw. welche Art von Betrug hier gemeint ist (möglicherweise der Steuerbetrug, den es in mitgliedstaatlichen Recht gibt, speziell im deutschen Recht jedoch nicht).

Aufschlussreich ist im Weiteren Erwägungsgrund 50, nach dem die Verarbeitung personenbezogener Daten für andere Zwecke als die, für die die personenbezogenen Daten ursprünglich erhoben wurden, nur zulässig sein sollte, „wenn die Verarbeitung mit den Zwecken, für die die personenbezogenen Daten ursprünglich erhoben wurden, vereinbar ist. In diesem Fall ist keine andere gesonderte Rechtsgrundlage erforderlich als diejenige für die Erhebung der personenbezogenen Daten. Ist die Verarbeitung für die Wahrnehmung einer Aufgabe erforderlich,

81 Erwägungsgrund 31 der Datenschutzgrundverordnung.

82 Kommission, $\operatorname{COM}(2016) 450$ final v. 05. 07. 2016, S. 39 ff.; siehe auch N. Müller, NZWiSt 3/ 2017, 87, 91.

83 Erwägungsgrund 47 der Datenschutzgrundverordnung. 
die im öffentlichen Interesse liegt oder in Ausübung öffentlicher Gewalt erfolgt, die dem Verantwortlichen übertragen wurde, so können im Unionsrecht oder im Recht der Mitgliedstaaten die Aufgaben und Zwecke bestimmt und konkretisiert werden, für die eine Weiterverarbeitung als vereinbar und rechtmäßig erachtet wird“. Zulässig sind danach insbesondere Archivzwecke, wissenschaftliche oder historische Forschungszwecke oder statistische Zwecke. Weiter heißt es: „Die im Unionsrecht oder im Recht der Mitgliedstaaten vorgesehene Rechtsgrundlage für die Verarbeitung personenbezogener Daten kann auch als Rechtsgrundlage für eine Weiterverarbeitung dienen. Um festzustellen, ob ein Zweck der Weiterverarbeitung mit dem Zweck, für den die personenbezogenen Daten ursprünglich erhoben wurden, vereinbar ist, sollte der Verantwortliche nach Einhaltung aller Anforderungen für die Rechtmäßigkeit der ursprünglichen Verarbeitung unter anderem prüfen, ob ein Zusammenhang zwischen den Zwecken, für die die personenbezogenen Daten erhoben wurden, und den Zwecken der beabsichtigten Weiterverarbeitung besteht, in welchem Kontext die Daten erhoben wurden, insbesondere die vernünftigen Erwartungen der betroffenen Person, die auf ihrer Beziehung zu dem Verantwortlichen beruhen, in Bezug auf die weitere Verwendung dieser Daten, um welche Art von personenbezogenen Daten es sich handelt, welche Folgen die beabsichtigte Weiterverarbeitung für die betroffenen Personen hat und ob sowohl beim ursprünglichen als auch beim beabsichtigten Weiterverarbeitungsvorgang geeignete Garantien bestehen.“ Wenn die Zweckbindung der Datenerhebung als einer der tragenden Grundsätze der Datenverarbeitung nicht bereits durch diese vagen und einzelfallabhängigen Erwägungen ausgehebelt wird, so doch durch nachfolgende Überlegungen, die einen Verzicht auf die Zweckbindung explizit statuieren: „Hat die betroffene Person ihre Einwilligung erteilt oder beruht die Verarbeitung auf Unionsrecht oder dem Recht der Mitgliedstaaten, was in einer demokratischen Gesellschaft eine notwendige und verhältnismäßige Maßnahme zum Schutz insbesondere wichtiger Ziele des allgemeinen öffentlichen Interesses darstellt, so sollte der Verantwortliche die personenbezogenen Daten ungeachtet der Vereinbarkeit der Zwecke weiterverarbeiten dürfen. In jedem Fall sollte gewährleistet sein, dass die in dieser Verordnung niedergelegten Grundsätze angewandt werden und insbesondere die betroffene Person über diese anderen Zwecke und über ihre Rechte einschließlich des Widerspruchsrechts unterrichtet wird. Der Hinweis des Verantwortlichen auf mögliche Straftaten oder Bedrohungen der öffentlichen Sicherheit und die Übermittlung der maßgeblichen personenbezogenen Daten in Einzelfällen oder in mehreren Fällen, die im Zusammenhang mit derselben Straftat oder derselben Bedrohung der öffentlichen Sicherheit stehen, an eine zuständige Behörde sollten als berechtigtes Interesse des Verantwortlichen gelten. Eine derartige Übermittlung personenbezogener Daten im berechtigten Interesse des Verantwortlichen oder deren Weiter- 
verarbeitung sollte jedoch unzulässig sein, wenn die Verarbeitung mit einer rechtlichen, beruflichen oder sonstigen verbindlichen Pflicht zur Geheimhaltung unvereinbar ist. “84 Das damit etablierte Recht, dass wichtige Ziele des allgemeinen öffentlichen Interesses eine Datenverarbeitung auch ohne Einwilligung des Betroffenen ermöglichen und der bloße Verdacht von (nicht näher eingegrenzten) Straftaten zu einem berechtigten Interesse erhoben wird, welches eine Datenverarbeitung unabhängig von der ursprünglichen Zweckbindung der Datenerhebung zulässt, scheint mit rechtstaatlichen Grundsätzen, insbesondere der Rechtsprechung des EuGH unvereinbar ${ }^{85}$. In Bezug auf das Geldwäscheregister und darin vorgehaltene Daten würde dies bedeuten, dass eine Weiterverarbeitung der Daten bei Verdacht einer anderen Straftat als Geldwäsche und Terrorismusfinanzierung ohne Weiteres möglich wäre, so dass die in der Vierten Geldwäscherichtlinie ohnehin schon weite Zugriffsmöglichkeit bei Verdacht auf Vortaten der Geldwäsche letztlich jedenfalls auf alle Straftaten ausgedehnt würde.

Als sensible personenbezogene Daten, denen ein besonderer Schutz zukommen soll, qualifizieren die Erwägungsgründe nachfolgend Daten, aus denen die rassische oder ethnische Herkunft hervorgeht sowie biometrische Daten, wobei auch hier Verarbeitungsmöglichkeiten vorgesehen $\operatorname{sind}^{86}$.

Die Datenschutzgrundverordnung thematisiert in den Erwägungsgründen außerdem das „Recht auf Vergessenwerden“" ${ }^{\text {“87 }}$. Dieses steht einer weiteren Datenspeicherung jedoch dann nicht entgegen, „wenn dies für die Ausübung des Rechts auf freie Meinungsäußerung und Information, zur Erfüllung einer rechtlichen Verpflichtung, für die Wahrnehmung einer Aufgabe, die im öffentlichen Interesse liegt oder in Ausübung öffentlicher Gewalt erfolgt, die dem Verantwortlichen übertragen wurde, aus Gründen des öffentlichen Interesses im Bereich der öffentlichen Gesundheit, für im öffentlichen Interesse liegende Archivzwecke, zu wissenschaftlichen oder historischen Forschungszwecken oder zu statistischen Zwecken oder zur Geltendmachung, Ausübung oder Verteidigung von Rechtsansprüchen erforderlich ist“" ${ }^{\text {*88 }}$.

Auch wenn die Datenverarbeitung rechtmäßig ist, soll dem Betroffenen in einer besonderen Situation, die er darzulegen hat, ein Widerspruchsrecht zustehen ${ }^{89}$.

84 Erwägungsgrund 50 der Datenschutzgrundverordnung.

85 Siehe EuGH, 08. 04. 2014, Rs. C-293/12 und C-594/12 (Digital Rights Ireland und Seitlinger u. a.) und EuGH, 21. 12. 2016, Rs. C-203/15 u. C-698/15 (Tele2 Sverige).

86 Erwägungsgrund $51 \mathrm{ff}$. der Datenschutzgrundverordnung.

87 Siehe auch Albrecht, CR 2016, 88, 93.

88 Erwägungsgrund 65 der Datenschutzgrundverordnung.

89 Erwägungsgrund 69 der Datenschutzgrundverordnung. 
Außerdem soll die betroffene Person keiner Entscheidung zur Bewertung von sie betreffenden persönlichen Aspekten unterworfen werden, „die ausschließlich auf einer automatisierten Verarbeitung beruht und die rechtliche Wirkung für die betroffene Person entfaltet oder sie in ähnlicher Weise erheblich beeinträchtigt, [...] ohne jegliches menschliche Eingreifen“. Dazu zähle insbesondere das sog. Profiling, bei dem personenbezogene Daten unter Bewertung der persönlichen Aspekte etwa auf ihre wirtschaftliche Lage und andere Aspekte „bewertet“ werden. Gedacht wurde hier wohl hauptsächlich an die Bewertung von Daten zum „Auslesen“ des Konsumverhaltens von Personen. Jedoch geht der Erwägungsgrund weiter, indem er darauf hinweist, dass eine solche Entscheidungsfindung erlaubt sein soll, ,wenn dies nach dem Unionsrecht oder dem Recht der Mitgliedstaaten, dem der für die Verarbeitung Verantwortliche unterliegt, ausdrücklich zulässig ist, auch um im Einklang mit den Vorschriften, Standards und Empfehlungen der Institutionen der Union oder der nationalen Aufsichtsgremien Betrug und Steuerhinterziehung $\mathrm{zu}$ überwachen und $\mathrm{zu}$ verhindern [...]. In jedem Fall sollte eine solche Verarbeitung mit angemessenen Garantien verbunden sein, einschließlich der spezifischen Unterrichtung der betroffenen Person und des Anspruchs auf direktes Eingreifen einer Person, auf Darlegung des eigenen Standpunkts, auf Erläuterung der nach einer entsprechenden Bewertung getroffenen Entscheidung sowie des Rechts auf Anfechtung der Entscheidung. Diese Maßnahme sollte kein Kind betreffen."90 Das Sammeln und Auswerten von personenbezogenen Daten zur Überwachung und Verhinderung von Betrug und Steuerhinterziehung ist damit zulässig.

Dabei macht Erwägungsgrund 73 nochmals deutlich, dass die zum Datenschutz geltenden Grundsätze (Recht auf Unterrichtung, Auskunft zu Berichtigung und Löschung, Widerspruch, Profiling etc.) im Unionsrecht und im Recht der Mitgliedstaaten beschränkt werden können, „soweit dies in einer demokratischen Gesellschaft notwendig und verhältnismäßig ist, um die öffentliche Sicherheit aufrechtzuerhalten, wozu unter anderem der Schutz von Menschenleben insbesondere bei Naturkatastrophen oder vom Menschen verursachten Katastrophen, die Verhütung, Aufdeckung und Verfolgung von Straftaten oder die Strafvollstreckung - was auch den Schutz vor und die Abwehr von Gefahren für die öffentliche Sicherheit einschließt - oder die Verhütung, Aufdeckung und Verfolgung von Verstößen gegen Berufsstandsregeln bei reglementierten Berufen, das Führen öffentlicher Register aus Gründen des allgemeinen öffentlichen Interesses sowie die Weiterverarbeitung von archivierten personenbezogenen Daten zur Bereitstellung spezifischer Informationen im Zusammenhang mit dem politi-

90 Erwägungsgrund 71 der Datenschutzgrundverordnung. 
schen Verhalten unter ehemaligen totalitären Regimen gehört, und zum Schutz sonstiger wichtiger Ziele des allgemeinen öffentlichen Interesses der Union oder eines Mitgliedstaats, etwa wichtige wirtschaftliche oder finanzielle Interessen, oder die betroffene Person und die Rechte und Freiheiten anderer Personen, einschließlich in den Bereichen soziale Sicherheit, öffentliche Gesundheit und humanitäre Hilfe, zu schützen. Diese Beschränkungen sollten mit der Charta und mit der Europäischen Konvention zum Schutz der Menschenrechte und Grundfreiheiten im Einklang stehen "91. Interessanterweise wird das Profiling - obschon es als „besonders gefährlich eingestufte Datensammlung“ qualifiziert wird und daher möglichst eingedämmt werden soll ${ }^{92}$, damit weniger restriktiven Vorgaben unterworfen als erwartet.

Die Datenübermittlung in Drittländer ist grundsätzlich nur möglich, soweit dort ein angemessenes Schutzniveau besteht, was zu prüfen ist. Datenübermittlungen sollten entweder möglich sein, wenn der Betroffene einwilligt oder „wenn sie zur Wahrung eines im Unionsrecht oder im Recht eines Mitgliedstaats festgelegten wichtigen öffentlichen Interesses erforderlich ist oder wenn sie aus einem durch Rechtsvorschriften vorgesehenen Register erfolgt, das von der Öffentlichkeit oder Personen mit berechtigtem Interesse eingesehen werden kann. In letzterem Fall sollte sich eine solche Übermittlung nicht auf die Gesamtheit oder ganze Kategorien der im Register enthaltenen personenbezogenen Daten erstrecken dürfen. Ist das betreffende Register zur Einsichtnahme durch Personen mit berechtigtem Interesse bestimmt, sollte die Übermittlung nur auf Anfrage dieser Personen oder nur dann erfolgen, wenn diese Personen die Adressaten der Übermittlung sind, wobei den Interessen und Grundrechten der betroffenen Person in vollem Umfang Rechnung zu tragen ist.“"93

Weiter heißt es in Erwägungsgrund 112: „Diese Ausnahmen sollten insbesondere für Datenübermittlungen gelten, die aus wichtigen Gründen des öffentlichen Interesses erforderlich sind, beispielsweise für den internationalen Datenaustausch zwischen Wettbewerbs-, Steuer- oder Zollbehörden, zwischen Finanzaufsichtsbehörden [...]." ${ }^{\text {94 }}$ Somit wären Datenübermittlungen aus dem Geldwäscheregister ohne Weiteres erfasst.

Hinzuweisen ist überdies auf die Passage im Erwägungsgrund 153, in der ausgeführt wird, dass für die Verarbeitung personenbezogener Daten ausschließlich zu journalistischen Zwecken Abweichungen und Ausnahmen von bestimmten Vorschriften dieser Verordnung gelten, ,wenn dies erforderlich ist, um das

91 Erwägungsgrund 73 der Datenschutzgrundverordnung.

92 Spindler, DB 2016, 937, 944.

93 Erwägungsgrund 111 der Datenschutzgrundverordnung.

94 Erwägungsgrund 112 der Datenschutzgrundverordnung. 
Recht auf Schutz der personenbezogenen Daten mit dem Recht auf Freiheit der Meinungsäußerung und Informationsfreiheit, wie es in Artikel 11 der Charta garantiert ist, in Einklang zu bringen." ${ }^{\text {"95 }}$ Spindler weist bezüglich dieses in Art. 85 der Verordnung verankerten Medienprivilegs darauf hin, dass der allgemeine Passus, die Mitgliedstaaten hätten die Rechte der Meinungs- und Informationsfreiheit mit dem Datenschutzrecht in Einklang zu bringen, sehr vage sei, zumal der Begriff des Journalismus nach Erwägungsgrund 120 im Hinblick auf die freie Meinungsäußerung möglichst weit ausgelegt werden soll ${ }^{96}$.

\section{cc) Grundsätze der Datenverarbeitung}

Als Grundsätze der Datenverarbeitung hebt Art. 5 der Verordnung hervor, dass personenbezogene Daten auf rechtmäßige Weise, nach Treu und Glauben und in einer für die betroffene Person nachvollziehbaren Weise verarbeitet, für festgelegte, eindeutige und legitime Zwecke erhoben und nicht in einer mit diesen Zwecken nicht zu vereinbarenden Weise weiterverarbeitet werden dürfen ${ }^{97}$. Des Weiteren muss die Datenverarbeitung dem Zweck angemessen und erheblich sowie auf das für die Zwecke der Verarbeitung notwendige Maß beschränkt sein. Die Daten müssen sachlich richtig und aktuell und ihre Speicherung muss begrenzt sein (Ausnahme: im öffentlichen Interesse liegende Archivzwecke u.a.). Die Daten müssen außerdem in einer Weise verarbeitet werden, die eine angemessene Sicherheit der personenbezogenen Daten gewährleistet, einschließlich dem Schutz vor unbefugter oder unrechtmäßiger Verarbeitung und vor unbeabsichtigtem Verlust, unbeabsichtigter Zerstörung oder unbeabsichtigter Schädigung durch geeignete technische und organisatorische Maßnahmen. Dies muss der Verantwortliche nachweisen können.

Nach Art. 6 der Verordnung gilt eine Datenverarbeitung u.a. als rechtmäßig, wenn entweder der Betroffene freiwillig eingewilligt hat, die Verarbeitung zur Erfüllung einer rechtlichen Verpflichtung, der der Verantwortliche unterliegt ${ }^{98}$, erforderlich ist, die Verarbeitung für die Wahrnehmung einer Aufgabe erforderlich ist, die im öffentlichen Interesse liegt oder in Ausübung öffentlicher Gewalt erfolgt, die dem Verantwortlichen übertragen wurde. Zudem soll eine Datenverarbeitung rechtmäßig sein, wenn sie zur Wahrung der berechtigten Interessen des Verantwortlichen oder eines Dritten erforderlich ist, sofern nicht die Interessen

95 Erwägungsgrund 153 der Datenschutzgrundverordnung.

96 Spindler, DB 2016, 937, $938 \mathrm{f}$.

97 Siehe auch Erwägungsgrund 45 der Datenschutzgrundverordnung; siehe auch Albrecht/Jotzo, Das neue Datenschutzrecht der EU, 2017, S. 51.

98 Dies wäre der Fall etwa bei den Geldwäscheverpflichteten, siehe Anm. 11. 
oder Grundrechte und Grundfreiheiten der betroffenen Person, die den Schutz personenbezogener Daten erfordern, überwiegen, insbesondere dann, wenn es sich bei der betroffenen Person um ein Kind handelt. Art. 6 Abs. 1 regelt dazu im letzten Satz jedoch, dass dies nicht für die von Behörden in Erfüllung ihrer Aufgaben vorgenommene Verarbeitung gelten soll. Spindler weist hier zu Recht darauf hin, dass es zur Feststellung des Erlaubnistatbestands der Wahrung berechtigter Interessen einer Abwägung der Interessen mit den Grundrechten der betroffenen Person bedarf, die Datenschutzgrundverordnung jedoch keinerlei Aussage dazu trifft, wann die Interessen der betroffenen Person überwiegen können ${ }^{99}$.

Im Weiteren legt Art. 6 Abs. 3 fest, dass es für eine rechtmäßige Datenverarbeitung durch Verantwortliche, die eine Rechtspflicht oder eine Aufgabe im öffentlichen Interesse erfüllen oder öffentliche Gewalt ausüben einer unionsrechtlichen oder mitgliedstaatlichen Rechtsgrundlage bedarf, die eine legitime Zweckbindung der Datenverarbeitung festlegt. Die Datenverarbeitung darf nach Art. 6 Abs. 4 der Verordnung auch zu einem anderen Zweck als zu demjenigen, $\mathrm{zu}$ dem die personenbezogenen Daten erhoben wurden, verarbeitet werden, wenn sie mit diesem Zweck vereinbar ist. Die Vereinbarkeit des ursprünglichen Zwecks der Datenerhebung mit dem neuen Zweck der Datenverarbeitung hängt dabei nicht von einer konkreten Bedingung ab. Art. 6 Abs. 4 der Verordnung gibt nur vor, was der Verantwortliche bei der Vereinbarkeit der Zwecke „unter anderem“ (also nicht abschließend) zu prüfen hat. Dies ist jede Verbindung zwischen den Zwecken, für die die personenbezogenen Daten erhoben wurden, und den Zwecken der beabsichtigten Weiterverarbeitung (lit. a), den Zusammenhang, in dem die personenbezogenen Daten erhoben wurden, insbesondere hinsichtlich des Verhältnisses zwischen den betroffenen Personen und dem Verantwortlichen (lit. b), die Art der personenbezogenen Daten (vor allem ob Daten nach Art. 9 und 10 verarbeitet werden., lit. c), die möglichen Folgen der beabsichtigten Weiterverarbeitung für die betroffenen Personen (lit. d) sowie das Vorhandensein geeigneter Garantien (etwa Verschlüsselung oder Pseudonymisierung, lit. e). Offen bleibt, wann der Verantwortliche dann zum Ergebnis kommen muss, dass der Zweck, zu dem nun die Daten verarbeitet werden sollen, mit dem ursprünglichen Erhebungszweck unvereinbar sind ${ }^{100}$.

Art. 7 regelt die Bedingungen der Einwilligung (freiwillig und jederzeit widerrufbar), die für Kinder nach Art. 8 nochmals spezifiziert wird. In Art. 9 geht es um

99 Spindler, DB 2016, 937, 940.

100 Albrecht/Jotzo, 2017, S. 76; Wybitul, BB 18.2015, 1077, 1081; Kühling/Martini, EuZW 2016, 448, 451. 
die Verarbeitung besonders sensibler Daten (aus denen sich die rassische und ethnische Herkunft, politische Meinungen, religiöse oder weltanschauliche Überzeugungen oder die Gewerkschaftszugehörigkeit ergeben bzw. genetische oder biometrische Daten zur eindeutigen Identifizierung einer natürlichen Person, Gesundheitsdaten oder Daten zum Sexualleben oder der sexuellen Orientierung), die grundsätzlich untersagt ist (Abs. 1). Allerdings sind auch hier in allen Fällen wieder Ausnahmen des Verbots vorgesehen, die ebenfalls teilweise äußerst bedenklich erscheinen. Genannt werden soll nur beispielhaft die Verarbeitung genetischer Daten durch politische oder andere Einrichtungen oder zur Beurteilung der Arbeitsfähigkeit des Beschäftigten, die nach Art. 9 Abs. 2 d) oder h) zulässig ist, oder aber die Verarbeitung dieser sensiblen Daten aus Gründen eines erheblichen öffentlichen Interesses nach Abs. $2 \mathrm{~g}$ ).

Bemerkenswert ist, dass nach Art. 10 der Verordnung hohe Hürden für die Verarbeitung personenbezogener Daten über strafrechtliche Verurteilungen und Straftaten geschaffen werden; diese ist nur unter behördlicher Aufsicht zulässig und nur, wenn es nach dem Unionsrecht oder mitgliedstaatlichem Recht, das die Rechte der betroffenen Personen schützt, vorgesehen ist. Wybitul entnimmt dem Wortlaut der Regelung von Art. 10 Datenschutzgrundverordnung, dass nur mögliche oder vermutete Straftaten nicht erfasst sind und leitet aus dem Kontext der Vorschrift ab, dass „,sie sich allein auf gerichtlich festgestellte Straftaten beziehen soll, etwa i. R. d. Erstellung von Registern"101. Dies ist insofern erstaunlich, als im Gegenzug mit dem Geldwäscheregister, das Daten präventiv vorhält und teilweise mit dem bloßen Verdacht von Vortaten arbeitet, sehr weitgehende Zugriffsmöglichkeiten verbunden sein sollen.

Im Kapitel III der Verordnung werden die Rechte der Betroffenen geregelt. Dazu gehören nach Art. 12, dass die Betroffenen transparent und verständlich über die Datenverarbeitung und ihre diesbezüglichen Rechte informiert werden. Zudem hat der Verantwortliche nach Art. 13 die betroffenen Personen im Rahmen der Datenerhebung über den Verantwortlichen der Datenverarbeitung, ihre Zwecke, die Rechtsgrundlage, die Empfänger der Daten bzw. die „Kategorien von Empfängern“ und ggf. über die Absicht des Verantwortlichen, Daten in ein Drittland zu übermitteln (sowie ggf. über das Fehlen eines Angemessenheitsbeschlusses) zu informieren. Zudem soll der Betroffene über die Dauer der Datenspeicherung, die ihm zustehenden Rechte und Pflichten, das Bestehen einer automatisierten Entscheidungsfindung (z. B. Profiling) sowie die Datenverarbeitung zu einem anderen als dem ursprünglich vorgesehenen Zweck informiert werden. Wie der Verantwortliche im Falle des Geldwäscheregisters, insbesondere

101 Wybitul, ZD-aktuell 2016, 04185. 
beim Zugriff von Personen mit einem berechtigten Interesse bzw. bei einem Online-Zugriff seinen Informationspflichten zur Datenweitergabe in ein Drittland nachkommen will, ist fraglich. Auch die Empfängerbenennung kann beim Datenzugriff von Personen mit berechtigtem Interesse nur in der äußerst abstrakten Kategorie „Personen mit berechtigtem Interesse“ vorgenommen werden.

Art. 14 regelt die Informationspflicht des Betroffenen, wenn die personenbezogenen Daten nicht bei der betroffenen Person erhoben wurden. Hier entsprechen die Vorgaben im Wesentlichen denen zur Datenerhebung beim Betroffenen, allerdings sind umfangreiche Einschränkungen dieser Informationspflicht vorgesehen, wenn der Betroffene bereits über die Informationen verfügt (Abs. 5 lit. a), „die Erteilung dieser Informationen sich als unmöglich erweist oder einen unverhältnismäßigen Aufwand erfordern würde; dies gilt insbesondere für die Verarbeitung für im öffentlichen Interesse liegende Archivzwecke, für wissenschaftliche oder historische Forschungszwecke oder für statistische Zwecke vorbehaltlich der in Artikel 89 Absatz 1 genannten Bedingungen und Garantien oder soweit die in Absatz 1 des vorliegenden Artikels genannte Pflicht voraussichtlich die Verwirklichung der Ziele dieser Verarbeitung unmöglich macht oder ernsthaft beeinträchtigt. In diesen Fällen ergreift der Verantwortliche geeignete Maßnahmen zum Schutz der Rechte und Freiheiten sowie der berechtigten Interessen der betroffenen Person, einschließlich der Bereitstellung dieser Informationen für die Öffentlichkeit“ (Abs. 5 lit. b). Die Informationspflicht entfällt auch, wenn „die Erlangung oder Offenlegung durch Rechtsvorschriften der Union oder der Mitgliedstaaten, denen der Verantwortliche unterliegt und die geeignete Maßnahmen zum Schutz der berechtigten Interessen der betroffenen Person vorsehen, ausdrücklich geregelt ist“ (Abs. 5 lit. c) oder „die personenbezogenen Daten gemäß dem Unionsrecht oder dem Recht der Mitgliedstaaten dem Berufsgeheimnis, einschließlich einer satzungsmäßigen Geheimhaltungspflicht, unterliegen und daher vertraulich behandelt werden müssen“ (Abs. 5 lit. d).

Obschon gerade in Fällen, in denen Daten nicht bei der betroffenen Person erhoben werden, höhere Schutzpflichten an die Datenverarbeitung anzunehmen sind, kann die Informationspflicht durch die Ausnahmeregelungen nach Art. 14 Abs. 5 komplett ausgehebelt werden. Dies etwa in Fällen, in denen die Informationspflicht einen „unverhältnismäßigen Aufwand bedeuten würde“, was sehr unbestimmt ist. Die Schutzmaßnahmen, die der Verantwortliche zugunsten des Betroffenen hier treffen muss, wiegen wohl kaum auf, dass der Betroffene über die Datenerhebung und seine damit verbundenen Rechte nie Kenntnis erlangt. Die Tatsache, dass der Betroffene nach Art. 15 ein entsprechendes Auskunftsrecht hat, wird ihm daher in der Praxis nicht weiterhelfen.

In den Art. $16 \mathrm{ff}$. sind Berichtigung und Löschung als Rechte des Betroffenen geregelt. Das Recht auf Löschung seiner personenbezogenen Daten, also das 
Recht auf Vergessenwerden nach Art. 17, steht dem Betroffenen u.a. zu, wenn seine Daten nicht mehr benötigt werden, er seine Einwilligung widerrufen hat, er Widerspruch gegen die Datenverarbeitung erhoben hat und (!) „keine vorrangigen berechtigten Gründe für die Verarbeitung vorliegen“ oder die personenbezogenen Daten unrechtmäßig verarbeitet wurden. Nach Art. 17 Abs. 3 gilt dies (u.a.) jedoch nicht, „soweit die Verarbeitung erforderlich ist zur Ausübung des Rechts auf freie Meinungsäußerung und Information“ (lit. a), zur Erfüllung einer Rechtspflicht, zur Wahrnehmung einer Aufgabe im öffentlichen Interesse oder in Ausübung öffentlicher Gewalt. Das bedeutet, dass auch unrechtmäßig erhobene Daten $u$. U. weiterverarbeitet und nicht gelöscht werden, etwa, weil hier ein Recht auf Information oder ein öffentliches Interesse (wie der Geldwäscheprävention ${ }^{102}$ ) besteht. Dies scheint vor den nachfolgend dargestellten Grundsätzen des Gerichtshofs zum Datenschutz nicht haltbar, weil damit das Recht auf Vergessenwerden selbst im Falle einer unrechtmäßigen Datenverarbeitung faktisch ohne Weiteres ausgehebelt werden kann.

Nach Art. 18 steht der betroffenen Person unter bestimmten Umständen ein Recht auf Einschränkung der Verarbeitung zu, nach Art. 19 eine Mitteilungspflicht im Zusammenhang mit der Berichtigung und Löschung personenbezogener Daten oder deren Einschränkung (wobei hier eine Mitteilung wieder entfallen kann, wenn sie für den Verantwortlichen mit „unverhältnismäßigen Aufwand“ verbunden ist).

Von Bedeutung in diesem Zusammenhang ist auch das Widerspruchsrecht nach Art. 21, welches die automatisierte Entscheidungsfindung und insbesondere das Profiling betrifft. Nach Art. 21 hat die betroffene Person das Recht, aus Gründen, die sich aus ihrer besonderen Situation ergeben, jederzeit gegen die Verarbeitung sie betreffender personenbezogener Daten, die aufgrund von Art. 6 Abs. 1 e) oder f) erfolgt, Widerspruch einzulegen; dies gilt auch für ein auf diese Bestimmungen gestütztes Profiling. Der Verantwortliche verarbeitet die personenbezogenen Daten nicht mehr, es sei denn, er kann zwingende schutzwürdige Gründe für die Verarbeitung nachweisen, die die Interessen, Rechte und Freiheiten der betroffenen Person überwiegen, oder aber die Verarbeitung dient der Geltendmachung, Ausübung oder Verteidigung von Rechtsansprüchen.

Leider lässt die Regelung offen, wie die besondere Situation, in der sich die betroffene Person befinden muss, auszusehen hat. Darüber hinaus muss auch der Widerspruch nach Art. 21 über Art. 17 Abs. 1 c) i. V.m. Abs. 3 nicht zwingend zu einer Löschung der personenbezogenen Daten führen.

102 So Rößler, WM 2015, 1406, 1411. 
Das Profiling ist nach Art. 22 zudem zulässig, wenn es zum Abschluss oder zur Erfüllung eines Vertrages erforderlich ist (lit. a), wenn es „aufgrund von Rechtsvorschriften der Union oder der Mitgliedstaaten, denen der Verantwortliche unterliegt, zulässig ist und diese Rechtsvorschriften angemessene Maßnahmen zur Wahrung der Rechte und Freiheiten sowie der berechtigten Interessen der betroffenen Person enthalten“ (lit. b) oder mit ausdrücklicher Einwilligung der betroffenen Person erfolgt (lit. c) ${ }^{103}$.

Nach den Art. 23 ff. der Verordnung (Abschnitt 5) können durch Rechtsvorschriften der Union oder der Mitgliedstaaten die Pflichten und Rechte bezüglich Transparenz und Information des Betroffenen, Berichtigung und Löschung der Daten, die Benachrichtigung des Betroffenen über die Verletzung des Schutzes seiner personenbezogenen Daten nach Art. 34 sowie die Grundsätze der Datenverarbeitung nach Art. 5 (Verarbeitung nach Treu und Glauben, legitimer Zweck) eingegrenzt werden. Voraussetzung dafür ist zum einen, dass die gesetzlichen Vorschriften der Union oder Mitgliedstaaten den diesbezüglichen Bestimmungen in den Art. 12 bis 22 entsprechen und zum anderen eine solche Beschränkung den Wesensgehalt der Grundrechte und Grundfreiheiten achtet. Darüber hinaus muss sie „in einer demokratischen Gesellschaft eine notwendige und verhältnismäßige Maßnahme“ darstellen, die u. a. die öffentliche Sicherheit gewährleistet oder aber der Verhütung, Ermittlung, Aufdeckung oder Verfolgung von Straftaten oder der Strafvollstreckung dient, einschließlich des Schutzes vor und der Abwehr von Gefahren für die öffentliche Sicherheit (Art. 23 lit. d). Die Beschränkung kann jedoch auch dem „Schutz sonstiger wichtiger Ziele des allgemeinen öffentlichen Interesses der Union oder eines Mitgliedstaats, insbesondere eines wichtigen wirtschaftlichen oder finanziellen Interesses der Union oder eines Mitgliedstaats, etwa im Währungs-, Haushalts- und Steuerbereich [...]“ dienen (Art. 23 lit. e). Des Weiteren werden als Schutzgut u.a. auch die „Kontroll-, Überwachungs- und Ordnungsfunktionen, die dauernd oder zeitweise mit der Ausübung öffentlicher Gewalt für die unter den Buchstaben a, b, c, d, e und g genannten Zwecke verbunden sind“ (Art. 23 lit. h) sowie der „Schutz der betroffenen Person oder der Rechte und Freiheiten anderer Personen" genannt (Art. 23 lit. i). Das bedeutet, dass die überwiegenden Zahl der Maßnahmen, welche in der Verordnung zum Schutz der Daten der Betroffenen Person etabliert werden, durch gesetzgeberische Maßnahmen der Union oder Mitgliedstaaten aufgehoben werden können. Art. 23 hält zwar fest, dass diese Maßnahmen verhältnismäßig sein müssen, statuiert jedoch zugleich dem Datenschutz gegenüberstehende Schutzgüter, denen implizit ein höherrangiger Wert zugewiesen wird. Zusammenfassend lässt

103 Siehe auch Albrecht/Jotzo, 2017, S. 79. 
sich daher festhalten, dass die Vereinbarkeit dieser Regelung - insbesondere soweit hier auch noch auf unbestimmte Rechtsbegriffe wie die „öffentliche Sicherheit“, das „öffentliche Interesse“ oder Wirtschafts- und Finanzinteressen der Union oder Mitgliedstaaten sowie pauschal „Kontroll-, Überwachungs- und Ordnungsfunktionen“, die im Rahmen der öffentlichen Gewalt vorgenommen werden, verwiesen wird - mit der europäischen Rechtsprechung des Gerichtshofs stark angezweifelt wird.

Im Abschnitt 2 der Verordnung werden mit den Art. 32ff. die Sicherheit der personenbezogenen Daten geregelt, nach denen der Verantwortliche grundsätzlich dazu verpflichtet ist, durch technische und organisatorische Maßnahmen ein dem Risiko für die Daten angemessenes Schutzniveau zu gewährleisten (Art. 32). Eine Verletzung des Datenschutzes hat er unverzüglich an die Aufsichtsbehörde (Art. 33) und ebenfalls dem Betroffenen (Art. 34) zu melden, wenn sich für diesen daraus ein hohes Risiko für seine persönlichen Rechte und Freiheiten ergibt. Seine Benachrichtigung unterbleibt jedoch u.a., wenn das hohe Risiko für die persönlichen Rechte und Freiheiten des Betroffenen ,aller Wahrscheinlichkeit nach“ nicht mehr besteht bzw. die Benachrichtigung für den Verantwortlichen einen „unverhältnismäßigen Aufwand“ bedeutet (Art. 34 Abs. 3 lit. c). Daraus folgt, dass der Verantwortliche im Ergebnis selbst entscheidet, ob er dem Betroffenen eine Datenschutzverletzung mitteilt oder nicht, weil er der Auffassung ist, dass das Risiko „aller Wahrscheinlichkeit nach nicht mehr besteht“. Wann ein „unverhältnismäßiger Aufwand“ (der im Übrigen eher dann gegeben sein wird, wenn der Verantwortliche eine große Zahl an Datenschutzverletzungen begeht) vorliegt oder wann ein hohes Risiko für die persönlichen Rechte und Freiheiten des Betroffenen ,aller Wahrscheinlichkeit nach“ nicht mehr besteht, ist zugunsten des Verantwortlichen äußerst interpretationsfähig, was den Vorgaben des Datenschutzes nach Art. 7 und 8 GRC kaum gerecht werden kann. Denn zu welchem Ergebnis eine solche Auslegung durch die Verantwortlichen in der Praxis gelangen wird, muss - in Anbetracht der Tatsache, dass diese sich u. U. schadensersatzpflichtig (siehe Art. 82) machen - nicht näher beleuchtet werden.

Anzumerken ist im vorliegenden Zusammenhang noch, dass Art. 85 der Verordnung ausdrücklich die Datenverarbeitung zu journalistischen Zwecken als Schutzgut, das ggf. mit dem Datenschutz in Einklang zu bringen ist, hervorhebt $^{104}$. Dies soll nachfolgend nochmals aufgegriffen werden.

104 Spindler, DB 2016, 937, $938 \mathrm{f}$. 


\section{dd) Zwischenergebnis}

In einer Gesamtschau der Verordnung ist festzustellen, dass die anfangs genannte Zielsetzung der Datenschutzgrundverordnung - die Grundrechte der Betroffenen zu wahren - nicht in allen Punkten der Verordnung erreicht zu werden scheint. Zwar werden (teils auch neue) Betroffenenrechte statuiert, die entsprechenden Regelungen werden jedoch mit Ausnahmeregelungen versehen, die teils wegen ihrer unbestimmten Weite die zuvor etablierten Rechte nachfolgend wieder völlig auszuhebeln vermögen. Auch entsteht mit Blick auf die Ausführungen in den Erwägungsgründen der Eindruck, der Verordnungsgeber hätte insbesondere die Vorgaben der Geldwäscherichtlinie einschließlich der Schaffung des Geldwäscheregisters bei der Ausarbeitung der Verordnung im Blick gehabt. Es scheint, als habe der Verordnungsgeber der Vierten Geldwäscherichtlinie und ihrem Register den Weg bereiten wollen, indem er die etwaigen datenschutzrechtlichen Probleme durch eine Lockerung des Datenschutzes an den entscheidenden Stellen auszuräumen versuchte. Damit setzt sich jedoch auch der Verordnungsgeber - wie nachfolgend aufgezeigt wird - zu den Vorgaben der europäischen Grundrechte und der entsprechenden Rechtsprechung des Gerichtshofs in Widerspruch $^{105}$. Es wäre auch nicht das erste Mal, dass der Gerichtshof Verordnungen der EU wegen ihrer Unvereinbarkeit mit Art. 7 und 8 GRC für (teil)unwirksam erklärt, so geschehen etwa in der in Sachen „Schecke“106. Schon der oberflächliche Blick auf die Verordnung zeigt, dass auch hier ein Machtwort des Gerichtshofs notwendig wäre; denn es gilt hier wie bei der Vierten Geldwäscherichtlinie bzw. dem 10-Punkte-Plan des Finanzministers und ebenso der geplanten Änderung der Vierten Geldwäscherichtlinie sowie der darauf basierenden Änderung des $\mathrm{GwG}^{107}$ - der Zweck heiligt nicht alle Mittel. Dazu nachfolgend mehr.

\section{Fazit}

Sowohl aus der Richtlinie 95/46/EG ${ }^{108}$, der Datenschutzgrundverordnung als auch aus der Verordnung (EG) Nr. 45/2001 (die etwas höhere Anforderungen an die Datenverarbeitung stellt) ergibt sich, dass es bei den europäischen Datenschutzvorschriften, an welchen sich die Vierte Geldwäscherichtlinie messen las-

105 Siehe auch Kraska, ZD-aktuell 2016, 04173; Gola, EuZW 2012, 332, 333.

$106 \mathrm{EuGH}$, 09. 11. 2010, Rs. C-92/09 und C-93/09, Slg. 2010, I-11063, Rdn. 89 (Schecke und Eifert v. Land Hessen).

107 Siehe dazu N. Müller, NZWiSt 3/2017, 87 ff. und NZWiSt 4/2017, $121 \mathrm{ff}$.

108 Anzumerken ist hierzu, dass der EuGH hier von einer Vollharmonisierung ausgeht, siehe Wolff/Stemmer, BayVBl 2016, 181, 185. 
sen muss, letztlich um ihre Abgrenzung zu den Grundrechten und Grundfreiheiten der betroffenen Personen geht. Die Verarbeitung personenbezogener Daten muss danach eindeutige und festgelegte legitime Zwecke verfolgen und verhältnismäßig sein. Es wird jedoch (insbesondere aus der Datenschutzgrundverordnung) deutlich, dass der Schutz der betroffenen Personen eingeschränkt werden darf, wenn gewichtige Gründe dies erfordern. Dabei handelt es sich etwa um Zwecke der Verhütung, Ermittlung, Feststellung und Verfolgung von schweren Straftaten, um ein wichtiges öffentliches Interesse, ein wichtiges wirtschaftliches oder finanzielles Interesse eines Mitgliedstaats oder der Europäischen Gemeinschaften bzw. die nationale und die öffentliche Sicherheit, wobei darauf hinzuweisen ist, dass gerade die Vorgaben der Datenschutzgrundverordnung mit Blick auf die Art. 7 und 8 GRC in ihren Beschränkungen des Datenschutzes teils $\mathrm{zu}$ weitgehend erscheinen. Erleichterungen sind unter bestimmten Umständen auch vorgesehen, wenn es um eine Datenverarbeitung geht, die einzig dem Zweck dient, ein Register zu führen, das der Öffentlichkeit oder Personen mit einem berechtigten Interesse zugänglich ist. Hintergrund dieser Regelung dürfte sein, eine Verfahrenserleichterung zu schaffen, wenn eine Vielzahl von Datenabfragen aus gleichgerichteten Gründen dies erfordert - etwa das Handelsregister. Letzteres hatte der Richtliniengeber der Vierten Geldwäscherichtlinie wohl auch im Kopf, als er die Regelungen der Art. 30 und 31 geschaffen hat. Dort wird nämlich explizit in Art. 30 Abs. 3 der Richtlinie auf das Handels- oder Zentralregister verwiesen.

Somit stellt sich die Frage, ob das in den Art. 30 und 31 der Vierten Geldwäscherichtlinie vorgesehene Register und die dort vorgehaltenen Daten mit den in den Handelsregistern vorgehaltenen Daten vergleichbar sind, bzw. ob die (berechtigten) Interessen der Personen, die auf das Register zugreifen möchten, mit denen vergleichbar sind, die auf die Auskunft aus einem Handelsregisters gerichtet sind bzw. ob nicht die Qualität der Daten, die im Geldwäscheregister vorgehalten werden sollen, es mit Blick auf die Grundrechte und Grundfreiheiten der betroffenen Personen erfordern, dass ein Datenzugriff nur unter höheren Voraussetzungen zulässig sein kann. Dazu nachfolgend mehr.

\section{Vereinbarkeit mit den Grundrechten und den mit der Charta anerkannten Grundsätzen}

Nach Erwägungsgrund 65 der Vierten Geldwäscherichtlinie steht diese „im Einklang mit den Grundrechten und den mit der Charta anerkannten Grundsätzen, insbesondere dem Recht auf Achtung des Privat- und Familienlebens, dem Recht auf Schutz personenbezogener Daten, der unternehmerischen Freiheit, dem Ver- 
bot von Diskriminierung, dem Recht auf einen wirksamen Rechtsbehelf und ein unparteiisches Gericht, der Unschuldsvermutung und den Rechten der Verteidigung“109. Auch durch den Bezug auf die Datenschutzrichtlinie 95/46/EG, die Verordnung (EG) Nr. 45/2001 sowie die Datenschutzgrundverordnung stellt sich wie gesehen - die Frage, inwieweit die Regelungen in Art. 30 und 31 der Vierten Geldwäscherichtlinie mit Grundrechten und Grundfreiheiten, insbesondere Art. 7 und 8 GRC, vereinbar sind.

Die Grundrechtecharta verweist wiederum auf zwei Rechtsquellen, die insbesondere bei der Auslegung von Art. 8 GRC i.V.m. Art. 52 Abs. 7 GRC zu berücksichtigen sind, nämlich zum einen das datenschutzrechtliche Sekundärrecht ${ }^{110}$ und zum anderen Art. 8 EMRK ${ }^{111}$ sowie das Übereinkommen Nr. 108 des Europarats vom 28. 01. 1981 ${ }^{112}$. Die besondere Bedeutung des Art. 8 EMRK ergibt sich für Art. 8 GRC daraus, dass er in Art. 7 GRC fast wortgleich seinen Niederschlag gefunden hat.

\section{a) Inhalte der Grundrechte nach Art. 7 und 8 GRC}

Nach Art. 7 der GRC hat jede Person das Recht auf Achtung ihres Privat- und Familienlebens, ihrer Wohnung sowie ihrer Kommunikation. Mit der Kommunikation ist hier die Individualkommunikation von einem bestimmten Absender zu einem oder mehreren bestimmten Empfängern gemeint ${ }^{113}$.

Nach Art. 8 der GRC hat jede Person das Recht auf den Schutz ihrer personenbezogenen Daten. Diese Daten dürfen nur nach Treu und Glauben für festgelegte Zwecke und mit Einwilligung der betroffenen Person oder auf einer sonstigen gesetzlich geregelten legitimen Grundlage verarbeitet werden. Jede Person hat das Recht, Auskunft über die sie betreffenden erhobenen Daten zu erhalten und die Berichtigung der Daten zu erwirken. Die Einhaltung dieser Vorschriften wird von einer unabhängigen Stelle überwacht (siehe auch Art. 16 AEUV, der diesbe-

109 ABl. EU v. 05. 06. 2015, L 141/79, Erwägungsgrund 65.

110 Hier sind vor allem die Richtlinie 95/46/EG sowie die Verordnung (EG) Nr. 45/2001 einschlägig (siehe oben).

111 Giegerich, DÖV 2016, 456.

112 Übereinkommen zum Schutz des Menschen bei der automatischen Verarbeitung von personenbezogenen Daten v. 28. 01. 1981, BGBl. II 1985, 539; siehe Brühann, in: von der Groeben/ Schwarze/Hatje (Hrsg.), Europäisches Unionsrecht, 7. Aufl. 2015, Art. 16 AEUV Rdn. 38; das Übereinkommen macht Vorgaben zu Grundsätzen des Datenschutzes, etwa zur Qualität der Daten, die Datensicherheit, Schutz sensibler Daten und Rechte der Betroffenen etc.; die hier niedergelegten Grundsätze finden sich auch in der RL 95/46/EG bzw. der Verordnung (EG) Nr. 45/2001 wieder.

113 Brühann, in: von der Groeben/Schwarze/Hatje (Anm. 94), Art. 16 AEUV Rdn. 21. 
züglich die einzige unionsrechtliche Rechtsgrundlage zur Gesetzgebung über den Schutz natürlicher Personen bei der Verarbeitung personenbezogener Daten und über den freien Datenverkehr ist ${ }^{114}$ ).

\section{aa) Art. 8 EMRK}

Nach Art. 8 EMRK hat jede Person das Recht auf Achtung ihres Privat- und Familienlebens, ihrer Wohnung und ihrer Korrespondenz. In die Ausübung dieses Rechts darf eine Behörde nur eingreifen, soweit der Eingriff gesetzlich vorgesehen und in einer demokratischen Gesellschaft notwendig ist für die nationale oder öffentliche Sicherheit, für das wirtschaftliche Wohl des Landes, zur Aufrechterhaltung der Ordnung, zur Verhütung von Straftaten, zum Schutz der Gesundheit oder der Moral oder zum Schutz der Rechte und Freiheiten anderer. Ein Eingriff in Art. 8 EMRK liegt somit immer dann vor, wenn es sich um den Eingriff einer öffentlichen Stelle in das Recht eines Einzelnen auf Schutz seiner Privatsphäre handelt; dabei ist es unerheblich, ob besonders sensible Daten betroffen sind oder der Einzelne durch den Zugriff bestimmte Nachteile erlitten hat. Den Begriff der Privatsphäre legt der EGMR weit aus. Ein solcher Eingriff kann jedoch unter drei Voraussetzungen gerechtfertigt sein: Dazu muss der Eingriff zuerst gesetzlich (vorhersehbar und eindeutig) bestimmt sein und zweitens einen nach Art. 8 Abs. 2 EMRK legitimen Zweck verfolgen. Drittens muss der Eingriff verhältnismäßig sein, also durch ein zwingendes gesellschaftliches Bedürfnis begründet werden und in einem angemessenen Verhältnis zu dem verfolgten berechtigten Zweck stehen ${ }^{115}$.

\section{bb) Personenbezogene Daten}

Nach der weiten Definition der Richtlinie 95/46/EG, der Verordnung (EG) Nr. 45/ 2001 sowie der Datenschutzgrundverordnung sind unter personenbezogenen Daten alle Informationen über bestimmte oder bestimmbare natürliche Personen zu verstehen, die mit diesen direkt oder indirekt in Verbindung gebracht werden können ${ }^{116}$. Dieses weite Begriffsverständnis wurde vom EuGH bestätigt ${ }^{117}$. Daten, wie sie nach Art. 30 und 31 der Vierten Geldwäscherichtlinie vorgehalten werden

114 Brühann, in: von der Groeben/Schwarze/Hatje (Anm. 94), Art. 16 AEUV Rdn. 27.

115 Brühann, in: von der Groeben/Schwarze/Hatje (Anm. 94), Art. 16 AEUV Rdn. 39.

116 Siehe auch Brühann, in: von der Groeben/Schwarze/Hatje (Anm. 94), Art. 16 AEUV Rdn. 49; näher Albrecht/Jotzo, 2017, S. 58.

117 EuGH, 09. 11. 2010, Rs. C-92/09 und C-93/09, Slg. 2010, I-11063, Rdn. 52 (Schecke und Eifert v. Land Hessen). 
sollen, namentlich Informationen über den wirtschaftlichen Eigentümer einer Gesellschaft, juristischen Person oder eines Trusts bzw. einer vergleichbaren Rechtsvereinbarung, die nach Art. 30 Abs. 4 der Vierten Geldwäscherichtlinie mindestens Namen, Geburtsdatum, Staatsangehörigkeit, Wohnsitzland und Umfang des wirtschaftlichen Interesses enthalten, sind somit ohne Weiteres von der Definition umfasst.

\section{cc) Schutzumfang des Art. 8 GRC und zu berücksichtigende Grundsätze}

Zum Schutzumfang von Art. 8 GRC macht dessen Absatz 2 gewisse Vorgaben, ohne dass diese abschließend zu verstehen wären. Es geht dort zunächst um die Datenverarbeitung nach Treu und Glauben, die auf einen unbestimmten Rechtsbegriff Bezug nimmt, der durch die Rechtsanwendung näher präzisiert werden muss $^{118}$. Ein weiterer Grundsatz ist die rechtmäßige Verarbeitung der Daten, die beinhaltet, dass alle Aspekte der Verarbeitung der Rechtmäßigkeitskontrolle unterliegen (siehe Art. 7 der Richtlinie 95/46/EG) ${ }^{119}$.

Die Datenverarbeitung muss weiter für festgelegte Zwecke erfolgen. Allgemeine Angaben wie „Bankgeschäfte“, „geschäftsmäßige Verarbeitung“ reichen dazu nicht aus. Die Zweckbestimmung unterliegt dabei dem Proportionalitätsgrundsatz (Zweckentsprechung, Erheblichkeit und Übermaßverbot) als Ausdruck des verfassungsrechtlichen Verhältnismäßigkeitsgrundsatzes. Die Prüfung umfasst Art und Umfang der zu verarbeitenden Daten, die am Maßstab des eng gefassten Zwecks zu messen ist; auch die Grundsätze der Richtigkeit der Daten sowie deren begrenzte Dauer der Speicherung sind Ausprägung des Verhältnismäßigkeitsprinzips ${ }^{120}$.

Wesentliche Grundsätze des Art. 8 GRC sind zudem das Recht der betroffenen Personen auf Auskunft über die Datenverarbeitung und ggf. das Recht der Berichtigung unzutreffender Daten ${ }^{121}$.

\section{b) Grundrechtseingriff in Art. 7 und 8 GRC}

Mit Blick auf die vorstehenden Ausführungen zu den Vorgaben der Art. 30 und 31 der Vierten Geldwäscherichtlinie ist ein grundsätzlicher Eingriff in Art. 7 und 8

118 Siehe etwa EuGH, 16. 12. 2008, Rs. C-524/06, Slg. 2008, I-9705, Rdn. 52 (Huber).

119 Brühann, in: von der Groeben/Schwarze/Hatje (Anm. 94), Art. 16 AEUV Rdn. 53; siehe auch Wedde, 2016, S. 14.

120 Brühann, in: von der Groeben/Schwarze/Hatje (Anm. 94), Art. 16 AEUV Rdn. 54.

121 Brühann, in: von der Groeben/Schwarze/Hatje (Anm. 94), Art. 16 AEUV Rdn. 55 f. 
GRC bereits deshalb zu bejahen, weil personenbezogene Daten i.S.d. Richtlinie 95/46/EG sowie der Verordnung (EG) Nr. 45/2001 bzw. der Datenschutzgrundverordnung verarbeitet werden sollen. Gegenstand der Regelung ist zunächst das präventive und proaktive Vorhalten von Daten - grundsätzlich auch ohne Bezug zu geldwäscherelevanten Verdachtsfällen.

\section{c) Rechtfertigung des Grundrechtseingriffs in Art. 7 und 8 GRC}

„Nach Art. 52 Abs. 1 der Charta muss jede Einschränkung der Ausübung der in der Charta anerkannten Rechte und Freiheiten gesetzlich vorgesehen sein und den Wesensgehalt dieser Rechte und Freiheiten achten; unter Wahrung des Grundsatzes der Verhältnismäßigkeit dürfen Einschränkungen nur vorgenommen werden, wenn sie erforderlich sind und den von der Union anerkannten dem Gemeinwohl dienenden Zielsetzungen oder den Erfordernissen des Schutzes der Rechte und Freiheiten anderer tatsächlich entsprechen“"122.

\section{aa) Kein Eingriff in den Wesensgehalt von Art. 7 bzw. 8 GRC}

Festzustellen ist, dass die Vierte Geldwäscherichtlinie (insbesondere Art. 30 und 31 der Richtlinie) zwar einen schwerwiegenden Eingriff in die in Art. 7 und 8 GRC garantierten Rechte darstellt, jedoch nicht geeignet ist, ihren Wesensgehalt anzutasten, da sie zum einen die Kenntnisnahme des Inhalts elektronischer Kommunikation als solchen nicht uneingeschränkt gestattet und im Kapitel V Vorschriften zum Datenschutz enthält bzw. auf die Geltung der in nationales Recht umgesetzte Richtlinie 95/46/EG sowie die Verordnung (EG) Nr. 45/2001 verweist ${ }^{123}$.

\section{bb) Legitimer Zweck}

Voraussetzung dafür, dass der Eingriff als gerechtfertigt betrachtet werden kann, ist, dass er „einer dem Gemeinwohl dienenden Zielsetzung entspricht“"124. Neben dem Ziel, durch eine Harmonisierung der Geldwäschevorschriften diesbezügliche

122 Siehe EuGH, 08. 04. 2014, Rs. C-293/12 und C-594/12 Rdn. 38 (Digital Rights Ireland und Seitlinger u.a.).

123 Vgl. EuGH, 08. 04. 2014, Rs. C-293/12 und C-594/12 Rdn. 39 und 40 (Digital Rights Ireland und Seitlinger u. a.).

124 Siehe EuGH, 08. 04. 2014, Rs. C-293/12 und C-594/12 Rdn. 41 (Digital Rights Ireland und Seitlinger u. a.). 
Hemmnisse zwischen den Mitgliedstaaten zu beseitigen ${ }^{125}$, geht es materiell in erster Linie darum, Geldwäsche und Terrorismusfinanzierung zu verhüten und damit Bedrohungen des Binnenmarktes und von den damit gewährten Grundfreiheiten - insbesondere dem freien Kapital- und Dienstleistungsverkehr abzuwehren ${ }^{126}$. Es liegt insofern eine dem Gemeinwohl dienende Zielsetzung der Vierten Geldwäscherichtlinie, insbesondere den Art. 30 und 31 der Richtlinie, zugrunde. Dies ergibt sich auch aus der Rechtsprechung des Gerichtshofs, der die Bekämpfung des internationalen Terrorismus zur Wahrung des Weltfriedens und der internationalen Sicherheit als eine dem Gemeinwohl dienende Zielsetzung der Union betrachtet ${ }^{127}$.

Es stellt sich daher die Frage, ob die Art. 30 und 31 der Richtlinie auch konkret geeignet sind, die genannten Zwecke zu erreichen.

Die Erwägungsgründe der Richtlinie führen aus, dass gesellschaftsrechtliche Konstruktionen häufig missbräuchlich genutzt werden, um den wirtschaftlichen Eigentümer zu verschleiern und so die Geldwäschevorgaben oder die Mittel gegen die Terrorismusfinanzierung zu unterlaufen. Daher sei die Verpflichtung zum Vorhalten präziser und aktueller Daten zum wirtschaftlichen Eigentümer „eine wichtige Voraussetzung für das Aufspüren von Straftätern, die ihre Identität ansonsten hinter einer Gesellschaftsstruktur verbergen könnten. Die Mitgliedstaaten sollten deshalb dafür sorgen, dass in ihrem Staatsgebiet gemäß dem nationalen Recht eingetragene Unternehmen zusätzlich zu den grundlegenden Informationen, wie Name und Anschrift der Gesellschaft, Nachweis der Gründung und des rechtlichen Eigentums, auch angemessene, präzise und aktuelle Angaben zu ihrem wirtschaftlichen Eigentümer beschaffen und vorhalten müssen. Im Interesse größerer Transparenz zwecks Bekämpfung des Missbrauchs von juristischen Personen sollten die Mitgliedstaaten sicherstellen, dass die Informationen über den wirtschaftlichen Eigentümer unter vollständiger Einhaltung des Unionsrechts in einem Zentralregister außerhalb der Gesellschaft gespeichert werden. Die Mitgliedstaaten können hierfür eine zentrale Datenbank, in der Informationen über wirtschaftliche Eigentümer gespeichert werden, das Handelsregister oder ein anderes Zentralregister verwenden. “128 Insofern scheinen die Vorgaben in Art. 30 und 31 der Richtlinie - einschließlich der Schaffung des entsprechenden Registers (gleich in welcher Form) - grundsätzlich zur Zweckerreichung geeignet. Dies gilt nicht nur vor dem Hintergrund der Panama Papers, sondern auch im

125 ABl. EU v. 05. 06. 2015, L 141/81f., Erwägungsgrund 59.

126 ABl. EU v. 05. 06. 2015, L 141/73., Erwägungsgrund 1, 2.

127 EuGH, 08. 04. 2014, Rs. C-293/12 und C-594/12 Rdn. 42 m.w. N. (Digital Rights Ireland und Seitlinger u.a.).

128 ABl. EU v. 05. 06. 2015, L 141/75, Erwägungsgrund 14. 
Hinblick darauf, dass die Vierte Geldwäscherichtlinie die Empfehlungen der FATF vom Februar 2012 umsetzt, deren Zweck eindeutig auf die Verhinderung von Geldwäsche und Terrorismusbekämpfung angelegt ist ${ }^{129}$. Fraglich ist daher, inwieweit die Regelungen der Art. 30 und 31 der Vierten Geldwäscherichtlinie Ausfluss der Vorgaben der FATF sind.

\section{(1) Vorgaben der FATF}

Ein Blick in die Vorgaben der FATF - insbesondere die Empfehlungen Nr. 24, 25 , 10 sowie 22 - macht deutlich, dass sich die Art. 30 und 31 der Vierten Geldwäscherichtlinie erkennbar an den Vorgaben der FATF orientiert haben. Allerdings handelt es sich bei den Vorgaben der Art. 30 und 31 der Vierten Geldwäscherichtlinie nicht um eine bloße Umsetzung der Empfehlungen der FATF, zu denen im Einzelnen doch erkennbare Unterschiede bestehen.

Deutlich wird zunächst, dass die Vorgaben der FATF in erster Linie darauf abzielen, den zuständigen Behörden, die konkret bestimmt werden als Behörden mit unmittelbarem Bezug zu Geldwäsche- und Terrorismusbekämpfung ${ }^{130}$, die Informationen über den wirtschaftlichen Eigentümer zeitnah und zutreffend zur Verfügung zu stellen. Darüber hinaus sollen auch die sog. Designated NonFinancial Businesses and Professions (DNFBPs), also genau bestimmte Personenund Berufsgruppen in speziellen Situationen dazu befugt sein, auf die Informationen über den wirtschaftlichen Eigentümer zugreifen zu können ${ }^{131}$; auch hier wird in den Vorgaben und Erläuterungen der FATF sehr deutlich, dass es um Zugang $\mathrm{zu}$ Informationen in einem speziellen geldwäscherelevanten Zusammenhang geht.

Hinsichtlich des Vorhaltens von Daten in einem Register werden die Ausführungen der FATF jedoch nicht so verstanden, dass zwingend ein Register geschaffen werden soll, in dem die Informationen über den wirtschaftlichen Eigentümer in allen Einzelheiten gesammelt und vorgehalten werden. Vielmehr zeigt die FATF auf, aus welchen Quellen diese Informationen erlangt werden können; hier spielt zunächst das Handelsregister, das naturgemäß die wichtigsten Kerndaten zu Gesellschaften vorhält, eine große Rolle. Soweit ein solches nicht vorhanden ist, soll die Gesellschaft verpflichtet werden, die Informationen an einem bestimmten Gesellschaftsstandort vorzuhalten, damit durch die zuständigen Behörden dort bei Bedarf zeitnah darauf zugegriffen werden kann. Weitere Quellen, aus

129 International Standards on combating money laundering and the financing of terrorism \& Proliferation, The FATF Recommendations, February 2012.

130 FATF Recommendations (Anm. 111), S. 86 u. 89.

131 FATF Recommendations (Anm. 111), S. $19 \mathrm{f}$. 
denen die zuständigen Behörden die Informationen über den wirtschaftlichen Eigentümer beziehen können, sind darüber hinaus andere zuständige Behörden (z.B. Steuerbehörden) und Finanzinstitute oder DNFBPs, die Daten im Zusammenhang mit ihren Sorgfaltspflichten erhoben haben ${ }^{132}$. Eine generelle Pflicht zur Schaffung eines zentralen Registers sehen die FATF-Vorgaben in Anbetracht der vorstehenden Ausführungen zu alternativen Quellen somit nicht zwingend vor.

Außerdem wird ausdrücklich darauf hingewiesen, dass Handelsregister Finanzinstituten und DNFBPs (also Geldwäscheverpflichteten) Zugang zu Daten gewähren sollen, die öffentlich sind (Erläuterung zur Empfehlung Nr. 24 Ziff. 4 a), Gesellschaftsnamen, Rechtsform und -status, Gesellschaftsadresse, Satzung, Liste der Geschäftsführer/Direktoren) sowie u.U. auch zu Daten nach den Erläuterungen zur Empfehlung Nr. 24 Ziff. 4 b) (Liste der Gesellschafter oder Teilhaber mit ihrem jeweiligen Anteil bzw. Stimmrecht ${ }^{133}$. Dagegen werden keinerlei sonstige Personen oder Organisationen genannt, die wegen eines berechtigten Interesses (schon gar nicht nur bezüglich etwaiger Vortaten der Geldwäsche) Zugang $\mathrm{zu}$ Informationen über den wirtschaftlichen Eigentümer haben sollen. Mangels Vorgaben zur Schaffung eines einheitlichen Registers wird auch selbstredend kein Online-Zugang gegen Gebühr erwähnt.

Zugriffsberechtigt auf die Informationen über den wirtschaftlichen Eigentümer bei Trusts und vergleichbaren Rechtskonstrukten sind laut Empfehlung Nr. 25 ebenfalls uneingeschränkt die zuständigen Behörden (sowie Strafverfolgungsbehörden) sowie auf Nachfrage auch Finanzinstitute und DNFBPs ${ }^{134}$. Letzteren gegenüber haben Trustees ihren Status bei Begründung einer Geschäftsbeziehung offen zu legen, damit diese ein damit verbundenes Risiko einschätzen können. Allerdings werden hier auch andere zuständige Behörden, Personen und Organisationen, die mit Trusts in einer Verbindung stehen, zu Zugriffsbefugten von Daten über Trusts gemacht: Sie sollen sich informieren dürfen über verschiedene Register, andere Behörden (z. B. Steuerbehörden) sowie Berater und Dienstleister von Trusts und vergleichbaren Rechtskonstrukten ${ }^{135}$. Da an anderer Stelle die FATF-Vorgaben sehr deutlich gemacht haben, dass die Daten über den wirtschaftlichen Eigentümer lediglich bestimmten Personen und nur bei einem deutlichen Bezug zu Geldwäsche- und Terrorismusbekämpfung zur Verfügung stehen sollen, wird die Erläuterung der FATF diesseits so verstanden, dass die genannten Behörden, Personen und Organisationen auf die Informationsquellen nur insoweit zugreifen können, als diese wiederum befugt sind, Auskunft zu geben (dies

132 FATF Recommendations (Anm. 111), S. $85 \mathrm{f}$.

133 FATF Recommendations (Anm. 111), S. 85.

134 FATF Recommendations (Anm. 111), S. 89.

135 FATF Recommendations (Anm. 111), S. 89. 
wird bei Steuerbehörden, Rechts- und Steuerberatern nur sehr eingeschränkt der Fall sein) oder die Daten öffentlich zugänglich sind.

Zusammenfassend ist festzuhalten, dass die FATF mit Blick auf die Empfehlungen Nr. 24 und 25, die eindeutig Vorbild waren für die Art. 30 und 31 der Vierten Geldwäscherichtlinie, bei allen Vorgaben einen eindeutigen Bezug zur Geldwäsche- und Terrorismusbekämpfung hergestellt hat - eine Zweckbindung, welche die Art. 30 und 31 der Vierten Geldwäscherichtlinie teilweise vermissen lassen. Die Abweichungen der diesbezüglichen Vorgaben gehen offenbar auf das Europäische Parlament zurück, welches diese in Verhandlungen mit dem Rat durchgesetzt hat ${ }^{136}$. Anzumerken ist jedoch, dass die Empfehlungen der FATF keinen verpflichtenden Charakter haben und es insofern den Mitgliedstaaten freisteht, die Vorschläge der FATF in anderer, modifizierter und insbesondere auch in strengerer Weise umzusetzen ${ }^{137}$.

\section{(2) Vergleichbarkeit mit dem Handelsregister}

Kernelement des Art. 30 der Vierten Geldwäscherichtlinie ist das zentrale Register, auf dessen Schaffung nach Art. 30 Abs. 3 der Richtlinie von den Mitgliedstaaten hinzuwirken ist. In einem solchen zentralen Register - vergleichbar dem Handels- und Gewerberegister nach Art. 3 der Richtlinie 2009/101/EG - oder in einem öffentlichen Register sind die Daten über den wirtschaftlichen Eigentümer aufzubewahren $^{138}$. Da die in besagtem Register vorgehaltenen Daten nicht nur richtig, sondern auch aktuell sein müssen, wird eine Pflicht der Gesellschaften oder sonstigen juristischen Personen dahingehend statuiert, Änderungen, welche die Person des wirtschaftlichen Eigentümers (oder seines wirtschaftlichen Interesses) betreffen, ebenfalls proaktiv gegenüber dem entsprechenden Register zu korrigieren. Insofern ist tatsächlich eine Vergleichbarkeit mit dem Handelsregister gegeben. Fraglich ist jedoch, ob das hier zu schaffende Register generell mit dem Handelsregister verglichen werden kann, wie es Art. 30 Abs. 3 der Richtlinie offensichtlich tut.

Die Aufgabe des Handelsregisters ist es, wesentliche Rechtsverhältnisse der Unternehmer und der Unternehmen des Handelsstandes zu offenbaren. Es dient als Publizitätsmittel der Sicherheit des Rechtsverkehrs und genießt öffentlichen Glauben. Die Einsicht in das Handelsregister ist jedem gestattet; die Register sollen möglichst in elektronischer Form geführt bzw. dahingehend umgestellt

136 So Krais, CCZ 2015, 251, 254 m.w. N.

137 Wobei bei einer Nichtumsetzung der Empfehlungen der FATF die Gefahr eines Blacklisting nicht ausgeschlossen werden kann.

138 Siehe auch Krais, CCZ 2015, 251, 255. 
werden (siehe $§ 9$ HGB) ${ }^{139}$. Der Kunde oder Geschäftspartner soll durch einen Blick in das Handelsregister die Möglichkeit haben, festzustellen, mit wem er es zu tun hat oder mit wem er sich ggf. rechtlich auseinanderzusetzen hat, also wer die Gesellschaft vertritt; insoweit gilt hier das Prinzip „know your customer“, das auch den Sorgfaltspflichten der Geldwäsche zugrunde liegt.

Dies ergibt sich auch aus der Richtlinie 2009/101/EG ${ }^{140}$, die in ihrem Erwägungsgrund 3 betont, dass die Offenlegung der Angaben dazu dient, dass Dritte „sich über die wesentlichen Urkunden der Gesellschaft sowie einige sie betreffende Angaben, insbesondere die Personalien derjenigen, welche die Gesellschaft verpflichten können“ informieren können ${ }^{141}$. Laut Art. 2 der Richtlinie sind Gegenstand der Offenlegungspflicht Angaben zur Gesellschaft (Satzung, Dauer, Sitz, Auflösung, gezeichnetes Kapital etc.) und ihren Organen, nicht jedoch zu wirtschaftlichen Eigentümern ${ }^{142}$. Auch mit Blick auf die Änderung der Richtlinie durch die Richtlinie 2012/17/EU lässt sich festhalten, dass ein Register - wie es die Geldwäscherichtlinie vorsieht - nicht bereits in den europäischen Vorgaben zu den Handelsregistern angelegt ist. So wird zum einen in der Richtlinie 2012/17/ EU $^{143}$ der Begriff der Angaben nicht neu bzw. erweitert bestimmt und zum anderen ausdrücklich darauf hingewiesen, dass die Richtlinie „nicht auf die Schaffung einer zentralen Registerdatenbank ab[zielt], in der aussagekräftige Informationen über Gesellschaften gespeichert werden“144.

Vorliegend sollen durch das Geldwäscheregister Geldwäsche und Terrorismus zum Schutz des Binnenmarktes bekämpft werden, indem einem missbräuchlichen Einsatz gesellschaftsrechtlicher Konstruktionen vorgebeugt wird. Sofern Verpflichtete oder zuständige Behörden bzw. zentrale Meldestellen im Rahmen ihrer sich aus der Geldwäscherichtlinie ergebenden Verpflichtungen auf Daten zum wirtschaftlichen Eigentümer einer Gesellschaft, juristischen Person oder eines Trusts i.S.d. Art. 31 der Richtlinie bzw. einer vergleichbaren Rechtsvereinbarung zugreifen, hält sich der Zugriff im Rahmen der rechtmäßigen Zwecksetzung nach Art. 8 GRC. Ein präventives Vorhalten von Daten in Form eines Geldwäscheregisters kann einem zeitnahen Zugriff der Auskunftsberechtigten und der Beschleunigung des Verfahrens dienen. Vor dem Hintergrund, dass bei einem konkreten Geldwäscheverdacht ein schnelles Handeln ohne eine Warnung des Betroffenen erforderlich ist, kann die Verfahrensbeschleunigung durch eine prä-

139 Siehe Art. 3 der Richtlinie 2009/101/EG.

140 Richtlinie 2009/101/EG v. 16. 09. 2009, ABl. EU L 258/11 ff.

141 Richtlinie 2009/101/EG v. 16. 09. 2009, ABl. EU L 258/11.

142 Richtlinie 2009/101/EG v. 16. 09. 2009, ABl. EU L 258/13.

143 Richtlinie 2012/17/EU v. 13. 06. 2012, ABl. EU L 156/1ff.

144 Richtlinie 2012/17/EU v. 13. 06. 2012, ABl. EU L 156/2. 
ventive Datenvorhaltung insoweit als dem Zweck der Geldwäschebekämpfung dienlich erachtet werden.

Auch ist das Vorhalten von Daten, beispielsweise zu Gesellschaft, Sitz, Gesellschafter und Stammkapital, im Handelsregister durchaus üblich. Insofern könnte man tatsächlich eine Parallele zum nach Art. 30 und 31 der Vierten Geldwäscherichtlinie zu statuierenden Register ziehen. Dennoch liegt dem Handelsregister eine völlig andere Ausgangslage zugrunde: Hier geht es um das Rechtsschutzbedürfnis des Einzelnen, der durch (alltägliche) Rechtsgeschäfte jederzeit in die Situation kommen kann, auf diese Auskunft zugreifen zu müssen. Kaufleute und Handeltreibende haben überdies quasi als Ausgleich für die Registerpublizität und die damit verbundene Verpflichtung, die dort zu veröffentlichenden Daten zu erbringen bzw. ggf. zu berichtigen, auch regelmäßig ein Interesse daran, im Geschäftsverkehr aufzutreten. Dies berechtigt, die Handelsregisterdaten in einem öffentlichen Register zu führen. Vorliegend geht es jedoch um die Schaffung eines Registers, auf dessen Zugriff gerade nicht Jedermann angewiesen ist, was sich bereits aus der zugrunde liegenden Zwecksetzung (Geldwäschebekämpfung) ergibt. Entsprechend sollen nur bestimmte Berechtigte zugreifen können. Die Schaffung eines öffentlichen Registers - wie dem Handelsregister - was Art. 30 Abs. 3 der Vierten Geldwäscherichtlinie irreführender Weise erwähnt - ist somit verfehlt und nicht mit dem des festgelegten Zweck nach Art. 8 Abs. 2 GRC vereinbar $^{145}$.

\section{(3) Zweckbindung und Zugriffsberechtigte}

Mit Blick auf die Zweckbindung der Datenverarbeitung nach Art. 8 Abs. 2 GRC ist überdies fraglich, ob ein zentrales Register geschaffen werden kann, auf welches die in Art. 30 Abs. 5 genannten Einrichtungen und Personen zugreifen können. Wie bereits aufgezeigt, kann ein Zugriff auf die in einem solchen Register vorgehaltenen Daten nur zulässig sein, wo ein konkreter Bezug zur Geldwäsche- und Terrorismusbekämpfung hergestellt ist. Dies ist dort unproblematisch, wo Geldwäscheverpflichtete auf die vorgehaltenen Daten zugreifen, um ihren rechtlichen Verpflichtungen nachzukommen. Kritisch zu sehen ist es, wenn zuständige Behörden und zentrale Meldestellen anlasslos - also ohne einen konkreten Geldwäscheverdacht - auf die Daten zugreifen; dies dürfte mit der Zweckbindung des Art. 8 Abs. 2 GRC unvereinbar sein.

145 Siehe auch Krais, CCZ 2015, 251, 255; dies wird auch insofern deutlich, als nach dem Entwurf des Bundesfinanzministeriums zum GwG vom dort vorgesehenenTransparenzregister kein öffentlicher Glaube ausgehen soll, s. N. Müller, NZWiSt 3/2017, 87, 92. 
Besonders bedenklich erscheint jedoch die Tatsache, dass darüber hinaus auch Personen und Organisationen mit „,berechtigtem Interesse“ auf das Register zugreifen können. Zum einen wird nicht hinreichend deutlich, was unter einem berechtigten Interesse in diesem Sinne zu verstehen ist. Art. 30 der Richtlinie sieht keine nähere Bestimmung der Begrifflichkeit vor. Auch ein Rückgriff auf die Erwägungsgründe kann diesen unbestimmten Rechtsbegriff nicht ausreichend konkretisieren. Dort heißt es lediglich: „Die Mitgliedstaaten sollten des Weiteren sicherstellen, dass anderen Personen, die ein legitimes Interesse im Zusammenhang mit Geldwäsche, Terrorismusfinanzierung und damit zusammenhängende Vortaten - wie Bestechung, Steuerstraftaten und Betrug - nachweisen können, im Einklang mit den Datenschutzbestimmungen Zugang zu den Informationen über den wirtschaftlichen Eigentümer gewährt wird." ${ }^{146}$ Offen bleibt, an wen der Richtliniengeber als Zugriffsberechtigten hier gedacht hat: Ein berechtigtes Interesse geltend machen könnten beispielsweise investigative Journalisten im Rahmen des sog. Medienprivilegs (siehe nachfolgend) oder - wenn es sich um geschäftlich aktive Gesellschaften oder juristische Personen handelt - durchaus auch Geschäftspartner, die behaupten, im Rahmen einer geschäftlichen Verbindung geldwäscherelevante Transaktionen vorzunehmen. Würde man diesen Personen bei einem entsprechenden Vorbringen ein legitimes Interesse am Datenzugriff zuerkennen, würde das Register letztlich zu einem mehr oder weniger öffentlichen Register. Dies gilt umso mehr, als nach dem zitierten Erwägungsgrund auch ein nicht näher spezifizierter Bezug zu den Vortaten der Geldwäsche ein legitimes Interesse an der Registerauskunft begründen kann. Dies würde bedeuten, dass selbst im Vorfeld der Geldwäsche - etwa beim Verdacht des Vorliegens einer Vortat der Geldwäsche - ein Zugriff auf die Daten möglich wäre, was nicht mehr mit der Zweckbindung nach Art. 8 Abs. 2 GRC in Einklang zu bringen sein dürfte. Dies gilt umso mehr, als in den verschiedenen Mitgliedstaaten die Vortaten zur Geldwäsche uneinheitlich geregelt sind; im Extremfall sind alle Straftaten geldwäscherelevante Vortaten, wodurch bereits jeder Verdacht einer (wie auch immer gearteten) Straftat den Zugriff auf das Register ermöglichen würde.

Ein berechtigtes Interesse an den privaten Daten kann auch nicht auf Elemente der Strafverfolgung oder der öffentlichen Ordnung gestützt werden, denn hierbei handelt es sich um Aufgaben des Staates. Das Interesse aufgrund eines rechtlichen Anspruchs würde kein Element der Geldwäsche und aufweisen und würde damit ebenfalls der legitimen Zwecksetzung nach Art. 8 GRC widersprechen.

146 ABl. EU v. 05. 06. 2015, L 141/75, Erwägungsgrund 14. 
Verschärft wird die Situation im Weiteren durch die in Art. 30 Abs. 5 der Richtlinie vorgesehene Möglichkeit der Schaffung eines Online-Registers zum Zugriff auf die vorgehaltenen Daten. Wie es im Rahmen eines automatisierten Zugriffs überhaupt möglich sein soll, sicherzustellen, dass ein legitimes Interesse von Personen oder Organisationen nach Art. 30 Abs. 5 c) der Richtlinie vorliegt, ist zweifelhaft. Vielmehr entsteht durch die Möglichkeit eines Online-Zugriffs die Gefahr, dass ein unkontrollierbarer Zugriff auf die im Register vorgehaltenen Daten auch ohne Bezug zur Geldwäsche- und Terrorismusbekämpfung stattfinden wird.

Es ist jedoch nicht von der Hand zu weisen, dass es hierzulande verschiedene (teils elektronisch geführte) Register gibt, die einem (mehr oder weniger) begrenzten Personenkreis den Zugriff ermöglichen und ebenfalls das berechtigtes Interesse als Zugriffsberechtigung ausreichen lassen. Prominentes Beispiel ist etwa das Grundbuch, das aus Vereinfachungsgründen ebenfalls teils elektronisch geführt wird und auf das Notare, andere öffentliche Stellen, aber auch Banken und Versicherungen zugreifen können, wenn ein berechtigtes Interesse nach $\S \S 12,12 \mathrm{c}$ GBO vorliegt.

Das berechtigte Interesse ist dabei gesetzlich nicht definiert und ist somit auslegungsbedürftig. Nach den h. M. reicht es aus, dass der Antragsteller ein „verständiges, durch die Sachlage gerechtfertigtes Interesse darlegt“. Ungenügend ist das reine Interesse, da dieses dem informationellen Selbstbestimmungsrecht des Betroffenen nicht gerecht würde; das Erfordernis eines rechtlichen Interesses dagegen würde die Registerpublizität zu sehr einschränken ${ }^{147}$.

Ein berechtigtes Interesse kann also in einem tatsächlichen, wirtschaftlichen, öffentlichen oder wissenschaftlichen Interesse bestehen, sofern es zur Überzeugung des Grundbuchamtes dargelegt ist. Es soll sichergestellt werden, dass die Einsicht nicht der Verfolgung unbefugter Zwecke oder bloßer Neugier dient $^{148}$. Ein berechtigtes Interesse öffentlicher Natur wurde etwa bei Einsichtnahmen in das Grundbuch durch die Presse bejaht, wenn die Belange der Betroffenen nicht beeinträchtigt werden ${ }^{149}$. Die Abwägung zwischen der Pressefreiheit und den Rechten des Betroffenen nimmt dabei das Grundbuchamt vor ${ }^{150}$, wobei eine Anhörung des Eingetragenen nicht erforderlich ist. Auch die Benachrichtigung des Eigentümers über die Einsichtnahme durch die Presse wird abge-

147 Wilsch, in: Beck'scher Online-Kommentar zur GBO, 26. Ed., Stand: 01. 11. 2016, § 12 Rdn. 1f. 148 Siehe Wilsch, in: BeckOK GBO (Anm. 129), § 12 Rdn. 2 m.w. N.

149 Wilsch, in: BeckOK GBO (Anm. 129), § 12 Rdn. 6; siehe auch BVerfG NJW 2001, 503, 504; BGH WuM 2011, 636; OLG München NJW-RR 2016, 806 Rdn. 7; OLG Düsseldorf NJW 2016, 89 Rdn. 24 ff. $150 \mathrm{Zu} \S 45 \mathrm{BMG}$ siehe Süßmuth, BMG, 32. Lfg. 2014, § 45 Rdn. 5. 
lehnt, da diese das Grundrecht auf Informationsbeschaffung einschränken wür$\mathrm{de}^{151}$.

Hintergrund dieses sog. Medienprivilegs (siehe auch § 41 BDSG), das ein berechtigtes Interesse an einer Registerauskunft etwa aus dem Grundbuch zu statuieren vermag, ist die Rechtsprechung des Bundesverfassungsgerichts, welches schon im Jahr 1979 entschied, dass die freie, nicht von der öffentlichen Gewalt gelenkte, keiner Zensur unterworfene Presse Wesenselement des freiheitlichen Staates sei. Sie vermittle „dem Bürger Informationen, die es ihm ermöglichen, die Meinungen anderer kennenzulernen und zu überprüfen, seinen eigenen Standpunkt $\mathrm{zu}$ finden, sich an der öffentlichen Diskussion $\mathrm{zu}$ beteiligen und politische Entscheidungen $\mathrm{zu}$ treffen. Die Freiheit der Presse stellt damit im heutigen demokratischen Staat letztlich eine wesentliche Voraussetzung für eine freie politische Willensbildung des Volkes dar“152. Weiter führt das Bundesverfassungsgericht aus: „Die in Art. 5 Abs 1 Satz 2 GG verbürgte Pressefreiheit gewährleistet sowohl als Grundrecht des Einzelnen wie als Garantie des Instituts ,Freie Presse ' nicht nur die Freiheit der Verbreitung von Nachrichten und Meinungen; sie schützt vielmehr auch den gesamten Bereich publizistischer Vorbereitungstätigkeit, zu der insbesondere die Beschaffung von Informationen gehört [...]. Dabei wird der Schutz des Art. 5 Abs 1 Satz 2 GG allen Presseorganen grundsätzlich unabhängig von der Art und Weise ihrer Berichterstattung zuteil, wiewohl diese bei der Abwägung zwischen der Pressefreiheit und anderen verfassungsrechtlich geschützten Rechtsgütern im Einzelfall zu berücksichtigen sein kann. "153

Das Bundesverfassungsgericht wies auch in seinem Beschluss vom 28. 08. 2000 explizit darauf hin, dass die in Art. 5 Abs. 1 Satz 2 verbürgte Pressefreiheit nicht nur die Freiheit der Verbreitung von Nachrichten und Meinungen gewährleistet, sondern „den gesamten Bereich publizistischer Vorbereitungstätigkeit, zu der insbesondere die Beschaffung von Informationen gehört. Erst der prinzipiell ungehinderte Zugang zur Information versetzt die Presse in den Stand, die ihr in der freiheitlichen Demokratie eröffnete Rolle wirksam wahrzunehmen“. Daher könne der Presse grundsätzlich ein berechtigtes Interesse an einer Grundbucheinsicht zustehen ${ }^{154}$.

Der BGH knüpfte in seiner Entscheidung vom 17. 08. 2011 an diese Rechtsprechung des Bundesverfassungsgerichts ${ }^{155}$ an und bejahte ein berechtigtes

151 Wilsch, BeckOK GBO (Anm. 129), § 12 Rdn. 73; einschränkend zu § 45 BMG, Süßmuth, BMG (Anm. 132), § 45 Rdn. 3.

152 BVerfG NJW 1979 1400, 1401.

153 BVerfG NJW 1979 1400, 1401.

154 BVerfG NJW 2001, 503, 504.

155 BVerfG NJW 2001, 503, 504. 
Interesse der Pressevertreter an einer Grundbucheinsicht, „da das Einsichtsgesuch der Antragstellerin auf die Beschaffung journalistisch verwertbarer Informationen im Zusammenhang mit dem Kauf des Grundstücks, für das Einsicht verlangt wird, zielt und somit der von dem Schutzbereich der Pressefreiheit (Art. 5 Abs. 1 Satz 2 GG) erfassten publizistischen Vorbereitungstätigkeit (BVerfGE 50, 234, 240) zuzuordnen ist“156. Er führte dazu aus, dass das Interesse des Eingetragenen an der Geheimhaltung hinter das Informationsinteresse der Presse zurücktreten muss, sofern ,es sich um eine Frage handelt, die die Öffentlichkeit wesentlich angeht - was vorliegend mit Blick auf die herausgehobene politische Stellung eines der Eigentümer der Fall ist - und wenn die Recherche der Aufbereitung einer ernsthaften und sachbezogenen Auseinandersetzung dient [...]. Dafür, dass es sich hier anders verhält und die aus den Nachforschungen der Antragstellerin möglicherweise resultierende Berichterstattung lediglich dazu diente, eine in der Öffentlichkeit vorhandene Neugierde und Sensationslust zu befriedigen [...], bestehen keine Anhaltspunkte“157. Weiter hielt der BGH fest, dass es auch nicht darauf ankomme, dass die Einsicht zu den erhofften Informationen führe. Das Grundbuchamt habe nur zu prüfen, ob das Rechercheinteresse in einem konkreten Bezug zu dem betreffenden Grundstück stehe. „Das Grundbuchamt darf von der Presse im Rahmen der dieser nach $\S 12$ Abs. 1 Satz 1 GBO in Bezug auf das berechtigte Interesse obliegenden Darlegungslast nur solche Konkretisierungen verlangen, die für die Prüfung, ob ein schutzwürdiges Informationsinteresse anzuerkennen ist, von Bedeutung sind [...]. Erforderlich ist, dass der dem Einsichtsbegehren zugrunde liegende - durch das Grundbuchamt inhaltlich nicht $\mathrm{zu}$ bewertende - Verdacht in dem Antrag mitgeteilt wird; außerdem muss für den Fall, dass sich die Vermutung als zutreffend erweist, eine publizistisch geeignete Information zu erwarten sein"158.

Das sehr weitreichende Einsichtsrecht bezieht sich dabei auf das Grundbuch insgesamt, also auch die Grundakten (§ 46 Abs. 1 GBV), sofern die Presse ein generelles Einsichtsrecht geltend macht. Dies, obschon die Grundakten in der Regel die den Eintragungen zugrunde liegenden schuldrechtlichen Vereinbarungen und damit umfassende Angaben zu persönlichen, familiären, sozialen, wirtschaftlichen oder finanziellen Verhältnissen der Betroffenen beinhalten. Eine Vorauswahl durch das Grundbuchamt verstößt nach Ansicht des BGH gegen das „Gebot staatlicher Inhaltsneutralität“"159.

156 BGH WuM 2011, 636.

157 BGH WuM 2011, 636.

158 BGH WuM 2011, 636, 637.

159 Wilsch, BeckOK GBO (Anm. 129), § 12 Rdn. 73; siehe auch OLG München NJW-RR 2016, 806 Rdn. 7; OLG Düsseldorf NJW 2016, 89 Rdn. 35, 39. 
Sofern Grundbücher elektronisch geführt werden, sind die Grundbuchdaten zentral gespeichert und online abrufbar. Beim automatisierten Abrufverfahren wird zwischen dem uneingeschränkten und eingeschränkten Abrufverfahren differenziert. Da das berechtigte Interesse beim automatisierten Abrufverfahren nicht im Einzelfall nachgeprüft wird, kommen für das uneingeschränkte Abrufverfahren nur solche Personen und Stellen in Betracht, die kein berechtigtes Interesse darzulegen brauchen. Behörden, Gerichte, Notare und öffentlich bestellte Vermessungsingenieure nehmen danach uneingeschränkt am automatisierten Auskunftsverfahren teil. Weiteren Auskunftsfragenden wird eingeschränkt Auskunft erteilt, sofern sie das Vorliegen bestimmter Voraussetzungen beim Ausfüllen der Bildschirmmaske in einer sog. „Darlegungserklärung“ versichern ${ }^{160}$.

Bestimmte (infolge ihrer Amtspflichten) Berechtigte werden in Anbetracht ihrer Funktion somit in die Lage versetzt, ohne Weiteres (und damit auch anlasslos) auf das Grundbuch zuzugreifen. Hintergrund dieser Ausgestaltung dürften rein pragmatische Erwägungen sein. Es würden die mit dem elektronischen Register geschaffenen Verfahrenserleichterungen stark relativiert, würde über jede Anfrage individuell entschieden und das berechtigte Interesse geprüft werden müssen.

So wird dies jedoch bei der erweiterten Auskunft aus dem Melderegister gehalten. Dort können weitergehende Informationen (z. B. Geburtsdatum, -ort, frühere Anschriften, Familienstand etc.) als die öffentlich Daten nach § 44 BMG mitgeteilt werden, sofern nach $\S 45$ (erweiterte Melderegisterauskunft) ein berechtigtes Interesse glaubhaft gemacht wird. Die Auskunft kann ebenfalls online beantragt werden und sieht vor, dass der Anfragende in einem kleinen Feld darlegt, inwiefern ein berechtigtes Interesse an den Daten der genannten Person hat. Dazu muss er keinerlei Unterlagen als Nachweis vorlegen, sondern glaubhaft machen, also plausibel behaupten, die Auskunft etwa wegen eines rechtlichen, wirtschaftlichen oder ideellen Interesses zu benötigen ${ }^{161}$. Dies wird (bzw. sollte) von Seiten der zuständigen Behörde im Einzelfall geprüft (werden). Im Anschluss wird dann ggf. Auskunft erteilt. Gleiches gilt etwa für die Auskunft aus dem Schiffsbauregister ( $\left(65\right.$ Abs. 2 SchRegO) ${ }^{162}$ und grundsätzlich auch für die Auskunft aus dem Register für Halter- und Fahrzeugdaten. Bezüglich Letzterem muss bei der einfachen Registerauskunft das in $\S 39 \mathrm{Abs}$. $1 \mathrm{StVG}$ spezifizierte rechtliche Interesse lediglich dargelegt (nicht glaubhaft gemacht) werden, während bei der erweiterten Registerauskunft nach $\S 39$ Abs. 2 StVG die Glaubhaftmachung eines

160 Siehe http://www.grundbuch-bw.de/pb/,Lde/Rechtliche+Voraussetzungen.

161 Süßmuth, BMG (Anm. 132), § 45 Rdn. 4, 15.

162 Krause, Praxishandbuch Schiffsregister, 2012, Rdn. 829. 
bestimmten rechtlichen Interesses sowie der Tatsache, dass die Daten auf andere Art und Weise nicht oder nur mit unverhältnismäßigem Aufwand erlangt werden können, erfolgen muss ${ }^{163}$.

Probleme bringen beide Vorgehensweisen mit sich: Die Methode der OnlineAuskunft - wie etwa beim Melderegister - führt nicht zu einer Verfahrenserleichterung, da jede Anfrage im Einzelfall geprüft werden muss. Ob und inwieweit dies tatsächlich geschieht, darüber kann nur spekuliert werden. Klar ist: Die Anforderungen an die Darlegung sind nicht wirklich hoch, eine halbwegs plausible Darlegung innerhalb eines kleinen Textfeldes ist ausreichend, um personenbezogene Daten zu erhalten.

Dagegen wird beim Online-Zugriff auf ein Register (wie dem elektronischen Grundbuch) einem bestimmten Personenkreis nach einmaliger Darlegung ihrer Amts- oder Berufspflichten ein auf Dauer angelegter Zugriff auf die im Register niedergelegten Daten zugestanden. Welche Gefahren dies birgt, zeigt sich deutlich an dem vom OLG Celle entschiedenen Fall, indem ein Notar als zum Grundbuch Zugangsberechtigter auf bloße Bitte eines Maklers hin, diesem im automatisierten Abrufverfahren einen Grundbuchauszug zur Verfügung gestellt hatte $^{164}$. Die Gefahr, dass Zugriffsberechtigte personenbezogene Daten an Nichtberechtigte weitergeben, besteht zwar ganz unabhängig von der Einführung oder Ausgestaltung eines Registers - ein automatisierter (und weitgehend anonymer) Zugriff dürfte die Hemmschwelle jedoch deutlich senken.

Würde nun aber der Presse in ihrer Funktion ein ständiger (automatisierter) Zugriff auf so ein Register gewährt, stellte sich die Frage, ob dem informationellen Selbstbestimmungsrecht der betroffenen Personen noch ausreichend Rechnung getragen wird. Es ist nämlich eins, ob einem Einsichtsgesuch der Presse anhand eines konkretisierten Anfangsverdachts nachgegeben wird (so der o.g. Fall) oder ob ihr die Daten quasi „zur Ausforschung“ nach interessanten Themen oder Fällen zur Verfügung stehen ${ }^{165}$. Nebenbei bemerkt tut sich hier ein weiteres Spannungsfeld auf zwischen dem konkretisierten Anfangsverdacht, den beispielsweise das OLG München als berechtigtes Interesse für eine Grundbucheinsicht der Presse verlangt ${ }^{166}$, und der vagen Bestimmung der Vierten Geldwäscherichtlinie, die lediglich den - wie auch immer gearteten Verdacht (einer Vortat) der Geldwäsche für einen Registerzugriff genügen lässt.

163 Dauer, in: König/Dauer (Hrsg.), Straßenverkehrsrecht, 2013, § 39 Rdn. 2.

164 OLG Celle, Urt. v. 15. 07. 2011, Not 7/11, BeckRS 2011, 18919.

165 Siehe dazu auch OLG München NJW-RR 2016, 806 Rdn. 9.

166 OLG München NJW-RR 2016, 806 Rdn. 9; anders dagegen OLG Düsseldorf NJW 2016, 89 Rdn. 34. 
Dieses Problem verschärft sich in Anbetracht der Tatsache, dass der Begriff der Presse weit, formal und entwicklungsoffen ist. Das Bundesverfassungsgericht stellt für den Schutz der Pressefreiheit darauf ab, dass eine Publikation nur in gedruckter und zur Verbreitung geeigneter und bestimmter Form am Kommunikationsprozess teilnimmt. Maßgeblich ist die Herstellungs- und Vervielfältigungsmethode, so dass der Schutz unabhängig vom Inhalt des Druckerzeugnisses bestehe ${ }^{167}$. Demnach gehören zur Presse alle zur Verbreitung geeigneten und bestimmten Druckerzeugnisse wie Bücher, Zeitungen oder Zeitschriften und andere Informationsträger, wenn sie der Informationsverbreitung eines Druckwerks dienen. Teils werden auch die sog. Online-Medien, also Daten, die als Datei vorliegen und über ein Netz abrufbar sind, deren Wesensmerkmal daher im Versenden ohne Trägermedium liegt, der Rundfunkfreiheit zugeordnet und Art. 5 Abs. 1 GG auch auf diese Medien erstreckt ${ }^{168}$. Es wird deutlich, dass damit auch der Personenkreis der Pressevertreter sehr weit (vom Buchverleger bis zur Lokalpresse) reicht. Wird damit „der Presse“ quasi institutionell ein Zugang zu elektronischen Registern gewährt, werden diese mehr oder weniger öffentlich, was mit Blick auf das informationelle Selbstbestimmungsrecht des Betroffenen bedenklich erscheint. Ein berechtigtes Interesse publizistisch tätigen Personen grundsätzlich zuzusprechen, verstößt nämlich - wie das OLG München zutreffend ausführt - gegen einfachgesetzliche Normen (siehe $\S 12$ Abs. 3 GBO) und das Verfassungsrecht ${ }^{169}$.

Insgesamt fragwürdig scheint bei der Online-Zugriffslösung, wie kontrolliert werden soll, ob Datenabfragen von einem berechtigten Interesse getragen sind und wie sichergestellt werden kann, dass sich der Betroffene andernfalls gegen den Datenzugriff wehren kann. Letzteres erscheint aussichtslos, so dass der Betroffene damit rechnen muss, dass seine Daten einer Vielzahl von Zugriffen ausgesetzt sein werden, deren Berechtigung im Einzelfall nicht geprüft wird.

Angesichts der dargestellten Register und ihrer Zugriffsvoraussetzungen könnte man nun mit guten Gründen die Auffassung vertreten, dass das Transparenzregister doch in Grundzügen den in Deutschland bereits vorhandenen Registern entspricht. Das Recht, sich als wirtschaftlicher Berechtigter einer in der Öffentlichkeit auftretenden juristischen Person zu bedienen, bedinge im Gegenzug, personenbezogene Daten einschließlich der wirtschaftlichen Interessen offenzulegen ${ }^{170}$. So würde es den Geldwäscheverpflichteten (insbesondere den

167 Schemmer, in: Beck’scher Online-Kommentar GG, 28. Ed., Stand: 01. 12. 2016, Art. 5 Rdn. 42; BVerfGE 25, 296, 307.

168 Schemmer, in: BeckOK GG (Anm. 149), Art. 5 Rdn. $42 \mathrm{f}$.

169 OLG München NJW-RR 2016, 806 Rdn. 8.

170 Näher dazu N. Müller, NZWiSt 4/2017, 121, $124 \mathrm{f}$. 
Banken, die auf die Einführung eines Registers gedrängt haben ${ }^{171}$ ) deutlich erleichtert, die geforderten Informationen $\mathrm{zu}$ Verfügung $\mathrm{zu}$ stellen, und eine Transparenz herbeigeführt, die „Kriminelle“ vor der Nutzung von Gesellschaften zu kriminellen Machenschaften (Geldwäsche und Terrorismusfinanzierung) abschrecken würde.

Dies ist sicherlich zutreffend. Dennoch ist Folgendes zu bedenken: Zunächst dürfen sich die Geldwäscheverpflichteten laut Vierter Geldwäscherichtlinie ausdrücklich nicht auf die Registerdaten verlassen, sondern haben - immer noch risikobasiert die Daten zu überprüfen, um dann - bei geringsten Zweifeln an deren Richtigkeit - Mitglieder der Führungsebene als wirtschaftliche Berechtigte zu identifizieren ${ }^{172}$. Inwieweit vor diesem Hintergrund in der Praxis Zweifel (und zugleich auch die Vorgaben des risikobasierten Ansatzes) verdrängt werden, vermag nicht eingeschätzt zu werden.

Zudem geht es vorliegend zwar um die Zwecke der Geldwäsche und Terrorismusbekämpfung, durch den das berechtigte Interesse begründeten Verdacht von Vortaten der Geldwäsche als Zugriffsberechtigung auf das Register findet jedoch durch die Hintertür eine Ausweitung auf Geldwäschevortaten und damit allgemein die Strafverfolgung statt, da - wie gesehen - Vortaten zur Geldwäsche u. U. alle Straftaten sein können. In diesem Zusammenhang ist darauf hinzuweisen, dass die Bekämpfung und Verfolgung von Straftaten nicht Aufgabe von Privaten ist und damit ein Registerzugriff nicht begründet werden kann ${ }^{173}$. Dies betrifft insbesondere Personen mit einem berechtigten Interesse.

Soweit auf die nationalen Register in Deutschland rekurriert wird, ist - wie gesehen - zu bedenken zu geben, dass die Glaubhaftmachung eines berechtigten Interesses keine hohen Hürden aufstellt. In zwei Sätzen zu behaupten, man habe den Verdacht, dass der Geschäftspartner Steuern hinterziehe oder man ggf. „,kontaminiertes“ Geld erhalten könne, dürfte für eine Auskunft ausreichen. Inwieweit solche Behauptungen einerseits als „glaubhaft“ bewertet werden können und andererseits nicht zugleich mit Blick auf das Legalitätsprinzip ein Tätigwerden der Strafverfolgungsorgane begründen müssten, soll dahingestellt bleiben. Jedenfalls sind beide Vorgehensweisen - sowohl die Online-Auskunft, erst recht jedoch der Online-Zugriff - mit erheblichen Schutzlücken für die schutzwürdigen Interessen des Betroffenen verbunden.

Zudem ist darauf hinzuweisen, dass auch der Inhalt der Daten der vorhandenen Register - also die weitergebene Information - im Vergleich zu den im Geld-

171 Zentes/Glaab, BB 2013, 707, 713.

172 Siehe nur von Drathen, WPg 2015, 1242, 1245f.

173 Eingehend dazu N. Müller, NZWiSt 4/2017, 121, $122 \mathrm{ff}$. 
wäscheregister vorzuhaltenden Daten über den wirtschaftlichen Eigentümer eine andere Brisanz aufweist. Zwar überschneiden sich die Daten inhaltlich teilweise mit denen des Melderegisters (Name, Geburtsdatum, Staatsangehörigkeit etc.), aber gerade die Angaben über die wirtschaftlichen Interessen, sprich: die Angabe, mit wieviel Kapital eine Person an einer Gesellschaft beteiligt ist oder mit welchen Beträgen sie von dieser finanziell begünstigt wird, geht über die aus dem Melderegister erhältlichen Daten hinaus ${ }^{174}$. Gewiss könnte man nun einwenden, dass auch das Grundbuch gewissermaßen Angaben zur Höhe des wirtschaftlichen Interesses macht, indem es nämlich offenlegt, welche Eigentumsverhältnisse bestimmter Personen an Grundstücken bestehen bzw. welche Verbindlichkeiten darauf lasten. Allerdings ist die Gefahr, wegen seines Vermögens wirtschaftlicher Repressalien ausgesetzt zu sein, höher einzustufen, wenn bekannt ist, dass eine Person von einer Gesellschaft bestimmte Erträge erhält bzw. eine hohe Beteiligung daran hält, da das Eigentum an einem Grundstück naturgemäß wenig über die Liquidität einer Person aussagt. Insofern steht $\mathrm{zu}$ vermuten, dass eher ein wirtschaftlicher Eigentümer oder eine ihm nahestehende Person Repressalien ausgesetzt sein wird, als ein Grundstückseigentümer, zumal beim Grundbuchregister - und das ist entscheidend - für den Eigentümer immer noch die Möglichkeit besteht, durch eine Treuhand-Konstellation nicht aufzuscheinen. Diese Möglichkeit soll dem (fiktiven) wirtschaftlichen Eigentümer durch das Geldwäscheregister aber gerade bewusst verbaut werden.

Außerdem ist es selbst beim elektronischen Grundbuch so, dass als Zugriffsberechtigung ein spezifiziertes berechtigtes Interesse geltend gemacht werden muss, meist ausgeübt durch Amtsträger. Obschon generell beim Grundbuch nur ein bestimmter Personenkreis auskunftsberechtigt ist (Eigentümer, Angrenzer etc.), wäre es - trotz Medienprivileg - kritisch zu betrachten, wenn der Presse per se eine Zugangsberechtigung zum elektronischen Grundbuch gewährt würde. Es besteht nämlich durchaus ein erheblicher Unterschied, ob Journalisten über das Medienprivileg im Einzelfall Zugriff auf personenbezogene Daten gewährt wird, weil in Bezug auf einen bestimmten Sachverhalt ein öffentliches Interesse an Aufdeckung und Information besteht. Die Zurverfügungstellung eines „Pools“ personenbezogener Daten zur Ausforschung medienwirksamer Sachverhalte ist vom Medienprivileg dagegen ersichtlich nicht gedeckt. Der Bezug zum berechtigten Interesse kann dabei auch nicht über die diffuse Begrifflichkeit des „Verdachts der Begehung von Vortaten der Geldwäsche“ hergestellt werden, denn unabhängig von der unbestimmten Weite des Begriffs (der - wie dargestellt -

174 Dies gilt erst recht für die im Fahrzeugregister (§§ $31 \mathrm{ff} . \mathrm{StVG}$ ) vorgehaltenen personenbezogenen Daten. 
sämtliche Straftaten einbeziehen kann) scheint dieser sich - siehe Panama Papers - insbesondere in Form der möglichen Steuerhinterziehung unschwer bezüglich wirtschaftlicher Eigentümer von Gesellschaften begründen zu lassen.

Insofern kann bezüglich der Einführung eines Geldwäscheregisters nicht auf die national schon vorhandenen Register verwiesen werden, auf die lediglich zuständige Behörden und Personen mit einem berechtigten Interesse zugreifen können - die mit dem Geldwäscheregister vorgesehenen Eingriffe in die dort vorzuhaltenden personenbezogenen Daten in Verbindung mit der Weite der dafür zu statuierenden Zugriffsberechtigung gehen über Auskünfte aus Grundbuch und Melderegister bzw. Abfragen von Kfz-Halterdaten hinaus.

Hinzuweisen ist in diesem Zusammenhang noch auf die in § 51 BMG vorgesehene Möglichkeit, eine Auskunftssperre in das Melderegister einzutragen, wenn Tatsachen die Annahme rechtfertigen, dass durch eine Auskunft eine Gefahr für Leben, Gesundheit, persönliche Freiheit oder ähnliche schutzwürdige Interessen erwachsen. Die Hürden an die Glaubhaftmachung solcher Tatsachen sind hoch; die zuständigen Behörden der Kommunen entscheiden dabei nach freiem Ermessen, ob die Auskunftssperre (die wiederum durch die Geltendmachung eines berechtigten Interesses überwunden werden kann) eingetragen wird. Wie häufig eine solche Eintragung in der Praxis vorkommt, lässt sich schwerlich nachvollziehen, wobei den Betroffenen in der Regel auch der Nachweis einer ungleichmäßigen Ermessensausübung mangels Einblick in die Verwaltungspraxis verwehrt bleiben wird. In Baden-Württemberg bestanden zwischen 2009 und 2014 laut Innenministerium 34.000 Auskunftssperren, was rund 0,3\% der gemeldeten Personen entsprach ${ }^{175}$. Es ist angesichts dieser Zahlen davon auszugehen, dass die Eintragung einer Auskunftssperre eher selten vorgenommen wird. In Anbetracht dessen und der Tatsache, dass $\S 51$ BMG in Bezug auf die schutzwürdigen Interessen vergleichsweise weit gefasst ist, während bei der Ausnahmeregelung des Art. 30 Abs. 9 der Vierten Geldwäscherichtlinie die Gefahr von Betrug, Entführung, Erpressung, Gewalt oder Einschüchterung nachgewiesen werden muss, wird deutlich, dass die in der Vierten Geldwäscherichtlinie vorgesehene Ausnahmeregelungen des Art. 30 (die im Übrigen für Art. 31 völlig fehlt) rechtstaatlichen Anforderungen nicht genügt ${ }^{176}$.

Insofern lassen die Regelung der Art. 30 und 31 der Vierten Geldwäscherichtlinie bei anlasslosen Zugriffen und Zugriffen auf personenbezogene Daten durch

175 Landtag von Baden-Württemberg, Drucks. 15/5710 v. 12. 09. 2014, S. 2 u. 4.

176 Dies gilt auch mit Blick auf die geplante Änderung der Vierten Geldwäscherichtlinie, die sowohl in Art, 30 und 31 eine gleichlautende Ausnahmeregelung vorsieht; zum Problem, dass die Ausnahmeregelung beim Betrug schon tatbestandlich nicht greifen kann, siehe N. Müller, NZWiSt 3/2017, 87, 91 . 
Personen mit einem „berechtigten Interesse“ eine Zweckbindung nach Art. 8 Abs. 2 GRC vermissen.

\section{cc) Verhältnismäßigkeit}

Der Grundsatz der Verhältnismäßigkeit verlangt nach ständiger Rechtsprechung des Gerichtshofs, dass die Handlungen der Unionsorgane geeignet sind, die mit der fraglichen Regelung zulässigerweise verfolgten Ziele zu erreichen, und nicht die Grenzen dessen überschreiten, was zur Erreichung dieser Ziele geeignet und erforderlich ist ${ }^{177}$.

Wie in Sachen Digital Rights Ireland ist auch vorliegend der Gestaltungsspielraum des Unionsgesetzgebers ,angesichts der besonderen Bedeutung des Schutzes personenbezogener Daten für das Grundrecht auf Achtung des Privatlebens" einerseits und des Ausmaßes und der Schwere des mit der Vierten Geldwäscherichtlinie, vor allem den Art. 30 und 31 der Richtlinie, bewirkten Eingriffs andererseits eingeschränkt, so dass die Richtlinie einer strikten Kontrolle unterliegt ${ }^{178}$.

In Sachen Digital Rights Ireland, wo es ebenfalls um die Datenverarbeitung zur Terrorismusbekämpfung ging ${ }^{179}$, hatte der EuGH festgestellt, dass eine Speicherung von Daten „auf Vorrat“ mit Blick auf die zunehmende elektronische Kommunikation zwar für die Strafverfolgungsbehörden eine Erleichterung ihrer Arbeit darstellen würde, die auch dem Zweck der Terrorismusbekämpfung, also der Bekämpfung schwerer Kriminalität, dienen würde ${ }^{180}$. Eine solche dem Gemeinwohl dienende Zielsetzung könne jedoch, so grundlegend sie auch sein möge, für sich genommen die Erforderlichkeit einer solchen Speicherungsmaßnahme für die Kriminalitätsbekämpfung nicht rechtfertigen, da laut EuGH der Schutz des Grundrechts auf Achtung des Privatlebens verlange, „dass sich die Ausnahmen vom Schutz personenbezogener Daten und dessen Einschränkungen auf das absolut Notwendige beschränken müssen“181. Insoweit sei darauf hin-

177 EuGH, 08. 04. 2014, Rs. C-293/12 und C-594/12 Rdn. 46 m.w. N. (Digital Rights Ireland und Seitlinger u.a.).

178 EuGH, 08. 04. 2014, Rs. C-293/12 und C-594/12 Rdn. 43 (Digital Rights Ireland und Seitlinger u. a.).

179 Zur Vergleichbarkeit der Ausgangslage, auch wenn es in der Entscheidung des EuGH um die Speicherung von Kommunikationsdaten „auf Vorrat“ ging, siehe N. Müller, NZWiSt 4/2017, 121, $124 \mathrm{f}$.

180 EuGH, 08. 04. 2014, Rs. C-293/12 und C-594/12 Rdn. 48 (Digital Rights Ireland und Seitlinger u. a.).

181 EuGH, 08. 04. 2014, Rs. C-293/12 und C-594/12 Rdn. 50 ff. (Digital Rights Ireland und Seitlinger u. a.). 
zuweisen, dass der Schutz personenbezogener Daten, zu dem Art. 8 Abs. 1 GRC ausdrücklich verpflichte, für das in ihrem Art. 7 verankerte Recht auf Achtung des Privatlebens von besonderer Bedeutung sei ${ }^{182}$. Eine Regelung, die darin eingreife müsse daher „klare und präzise Regeln für die Tragweite und die Anwendung der fraglichen Maßnahme vorsehen und Mindestanforderungen aufstellen, so dass die Personen, deren Daten auf Vorrat gespeichert wurden, über ausreichende Garantien verfügen, die einen wirksamen Schutz ihrer personenbezogenen Daten vor Missbrauchsrisiken sowie vor jedem unberechtigten Zugang zu diesen Daten und jeder unberechtigten Nutzung ermöglichen“"183. Dieses Erfordernis sei umso bedeutsamer, je größer die Gefahr eines unberechtigten Zugangs zu den vorgehaltenen Daten sei $^{184}$.

In diesem Zusammenhang ist festzustellen, dass - soweit in diesem Urteil des EuGH das (präventive) Sammeln und Vorhalten von Daten über den wirtschaftlichen Eigentümer einer Gesellschaft, juristischen Person, eines Express Trusts oder einer vergleichbaren Rechtsperson oder -vereinbarung vorgesehen ist - eine gewisse Parallele zu den Art. 30 und 31 der Vierten Geldwäscherichtlinie gezogen werden kann. Auch dort sollen personenbezogene Daten ,auf Vorrat“ gesammelt werden, damit Behörden oder Geldwäscheverpflichtete und ggf. sonstige Personen und Organisationen mit berechtigtem Interesse darauf zugreifen können. Somit können die Ausführungen des EuGH in Sachen Digital Rights Ireland zu einer gewissen Orientierung bei der Bewertung der Verhältnismäßigkeit dienen.

Der EuGH betonte in seinem Urteil in Sachen Digital Rights Ireland weiter, dass die dort gegenständliche Richtlinie 2006/24 zum einen in die Grundrechte sehr vieler europäischer Bürger eingreife und zum anderen auch die Personen erfasst würden, die keinen Anlass für eine Strafverfolgung bieten würden. Zudem sehe sie keine Ausnahme für Berufsträger vor, die der Schweigepflicht unterliegen $^{185}$. Diese Ausgangslage liegt auch nach den Vorgaben der Art. 30 und 31 der Vierten Geldwäscherichtlinie vor, da personenbezogene Daten sämtlicher wirtschaftlicher Eigentümer von Gesellschaften, juristischen Personen, Express Trusts

182 EuGH, 08. 04. 2014, Rs. C-293/12 und C-594/12 Rdn. 53 (Digital Rights Ireland und Seitlinger u.a.).

183 EuGH, 08. 04. 2014, Rs. C-293/12 und C-594/12 Rdn. 54 (Digital Rights Ireland und Seitlinger u. a.); bestätigt in EuGH, 06. 10. 2015, Rs. C-362/15, Rdn. 91 (Maximilian Schrems v. Data Protection Commissioner).

184 EuGH, 08. 04. 2014, Rs. C-293/12 und C-594/12 Rdn. 55 (Digital Rights Ireland und Seitlinger u. a.).

185 EuGH, 08. 04. 2014, Rs. C-293/12 und C-594/12 Rdn. 56-58 (Digital Rights Ireland und Seitlinger u.a.). 
oder vergleichbaren Rechtspersonen oder -vereinbarungen in einem zentralen Register gesammelt werden sollen; der überwiegende Teil davon wird jedoch keinen Anlass für einen Geldwäscheverdacht oder einen Bezug zur Terrorismusfinanzierung bieten ${ }^{186}$. Dies gilt umso mehr, als mit der Bestimmung des (fiktiven) wirtschaftlichen Berechtigten auch Personen erfasst werden, die weder direkt noch indirekt Eigentum oder Kontrolle an Gesellschaften ausüben und es im Gegensatz zu dem vom EuGH entschiedenen Fall nicht um Strafverfolgung per se, sondern um Prävention von Geldwäsche und Terrorismusfinanzierung geht ${ }^{187}$. Auch ist die Ausnahmeregelung des Art. 30 der Vierten Geldwäscherichtlinie unzureichend.

Überdies ist im Rahmen der Abwägung zu berücksichtigen, dass ein Grundrechtsträger in der Ausübung seiner Freiheitsrechte eingeschränkt werden kann, wenn die Kenntnis von der Offenlegung seiner personenbezogenen Daten in einem Register ihn beispielsweise davon abhält, die Position als wirtschaftlicher Eigentümer (etwa aus Angst vor damit einhergehenden Repressalien) einzunehmen, womit auch sein Recht aus Art. 16 GRC tangiert ist.

Weiter führte der EuGH aus: „Zum anderen soll die Richtlinie zwar zur Bekämpfung schwerer Kriminalität beitragen, verlangt aber keinen Zusammenhang zwischen den Daten, deren Vorratsspeicherung vorgesehen ist, und einer Bedrohung der öffentlichen Sicherheit; insbesondere beschränkt sie die Vorratsspeicherung weder auf die Daten eines bestimmten Zeitraums und/oder eines bestimmten geografischen Gebiets und/oder eines bestimmten Personenkreises, der in irgendeiner Weise in eine schwere Straftat verwickelt sein könnte, noch auf Personen, deren auf Vorrat gespeicherte Daten aus anderen Gründen zur Verhütung, Feststellung oder Verfolgung schwerer Straftaten beitragen könnten." ${ }^{188}$

Vorliegend wird der Personenkreis, dessen personenbezogene Daten im Register erfasst werden, zwar dadurch eingeschränkt, dass diese Personen wirtschaftliche Eigentümer der vorgenannten Rechtspersonen und Rechtsvereinbarungen sind, ein Bezug zu Geldwäsche und Terrorismusfinanzierung wird freilich dennoch nur pauschal durch den Hinweis auf die Missbrauchsanfälligkeit gesellschaftsrechtlicher Konstruktionen hergestellt; dies erscheint mit Blick auf die Ausführungen des EuGH als nicht hinreichende Bestimmung der Zwecksetzung.

186 So auch Krais, CCZ 2015, 251, 255.

187 Siehe Krais, CCZ 2015, 251, 254.

188 EuGH, 08. 04. 2014, Rs. C-293/12 und C-594/12 Rdn. 59 (Digital Rights Ireland und Seitlinger u.a.). 
Überdies monierte der EuGH, dass die Richtlinie kein objektives Kriterium vorsieht, welches den Datenzugang durch die nationalen zuständigen Behörden dahingehend einschränkt, dass nur hinreichend schwere Straftaten es rechtfertigen, Art. 7 und 8 GRC einzuschränken ${ }^{189}$. Zudem seien auch keine materiell- und verfahrensrechtlichen Voraussetzungen für den Zugang der zuständigen nationalen Behörden zu den Daten und deren spätere Nutzung derart vorgesehen, dass die Nutzung strikt auf Zwecke der Verhütung und Feststellung genau abgegrenzter schwerer Straftaten oder der sie betreffenden Strafverfolgung zu beschränken sind, sondern es sei lediglich vorgesehen, dass jeder Mitgliedstaat das Verfahren und die Bedingungen festlegt, die für den Zugang zu den auf Vorrat gespeicherten Daten gemäß den Anforderungen der Notwendigkeit und der Verhältnismäßigkeit einzuhalten sind ${ }^{190}$.

Diese Ausführungen treffen ebenfalls auf das Geldwäscheregister zu, da dort den zuständigen Behörden einschränkungs- und anlasslos Zugriff auf die vorgehaltenen Daten ermöglicht werden soll und es keinerlei Vorgaben zur weiteren Nutzung der Daten durch die Zugriffsberechtigten gibt. Insbesondere die Regelung des Art. 7 Abs. 1 der Vierten Geldwäscherichtlinie, wonach jeder Mitgliedstaat angemessene Schritte zu unternehmen hat, um die für ihn bestehenden Risiken der Geldwäsche und Terrorismusfinanzierung sowie alle Datenschutzprobleme in diesem Zusammenhang zu ermitteln, zu bewerten, $\mathrm{zu}$ verstehen und $\mathrm{zu}$ mindern ${ }^{191}$, erscheint mit Blick auf (auch die weiteren) Ausführungen des EuGH als nicht ausreichend bestimmt. Als besonders kritisch wird dort erachtet, dass die Richtlinie kein objektives Kriterium vorsieht, „das es erlaubt, die Zahl der Personen, die zum Zugang zu den auf Vorrat gespeicherten Daten und zu deren späterer Nutzung befugt sind, auf das angesichts des verfolgten Ziels absolut Notwendige zu beschränken. Vor allem unterliegt der Zugang der zuständigen nationalen Behörden zu den auf Vorrat gespeicherten Daten keiner vorherigen Kontrolle durch ein Gericht oder eine unabhängige Verwaltungsstelle, deren Entscheidung den Zugang zu den Daten und ihre Nutzung auf das zur Erreichung des verfolgten Ziels absolut Notwendige beschränken soll und im Anschluss an einen mit Gründen versehenen Antrag der genannten Behörden im Rahmen von Verfahren zur Verhütung, Feststellung oder Verfolgung von Straftaten ergeht. Auch sieht die Richtlinie keine präzise Verpflichtung der Mitgliedstaaten vor, solche

189 EuGH, 08. 04. 2014, Rs. C-293/12 und C-594/12 Rdn. 60 (Digital Rights Ireland und Seitlinger u.a.).

190 EuGH, 08. 04. 2014, Rs. C-293/12 und C-594/12 Rdn. 61 (Digital Rights Ireland und Seitlinger u. a.); so auch EuGH, 06. 10. 2015, Rs. C-362/15, Rdn. 93 (Maximilian Schrems v. Data Protection Commissioner).

191 ABl. EUv. 05. 06. 2015, L 141/89. 
Beschränkungen zu schaffen.“"192 Dies gilt im Hinblick auf das mit Art. 30 und 31 der Vierten Geldwäscherichtlinie zu schaffende Register in besonderer Form: Dort wird nicht nur den zuständigen Behörden anlasslos ohne weitere Vorgaben zur Nutzung ein Datenzugriff erlaubt, auch für die Geldwäscheverpflichteten (bezüglich derer zumindest ein inhaltlicher Bezug zu geldwäscherelevanten Tätigkeiten besteht) gibt es keinerlei weitere Regelungen bezüglich des Umgangs mit den erhaltenen Daten; eine interne (ggf. zweckfremde) Weitergabe - und damit eine Vertiefung des Grundrechtseingriffs - erscheint daher als nicht ausgeschlossen.

Besonders fragwürdig ist in diesem Zusammenhang jedoch der Zugriff durch Personen und Organisationen, die ein berechtigtes Interesse nach Art. 30 Abs. 5 c) der Vierten Geldwäscherichtlinie nachweisen. Hier stellt sich zunächst das Problem, dass infolge der Unbestimmtheit des Geldwäschebezugs (der Vortatenbezug ist ohnehin unzulässig) eine Beschränkung des Datenzugriffs auf das Notwendigste nicht vorgenommen werden kann. Dies gilt umso mehr, als für diesen - nicht weiter bestimmbaren Personenkreis - keinerlei Vorgaben zur weiteren Nutzung der Daten bestehen. Das Problem verschärft sich zudem, wenn ein Online-Zugriff auf die personenbezogenen Daten der wirtschaftlichen Eigentümer eingeräumt wird, weil im Rahmen eines automatisierten Zugriffs eine Kontrolle des berechtigten Interesse kaum möglich ist bzw. ein missbräuchlicher Zugriff auf die Daten sogar sehr nahe liegt. Dies gilt insbesondere, als es sich hierbei um Daten mit beträchtlichem wirtschaftlichem Wert handelt, deren Verkauf nach einem unberechtigten Zugriff als äußerst gewinnbringend erscheint. Davon abgesehen, lässt eine unberechtigte Weitergabe oder Veröffentlichung dieser Daten möglicherweise weitere Gefahren entstehen - indem nicht nur die wirtschaftlichen Eigentümer, sondern auch Unternehmen und andere Gesellschaften auf eine Art transparent werden, die nicht nur die Datenschutzgrundrechte, sondern auch die unternehmerische Freiheit sowie die Wettbewerbsfreiheit beeinträchtigen; auch die wirtschaftlichen Eigentümer selbst haben womöglich mit Repressalien oder kriminellen Handlungen angesichts offengelegter Vermögensanteile zu rechnen. Diese Gefahren scheint die Ausnahmeregelung in Art. 30 Abs. 9 der Vierten Geldwäscherichtlinie bei Weitem nicht ausreichend abzufedern, zumal die Hürden des Nachweises von drohenden Repressalien oder Gefahren vollkommen unklar sind und ebenso unpraktikabel erscheinen, da die Daten - waren sie einmal im (Online)Register erfasst - in der digitalen Welt existent sind, mögen sie nachfolgend wegen der Gefahr einer kriminellen Hand-

192 EuGH, 08. 04. 2014, Rs. C-293/12 und C-594/12 Rdn. 62 (Digital Rights Ireland und Seitlinger u. a.); so auch EuGH, 06. 10. 2015, Rs. C-362/15, Rdn. 92 (Maximilian Schrems v. Data Protection Commissioner). 
lung auch gelöscht werden. Anzumerken ist hier nochmals, dass Art. 31 der Vierten Geldwäscherichtlinie eine wie auch immer geartete Ausnahmeregelung überhaupt nicht vorsieht ${ }^{193}$.

Der EuGH kritisierte in Sachen Vorratsdatenspeicherung besonders, dass die Richtlinie keine Differenzierungsmöglichkeit zwischen den verschiedenen Zugriffsberechtigten und den verfolgten Zwecken vorsieht, durch welche sichergestellt wird, dass der Datenzugriff auf das Notwendigste beschränkt bleibt ${ }^{194}$. Vorliegend scheint das zentrale Register nach Art. 30 und 31 der Vierten Geldwäscherichtlinie sogar auf Dauer angelegt zu sein - vergleichbar dem Handelsregister. Eine Löschung der Daten scheint insofern (mit Ausnahme durch die Ausnahmeregelung des Art. 30 Abs. 9 der Richtlinie) nur dann zulässig, wenn die Gesellschaft, juristische Person oder sonstige Rechtsperson aufhört zu existieren oder den wirtschaftlichen Eigentümer wechselt. Dies verdeutlicht wiederum, dass die Führung des Registers zwar einen Bezug zur Geldwäsche- und Terrorismusfinanzierung aufweist, jedoch die enge Zweckbindung, die Art. 8 GRC voraussetzt, vermissen lässt.

Der EuGH stellte in Sachen Digital Rights Ireland daher insgesamt fest, die Richtlinie zur Vorratsdatenspeicherung sehe „keine klaren und präzisen Regeln zur Tragweite des Eingriffs in die in Art. 7 und Art. 8 der Charta verankerten Grundrechte“ und zur Gewährleistung, dass der Eingriff tatsächlich auf das absolut Notwendige beschränkt bleibe, vor ${ }^{195}$. Außerdem sehe die Richtlinie keine Bestimmungen vor, die den erfassten Daten wirksamen Schutz vor Missbrauchsrisiken sowie vor jedem unberechtigten Zugang und jeder unberechtigten Nutzung bieten. Auch sehe die Richtlinie keine präzise Verpflichtung der Mitgliedstaaten vor, solche Regeln $\mathrm{zu}$ schaffen ${ }^{196}$. Dies ist nach den vorstehenden Ausführungen für Art. 30 und 31 der Vierten Geldwäscherichtlinie ebenfalls zu bejahen; Art. 7 Abs. 1 dieser Richtlinie vermag an dieser Beurteilung - wie gesehen - nichts zu ändern. Erschwerend kommt hinzu, dass die Gefahr einer Datenweitergabe in Drittländer ohne angemessenes Schutzniveau besteht. Dies erscheint auch im Hinblick auf die Rechtsprechung des EuGH in Sachen

193 Dem trägt der Kommissionsvorschlag zur Änderung der Vierten Geldwäscherichtlinie allerdings Rechnung, indem er die - jedoch faktisch kaum zum Tragen kommende - Ausnahmeregelung sowohl in Art. 30 als auch in Art. 31 vorsieht, s. Kommission, COM(2016) 450 final v. 05. 07. 2016, S. 39f.; siehe auch N. Müller, NZWiSt 3/2017, 87, 90 f.

194 EuGH, 08. 04. 2014, Rs. C-293/12 und C-594/12 Rdn. 63f. (Digital Rights Ireland und Seitlinger u.a.).

195 EuGH, 08. 04. 2014, Rs. C-293/12 und C-594/12 Rdn. 65f. (Digital Rights Ireland und Seitlinger u.a.).

196 EuGH, 08. 04. 2014, Rs. C-293/12 und C-594/12 Rdn. 66 (Digital Rights Ireland und Seitlinger u.a.). 
Schrems ${ }^{197}$ bedenklich, da zum einen ein Widerspruchsrecht infolge der nicht vorhandenen bzw. nur schwer durchsetzbaren Ausnahmeregelung in Art. 30 und 31 der Vierten Geldwäscherichtlinie faktisch kaum vorhanden ist und zum anderen der Betroffene schwerlich darüber Kenntnis erlangen wird, ob und wann seine im Register vorgehaltenen Daten in ein Drittland gelangen (insbesondere im Fall des Online-Registers).

Schließlich konstatiert der EuGH in Sachen Digital Rights Ireland, dass auch eine ausreichende Überwachung der Erfordernisse des Datenschutzes und der Datensicherheit, wie in Art. 8 Abs. 3 der Charta ausdrücklich gefordert, durch eine unabhängige Stelle nicht sichergestellt ist. „Eine solche Überwachung auf der Grundlage des Unionsrechts ist aber ein wesentlicher Bestandteil der Wahrung des Schutzes der Betroffenen bei der Verarbeitung personenbezogener Daten“198. Es wurde bereits ausgeführt, dass die Einführung eines Registers, in dem es einfach nur um das Vorhalten von Daten geht, nach der Richtlinie 95/46/EG sowie der Datenschutzgrundverordnung erleichterten Verfahrensvoraussetzungen unterliegen soll, die dazu führen, dass eine nachträgliche Kontrolle durch ein unabhängiges Kontrollorgan nur eingeschränkt stattfinden soll. Dies dürfte nach den Erwägungen des EuGH unzulässig sein ${ }^{199}$.

Zusammenfassend stellte der EuGH in Sachen Digital Rights Ireland fest, dass der Unionsgesetzgeber beim Erlass der Richtlinie 2006/24 die Grenzen überschritten hat, die er zur Wahrung des Grundsatzes der Verhältnismäßigkeit im Hinblick auf die Art. 7, 8 und 52 Abs. 1 GRC einhalten musste ${ }^{200}$. Gleiches ist auch für die Vierte Geldwäscherichtlinie, insbesondere ihre Regelungen in Art. 30 und 31, zu konstatieren.

\section{d) Fazit}

Mag das in Art. 30 und 31 der Vierten Geldwäscherichtlinie vorgesehene Geldwäscheregister vor dem Hintergrund der Panama Papers kriminalpolitisch Aufwind erfahren, so ist es doch mit Blick auf datenschutzrechtliche Vorgaben als

197 EuGH, 06. 10. 2015, Rs. C-362/15, Rdn. 99 ff. (Maximilian Schrems v. Data Protection Commissioner).

198 EuGH, 08. 04. 2014, Rs. C-293/12 und C-594/12 Rdn. 68 (Digital Rights Ireland und Seitlinger u.a.).

199 So auch EuGH, 06. 10. 2015, Rs. C-362/15, Rdn. 99 ff. (Maximilian Schrems v. Data Protection Commissioner).

200 EuGH, 08. 04. 2014, Rs. C-293/12 und C-594/12 Rdn. 69 (Digital Rights Ireland und Seitlinger u.a.). 
überaus kritisch zu betrachten. Dies gilt nicht nur angesichts des nur pauschalen Bezugs zum Zweck der Bekämpfung von Geldwäsche und Terrorismusfinanzierung, der mit dem Verweis auf die Missbrauchsanfälligkeit gesellschaftsrechtlicher Konstruktionen hergestellt wird. Auch dass auf das Register durch die zuständigen Behörden einschränkungs- und anlasslos zugegriffen werden kann und es keinerlei Vorgaben zur weiteren Nutzung der Daten durch die Zugriffsberechtigten gibt, erscheint äußerst bedenklich und mit der Rechtsprechung des EuGH nicht vereinbar, wie zuletzt mit Urteil vom 21. 12. 2016 in Sachen Tele2 Sverige eindrucksvoll bestätigt wurde ${ }^{201}$.

Neben einem öffentlichen Registerzugang - wie ihn die geplante Änderung der Vierten Geldwäscherichtlinie vorsieht ${ }^{202}$ - ist als besonders problematisch die Zugriffsberechtigung von Personen mit einem berechtigten Interesse $\mathrm{zu}$ werten, da der Begriff der Berechtigung mit seinem Bezug zum Verdacht von geldwäscherelevanten Vortaten zum einen sehr unbestimmt ist und zum anderen sich ein berechtigtes Interesse an privaten Daten nicht auf Elemente der Strafverfolgung oder der öffentlichen Ordnung als Aufgabe des Staates stützen kann. Ein berechtigtes Interesse aufgrund eines rechtlichen Anspruchs würde kein Element der Geldwäsche aufweisen und wäre daher in der Richtlinie deplatziert. Ein Interesse der Öffentlichkeit neben den Ermittlungsbehörden legt zudem nahe, dass diese ihre Pflichten verabsäumen ${ }^{203}$.

Hinzuweisen ist außerdem darauf, dass auch die Regelungen der Art. 30 und 31 der Vierten Geldwäscherichtlinie über die Vorgaben der FATF hinausgehen, da dort weder zwingend ein zentrales Register vorgesehen wird noch Personen oder Organisationen mit berechtigtem Interesse im Sinne des Art. 30 Abs. 5 c) der Vierten Geldwäscherichtlinie als Zugriffsberechtigte genannt werden. Bezüglich Letzteren stellt sich zudem das Problem, dass der vage Bezug zu Vortaten der Geldwäsche keine Zweckbindung nach Art. 8 Abs. 2 GRC zum legitimen Zweck der Geldwäsche- und Terrorismusbekämpfung darstellen kann, da es sich hier um Taten noch im Vorbereitungsstadium einer möglichen Geldwäsche handelt (noch kein Versuchseintritt). Ein undifferenzierter Zugang zu den in einem zentralen Register vorgehaltenen Daten widerspricht überdies dem risikobasierten Ansatz,

201 EuGH, 21. 12. 2016, Rs. C-203/15 u. C-698/15 (Tele2 Sverige u.a.); näher dazu N. Müller, NZWiSt 3/2017, 87 ff.

202 Kommission, COM(2016) 450 final v. 05. 07. 2016, S. 18 f.; N. Müller, NZWiSt 3/2017, 87 ff. und NZWiSt 4/2017, $121 \mathrm{ff}$.

203 Zur Kritik der Einbeziehung Privater zur Unterstützung der Strafverfolgungsbehörden, wie es der Kommissionsvorschlag zur Änderung der Vierten Geldwäscherichtlinie offenbar intendiert, eingehend N. Müller, NZWiSt 4/2017, 121, $123 \mathrm{f}$. 
dem sowohl in der Richtlinie (und den Vorgängerrichtlinien) selbst sowie auch bei der FATF große Bedeutung zugemessen wird ${ }^{204}$.

Nach den vorstehenden Ausführungen sind die mit der Schaffung des Registers verbundenen schweren Eingriffe in die Grundrechte nach Art. 7 und 8 GRC, die viele Bürger unabhängig von einem Verdacht der Geldwäsche oder Terrorismusfinanzierung betreffen, solange sie wirtschaftlicher Eigentümer einer Gesellschaft, juristischen Person, eines Trusts oder einer sonstigen Rechtsperson sind, nicht durch ausreichende Bestimmungen innerhalb der Richtlinie auf den notwendigsten Zugriff beschränkt; auch finden sich keine Bestimmungen zum wirksamen Schutz vor Missbrauchsrisiken (insbesondere im Hinblick auf den OnlineZugang). Insgesamt lassen die Vorgaben der Art. 30 und 31 der Vierten Geldwäscherichtlinie den notwenigen Bezug zur Zielsetzung der Geldwäsche- und Terrorismusbekämpfung vermissen. Insofern ist davon auszugehen, dass sie mit der strengen Haltung des Gerichtshofs in Sachen Datenschutz nicht in Einklang zu bringen sind ${ }^{205}$. Dies gilt im Besonderen für die geplante Änderung der Vierten Geldwäscherichtlinie und den darauf basierenden Umsetzungsentwurf des Bundesfinanzministeriums, die einen grundsätzlich öffentlichen Registerzugriff vorsehen. ${ }^{206}$ Entsprechend hat der französische Verfassungsrat die Einrichtung eines öffentlichen Registers mit Daten zum wirtschaftlich Berechtigten als offensichtlich unverhältnismäßigen Eingriff in das Recht auf Respektierung des Privatlebens als verfassungswidrig abgelehnt ${ }^{207}$.

\section{e) Grundrechtsverträgliche Umsetzung}

Zusammenfassend ist somit festzuhalten, dass die Regelungen der Art. 30 und 31 der Vierten Geldwäscherichtlinie mit den Vorgaben der Art. 7 und 8 GRC nicht vereinbar sind. Der dadurch bewirkte Grundrechtseingriff ist nicht gerechtfertigt. Für eine grundrechtsverträgliche Modifikation bzw. Umsetzung der Vorgaben bedürfte es eines Datenzugriffs ausschließlich der zuständigen Behörden und

204 Siehe nur FATF Recommendations (Anm. 111), S. 11, 31; so auch Krais, CCZ 2015, 251, 255; von Drathen, WPg 2015, 1242, 1243.

205 EuGH, 06. 10. 2015, Rs. C-362/15 (Maximilian Schrems v. Data Protection Commissioner); EuGH, 08. 04. 2014, Rs. C-293/12 und C-594/12 Rdn. 69 (Digital Rights Ireland und Seitlinger u. a.); siehe auch Wolff/Stemmer, BayVBl 2016, 181, 184.

206 Kommission, COM(2016) 450 final v. 05. 07. 2016, S. 18 f.; eingehend dazu N. Müller, NZWiSt 3/2017, $87 \mathrm{ff}$.

207 Conseil Constitutionnel Décision n 2016-591 QPC, 21. 10. 2016 (Mme Helen S.); näher dazu N. Müller, NZWiSt 4/2017, 121, 128; siehe auch Lachenmann, Die Öffentliche Verwaltung 12/2016, $501 \mathrm{ff}$. 
Geldwäscheverpflichteten im Rahmen eines konkreten Zusammenhangs mit Sorgfaltspflichten oder beim Verdacht von geldwäsche- und terrorismusrelevanten Handlungen außerhalb eines zentralen Registers. Die Daten sollten bei Bedarf (vergleichbar den Empfehlungen der FATF) bei den Gesellschaften selbst, bei Finanzinstituten, DNFBPs oder sonstigen Behörden (z. B. Steuerbehörden) eingeholt werden. Es müssten zudem Regelungen zum Umgang mit den Daten bei den Zugriffsberechtigten, zum Auskunfts- und Widerspruchsrecht sowie zur Dauer der Speicherung und Löschung der Daten geschaffen werden, um sicherzustellen, dass die Datenverarbeitung auf das Notwendigste beschränkt bleibt. Ob solche Einschränkungen bzw. ein Verzicht auf ein zentrales Register sich vor dem Hintergrund der Panama Papers und dem damit verbundenen kriminalpolitischen Druck durchsetzen lassen, scheint mit Blick auf den Kommissionsvorschlag zur Änderung der Vierten Geldwäscherichtlinie und den vom Bundesfinanzministeriums vorgelegten Entwurf zu Änderung des Geldwäschegesetzes, in dem die dortigen Verschärfungen in „,vorauseilendem Gehorsam“ unkritisch übernommen wurden, als unrealistisch.

Nur nebenbei bemerkt ist mit Blick auf die Rechtsprechung des Bundesverfassungsgerichts insbesondere zur Vorratsdatenspeicherung ${ }^{208}$ sowie zur (teilweisen) Verfassungswidrigkeit des BKA-Gesetzes davon auszugehen, dass eine Umsetzung der Art. 30 und 31 der Vierten Geldwäscherichtlinie auch dort auf Bedenken stoßen würde. Zwar wurden bezüglich letzterem Gesetze zur Verarbeitung und Weitergabe personenbezogener Daten, die durch schwere (heimliche) Eingriffsmaßnahmen (Wohnraumüberwachung und Online-Durchsuchung) gewonnen wurden, als verfassungswidrig erklärt, so dass die Ausgangssituation mit dem offenen (zwangsweisen) Zurverfügungstellen personenbezogener Daten zum wirtschaftlichen Eigentümer nicht völlig vergleichbar erscheint. Dennoch geht in Fortsetzung der früheren Rechtsprechungslinie ${ }^{209}$ auch aus diesem Urteil hervor, dass das Bundesverfassungsgericht (zu Recht) hohe Hürden an einer Datenverarbeitung stellt, wenn anlassunabhängig und präventiv ${ }^{210}$ - und somit mehr oder weniger losgelöst vom Erhebungszweck - Daten gesammelt, vorgehalten und (insbesondere ins Ausland ${ }^{211}$ ) weitergegeben werden. Letzteres wird durch die Ausführungen des Gerichts zur hypothetischen Datenneuerhebung ${ }^{212}$ deutlich, die das Gericht fortführt. Es ist vor diesem Hintergrund nicht anzunehmen, dass das Bundesverfassungsgericht eine Verarbeitung personenbezogener Daten von

208 BVerfG NJW 2010, 833, 838 Rdn. 210 ff.

209 Siehe nur BVerfG NJW 2010, 833, 838 Rdn. 210; NJW 2008, 1505, 1515 Rdn. 172.

210 BVerfG NJW 2016, 1781, 1803 Rdn. $302 \mathrm{ff}$.

211 BVerfG NJW 2016, 1781, 1805 Rdn. $324 \mathrm{ff}$.

212 BVerfG NJW 2016, 1781, 1801 Rdn. 287 ff. 
Betroffenen billigen würde, die keinerlei Anlass für einen Verdacht wegen Geldwäsche oder Terrorismusfinanzierung bieten ${ }^{213}$. Dies gilt im Speziellen im Hinblick auf die weite Fassung des (fiktiv) wirtschaftlich Berechtigten nach Art. 3 Ziff. 6 der Vierten Geldwäscherichtlinie ${ }^{214}$.

Zudem betont auch das Bundesverfassungsgericht die Bedeutung der datenschutzrechtlichen Sonderstellung von Berufsgeheimnisträgern, auf die in der Vierten Geldwäscherichtlinie nicht eingegangen wurde ${ }^{215}$, die Wichtigkeit der Kontrolle, Protokollierung und Sanktionierung von datenschutzrechtlichen Verstößen ${ }^{216}$ sowie die Möglichkeit der Löschung von Daten ${ }^{217}$, die allesamt in der Vierten Geldwäscherichtlinie unzureichend geregelt wurden ${ }^{218}$.

Mit Blick auf die Panama Papers und den damit verbundenen Verdacht gegenüber wirtschaftlichen Eigentümern von Gesellschaften oder Trusts bzw. vergleichbaren Strukturen darf schließlich nicht vergessen werden, dass durchaus auch legitime und nachvollziehbare Interessen Grund dafür sein können, warum wirtschaftliche Eigentümer ihre finanziellen Interessen oder Beteiligungen nicht über ein mehr oder weniger frei zugängliches Register offenlegen wollen $^{219}$. Welche Prangerwirkung aber von den öffentlich gewordenen Daten ausgehen kann, zeigt sich eindrucksvoll an den in den Medien bekannt gewordenen Fällen von prominenter Beteiligung an offshore-Gesellschaften ${ }^{220}$.

213 So stellte das Bundesverfassungsgericht in Sachen „Automatisierte Kennzeichenerfassung“ fest, dass es mit dem Verhältnismäßigkeitsprinzip nicht vereinbar ist, „dass die angegriffenen Vorschriften aufgrund ihrer unbestimmten Weite anlasslos erfolgende oder [...] flächendeckend durchgeführte Maßnahmen der automatisierten Erfassung und Auswertung von Kraftfahrzeugkennzeichnen ermöglichen“, BVerfG NJW 2008, 1505, 1515 Rdn. 172.

214 Dies gilt entsprechend bzw. erst recht mit Blick auf den Referentenentwurf zur Änderung des GwG bzw. den Änderungsvorschlag der Kommission; näher zur Bestimmung des Kreises der wirtschaftlich Berechtigten im Änderungsvorschlag der Kommission zur Vierten Geldwäscherichtlinie bzw. zur Regelung im Referentenentwurf des Bundesfinanzministeriums, N. Müller, NZWiSt 3/2017, 87, $91 \mathrm{f}$.

215 BVerfG NJW 2016, 1781, 1788 Rdn. $131 \mathrm{ff}$.

216 BVerfG NJW 2016, 1781, 1789 Rdn. 139 ff.

217 Entsprechend kommt ein Gutachten des Wissenschaftlichen Dienstes des Bundestags zum Ergebnis, dass das Gesetz zur Einführung einer Speicherpflicht und einer Höchstspeicherfrist für Verkehrsdaten v. 10. 12. 2015 (BGBl. 2015, I, S. 2218) mit den Vorgaben des EuGH nicht vereinbar ist, siehe https://www.heise.de/newsticker/meldung/Bundestagsgutachten-Neue-Vorratsdatenspeicherung-ist-rechtswidrig-3617806.html.

218 BVerfG NJW 2016, 1781, 1789 Rdn. 144.

219 Siehe N. Müller, NZWiSt 4/2017, 121, $124 \mathrm{f}$.

220 Siehe dazu auch T. Schröder, NZWiSt 2016, 452 ff.; näher zum „name and shame“ Ch. Dannecker, JZ 2013, 924, 933 und N. Müller, NZWiSt 3/2017, 87, 98 f. 